\title{
Reference grass evapotranspiration with reduced data sets: Parameterization of the FAO Penman-Monteith temperature approach and the Hargeaves- Samani equation using local climatic variables
}

\author{
P. Paredes $^{\mathrm{a}, *}$, L.S. Pereira ${ }^{\mathrm{a}}$, J. Almorox ${ }^{\mathrm{b}}$, H. Darouich ${ }^{\mathrm{a}}$ \\ a Centro de Investigação em Agronomia, Alimentos, Ambiente e Paisagem (LEAF), Instituto Superior de Agronomia, Universidade de Lisboa, Tapada da Ajuda, $1349-017$ \\ Lisboa, Portugal \\ ${ }^{\mathrm{b}}$ Departamento de Producción Agraria, ETSIAAB, Universidad Politécnica de Madrid, UPM, Avd. Puerta de Hierro, 2, Madrid 28040, Spain
}

\section{A R T I C L E I N F O}

\section{Keywords:}

Estimating dew-point temperature Default vs. average wind speed

Solar radiation computed upon temperature Radiation adjustment coefficient $\mathrm{k}_{\mathrm{Rs}}$ Multiple linear $\mathrm{k}_{\mathrm{Rs}}$ regressions

$\mathrm{PMT}$ and HS performance using $\mathrm{k}_{\mathrm{Rs}}$ equations

\begin{abstract}
A B S T R A C T
The computation of the grass reference evapotranspiration with the FAO56 Penman-Monteith equation (PM-ET $\left.{ }_{\mathrm{o}}\right)$ requires data on maximum and minimum air temperatures $\left(\mathrm{T}_{\max }, \mathrm{T}_{\min }\right)$, actual vapour pressure $\left(\mathrm{e}_{\mathrm{a}}\right)$, shortwave solar radiation $\left(R_{s}\right)$, and wind speed at $2 \mathrm{~m}$ height $\left(\mathrm{u}_{2}\right)$. Nonetheless, related datasets are often not available, are incomplete, or have uncertain quality. To overcome these limitations, several alternatives were considered in FAO56, while many other procedures were tested and proposed in very numerous papers. The present study reviews the computational procedures relative to predicting the missing variables from temperature, i.e., the PM temperature approach (PMT), and estimating $\mathrm{ET}_{\mathrm{o}}$ with the Hargreaves-Samani (HS) equation. For the PMT approach, procedures refer to predicting: (a) the dew point temperature $\left(\mathrm{T}_{\mathrm{dew}}\right)$ from the minimum or the mean air temperature; (b) shortwave solar radiation $\left(R_{s}\right)$ from the air temperature difference $\left(T D=T_{\max }-T_{\min }\right)$ combined with a calibrated radiation adjustment coefficient $\left(\mathrm{k}_{\mathrm{Rs}}\right)$; and $(\mathrm{c})$ wind speed $\left(\mathrm{u}_{2}\right)$ using a default value or a regional or local average. The adequateness of computing $\mathrm{T}_{\mathrm{dew}}$ from air temperature was reassessed and the preference for using an average $\mathrm{u}_{2}$ has been defined. To ease the estimation of $\mathrm{R}_{\mathrm{s}}$, for the PMT approach and the coefficient of the HS equation, multiple linear regression equations for predicting $\mathrm{k}_{\mathrm{Rs}}$ were developed using local averages of the temperature difference (TD), relative humidity (RH) and wind speed as independent variables. All variables were obtained from the Mediterranean set of CLIMWAT climatic data. Two types of $k_{\mathrm{Rs}}$ equations were developed: climate-focused equations specific to four climate types - humid, sub-humid, semi-arid, and hyper-arid and arid -, and a global one, applicable to any type of climate. The usability of the $\mathrm{k}_{\mathrm{Rs}}$ equations for the PMT and HS methods was assessed with independent data sets from Bolivia, Inner Mongolia, Iran, Portugal and Spain, covering a variety of climates, from hyper-arid to humid. With this purpose, ET $_{\mathrm{o}}$ estimated with PMT and $\mathrm{HS}$ (ET $\mathrm{ET}_{\mathrm{O} \text { PMT }}$ and $\mathrm{ET}_{\mathrm{o} \text { HS }}$ ) were compared with PM-ET $\mathrm{P}_{\mathrm{o}}$ computed with full data sets to evaluate the usability of the $\mathrm{k}_{\mathrm{Rs}}$ equations. Adopting the climate-focused $\mathrm{k}_{\mathrm{Rs}}$ equations with $\mathrm{ET}_{\mathrm{o} \text { PMT, }}$, the RMSE averaged 0.59, 0.64, 0.65 and $0.72 \mathrm{~mm} \mathrm{~d}^{-1}$ for humid, sub-humid, semi-arid, and arid and hyper-arid climates, respectively, while the RMSE values relative to $\mathrm{ET}_{\mathrm{o}} \mathrm{HS}$ when using the respective climate-focused $\mathrm{k}_{\mathrm{Rs}}$ equations averaged $0.58,0.60$, 0.60 and $0.69 \mathrm{~mm} \mathrm{~d}^{-1}$ for the same climates. These results are similar to those obtained with the $\mathrm{k}_{\mathrm{Rs}}$ global equation. The accuracy of the PMT approach when using the $\mathrm{k}_{\mathrm{Rs}}$ equations was also evaluated when one, two, or all three $T_{\text {dew }}, R_{s}$ and $u_{2}$ variables are missing and the resulting goodness-of-fit indicators demonstrated the advantage of the combined use of observed and estimated weather variables. The usability of the $\mathrm{k}_{\mathrm{Rs}}$ equations for an efficient parameterization of both the PMT approach and the HS equation is demonstrated with similar performance of PMT and HS procedures for a variety of climates. Because the $\mathrm{ET}_{\mathrm{o}}$ Hs results depend almost linearly on temperature, the PMT approach, using estimates of the weather variables, is able to mitigate those temperature impacts, which trends may be contrary to those of other variables that determine $\mathrm{ET}_{\mathrm{o}}$. The clear advantage of the PMT approach is that it allows using the available weather data in combination with estimates of the missing variables, which provides for more accurate $\mathrm{ET}_{\mathrm{o}}$ computations.
\end{abstract}

\footnotetext{
* Corresponding author.

E-mail address: pparedes@isa.ulisboa.pt (P. Paredes).
} 


\section{Introduction}

Evapotranspiration (ET) is a key variable in the hydrological cycle to quantify the water balance at all scales, from the field to the basin, aiming at better understanding the hydrological behaviour of natural and man-made landscapes, and improving water resource planning and management (Jensen and Allen, 2016). Multipurpose projects in irrigation, hydropower, water transportation, flood control, and municipal and industrial water uses require accurate estimation of ET. As competition for water is increasing and water resources are gradually depleted, the need to cope with water scarcity makes knowledge and accuracy of ET estimates increasingly relevant. Reducing the water use in agriculture in response to global change and environmental challenges requires improved use of ET information, namely reference ET at various scales. For most of those purposes, the accuracy in estimating the grass reference evapotranspiration $\left(\mathrm{ET}_{\mathrm{o}}, \mathrm{mm} \mathrm{d}^{-1}\right)$, often referred as potential evapotranspiration, plays an essential role (Allen et al., 1998; Pereira et al., 2009; Pereira, 2017).

Agricultural water management practices require that crop water and irrigation requirements be accurately estimated, which in turn demands accurate knowledge of crop evapotranspiration $\left(\mathrm{ET}_{\mathcal{c}}, \mathrm{mm} \mathrm{d}^{-1}\right)$. There are various approaches for measuring and estimating ET at the various scales, depending upon the available data and the goals of each study (Farahani et al., 2007; Allen et al., 2011; Jensen and Allen, 2016). McMahon et al. (2016) reviewed a variety of equations and model approaches on ET, from the work of Dalton, published by 1802, to present. A commonly used $\mathrm{ET}_{\mathrm{c}}$ estimation method at the field scale consists of using the $\mathrm{K}_{\mathrm{c}}-\mathrm{ET}_{\mathrm{o}}$ approach combining the grass reference evapotranspiration $\left(\mathrm{ET}_{\mathrm{o}}\right.$ ) with a crop coefficient $\left(\mathrm{K}_{\mathrm{c}}\right)$ (Allen et al., 1998). In this approach $\mathrm{ET}_{\mathrm{o}}$ represents the evaporative demand of the atmosphere (Allen et al., 1998; Pereira et al., 1999) and $\mathrm{K}_{\mathrm{c}}$ embodies an integration of the effects of the main characteristics that distinguish the crop from the grass reference. Applications worldwide are quite successful as recently overviewed (Pereira et al., 2015a, 2020a,b,c).

The computation of the Penman-Monteith $\mathrm{ET}_{\mathrm{o}}$ equation $\left(\mathrm{PM}^{\mathrm{E}} \mathrm{ET}_{\mathrm{o}}\right.$ ), described in next section, requires data on maximum and minimum air temperatures $\left(\mathrm{T}_{\max }\right.$ and $\left.\mathrm{T}_{\min }\right)$, solar radiation, air humidity and wind speed. However, in many regions and locations these weather variables are not observed, are not freely available from the relevant meteorological services, or are of poor quality due to insufficient quality control. It results that only reduced data sets are available, often consisting of $\mathrm{T}_{\max }$ and $\mathrm{T}_{\min }$ only. Research has developed a variety of tools and procedures to overcome the unavailability of data, namely by using alternative ET equations or heuristic approaches that use reduced weather data sets. However, various among those developed solutions, mainly the heuristic ones, do not use the basic physics underlying the

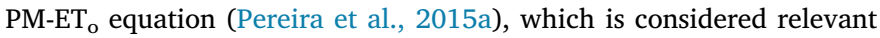
when selecting alternative approaches to compute $\mathrm{ET}_{\mathrm{o}}$ with reduced data sets.

As previously reviewed by Pereira et al. (2015a), limitations in

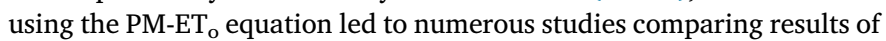

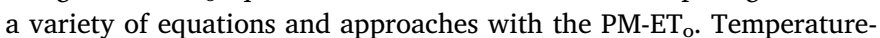
based evapotranspiration equations have shown to be quite useful in those conditions, but comparisons extended to a wide number of equations, including several versions of the Penman equation. Moreover, recently, various researchers tried to assess the validity of the PM$\mathrm{ET}_{\mathrm{o}}$ equation comparing $\mathrm{ET}_{\mathrm{o}}$ computed values with lysimeter $\mathrm{ET}_{\mathrm{o}}$ measured under non-standard grass conditions, thus not under com-

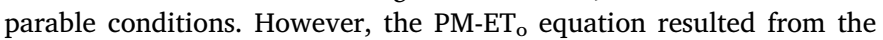
Penman-Monteith combination equation (Monteith, 1965) when calibrated for grass adopting standard grass aerodynamic parameters (Smith et al., 1991; Allen et al., 1994a, 1994b, 1998; Pereira et al., 1999). Former lysimeter grass $\mathrm{ET}_{\mathrm{o}}$ studies were developed focusing on the ET processes and their results contributed to improve the use of the

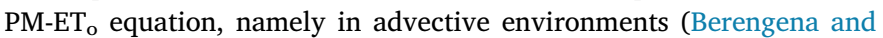
Gavilán, 2005), and mainly proposing different day and night bulk surface resistances (Todorovic, 1999; Wright et al., 2000; Lecina et al., 2003; Steduto et al., 2003) as adopted for the hourly calculation of $\mathrm{ET}_{\mathrm{o}}$ (Allen et al., 2006). Thus, contrarily to the former studies, the recent ones did not contribute to improving the concept of reference evapotranspiration, nor on its use in practice. Different $\mathrm{ET}_{\mathrm{o}}$ research approaches were meanwhile developed to search the use of diverse sources of weather data, such as reanalysis weather and $\mathrm{ET}_{\mathrm{o}}$ data products, gridded weather data of various sources, or geostationary satellite data. In addition to computation with reduced data sets, this review also provides for an overview of alternative solutions that allow overcoming related difficulties.

The main goal of this article, as a part of the current Special Issue on FAO56 crop water requirements method, is to present a consolidated step-by-step method to parameterize the FAO Penman-Monteith temperature (PMT) approach and the Hargeaves-Samani (HS) equation. The specific objectives consist of: (1) proposing a coherent methodology for estimating the lacking weather variables from temperature and then computing $\mathrm{ET}_{\mathrm{o}}$ with the PMT approach, namely using multiple linear equation to estimate the radiation adjustment coefficient $\mathrm{k}_{\mathrm{Rs}}$ from local long-term average TD, RH and $\mathrm{u}_{2}$; (2) developing a new and simple procedure to parameterize the Hargreaves-Samani (HS) equation, also estimating $\mathrm{k}_{\mathrm{Rs}}$ from local $\mathrm{TD}_{\mathrm{avg}}, \mathrm{RH}_{\mathrm{avg}}$ and $\mathrm{u}_{2}$ avg; (3) assessing the usability of the $\mathrm{k}_{\mathrm{Rs}}$ equations by evaluating the accuracy of $\mathrm{ET}_{\mathrm{o}}$

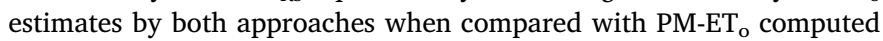
with full datasets, and (4) discussing about the relative advantages of both computational approaches.

Following the current introduction of the subject of this study, Section 2 consists of a review of various approaches to compute $\mathrm{ET}_{\mathrm{o}}$ with reduced data sets. Section 3 refers to Material and Methods, thus including descriptions of the datasets used, of the approach adopted for parameterizing the PMT and HS methods, as well as of the goodness-offit indicators adopted for validating the various $\mathrm{ET}_{\mathrm{o}}$ estimation ap-

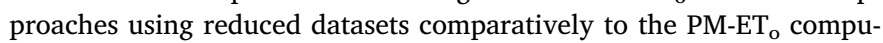
tation with full data sets. Section 4 consists of describing and testing the PMT approach for computing $\mathrm{ET}_{\mathrm{o}}$ when only temperature data are available, as well as when only relative humidity, wind speed and/or solar radiation data are lacking. Section 5 focus on parameterizing the HS equation from characteristic local climate variables and assessing the resulting performance of the HS equation. Finally, Section 6 discusses the previous analysed applications and provides recommendations for users.

\section{Grass reference evapotranspiration and its computation with reduced datasets}

$\mathrm{ET}_{\mathrm{o}}$ is defined as the rate of evapotranspiration from a hypothetical reference crop with an assumed crop height $\mathrm{h}=0.12 \mathrm{~m}$, a fixed daily canopy resistance $r_{s}=70 \mathrm{~s} \mathrm{~m}^{-1}$, and an albedo of 0.23 , closely resembling the evapotranspiration from an extensive surface of green grass of uniform height, actively growing, completely shading the ground and not short of water (Allen et al., 1998). This definition corresponds to the application of the Penman-Monteith combination equation (Monteith, 1965) to a grass crop cultivated in standard, optimal conditions, with $\mathrm{ET}_{\mathrm{o}}\left(\mathrm{mm} \mathrm{d}^{-1}\right)$ described by the daily PM-ET o equation:

$\mathrm{ET}_{\mathrm{o}}=\frac{0.408 \Delta\left(\mathrm{R}_{\mathrm{n}}-\mathrm{G}\right)+\gamma \frac{900}{\mathrm{~T}_{\text {mean }}+273} \mathrm{u}_{2}\left(\mathrm{e}_{\mathrm{s}}-\mathrm{e}_{\mathrm{a}}\right)}{\Delta+\gamma\left(1+0.34 \mathrm{u}_{2}\right)}$

where $R_{n}$ is the net radiation at the crop surface (MJ m ${ }^{-2} \mathrm{~d}^{-1}$ ), G is the soil heat flux density ( $\left.\mathrm{MJ} \mathrm{m}^{-2} \mathrm{~d}^{-1}\right), \mathrm{T}_{\text {mean }}$ is the mean daily air temperature at $2 \mathrm{~m}$ height $\left({ }^{\circ} \mathrm{C}\right)$ computed from maximum and minimum air temperature $\left(\mathrm{T}_{\max }\right.$ and $\left.\mathrm{T}_{\min },{ }^{\circ} \mathrm{C}\right), \mathrm{u}_{2}$ is the wind speed at $2 \mathrm{~m}$ height $\left(\mathrm{m} \mathrm{s}^{-1}\right), \mathrm{e}_{\mathrm{s}}-\mathrm{e}_{\mathrm{a}}$ is the vapour pressure deficit (VPD, $\mathrm{kPa}$ ) computed from the saturation vapour pressure $\left(\mathrm{e}_{\mathrm{s}}, \mathrm{kPa}\right)$ and the actual vapour pressure $\left(\mathrm{e}_{\mathrm{a}}, \mathrm{kPa}\right), \Delta$ is the slope of vapour pressure curve $\left(\mathrm{kPa}{ }^{\circ} \mathrm{C}^{-1}\right)$, and $\gamma$ is the psychrometric constant $\left(\mathrm{kPa}{ }^{\circ} \mathrm{C}^{-1}\right)$. That definition has been further 
extended to hourly time steps adopting different parameters for day- and night-hours (Allen et al., 2006). Main equations used to compute the parameters of the PM-ET $\mathrm{O}_{\mathrm{o}}$ Eq. (1) are given as Supplementary Information.

Due to its easier application to compute $\mathrm{ET}_{\mathrm{o}}$ with temperature data only, the main focus of research has been on the use of the HargreavesSamani (HS) equation (Hargreaves and Samani, 1982, 1985; Hargreaves et al., 1985; Hargreaves, 1994). Following the recommendation by Allen et al. (1998), and due to its simplicity, the HS equation became the most popular approach to compute $\mathrm{ET}_{\mathrm{o}}$ (Eq. 1) when only reduced data sets are available. This equation may be written as

$E T_{o-H S}=0.0135 \mathrm{k}_{R s} \frac{R_{a}}{\lambda}\left(T_{\max }-T_{\min }\right)^{0.5}\left(T_{\text {mean }}+17.8\right)$

where $\mathrm{ET}_{\mathrm{o}-\mathrm{HS}}$ corresponds to the daily grass reference evapotranspiration $\left(\mathrm{mm} \mathrm{d}^{-1}\right), \mathrm{T}_{\max }, \mathrm{T}_{\min }$ and $\mathrm{T}_{\text {mean }}$ are respectively the maximum, minimum and mean temperature $\left({ }^{\circ} \mathrm{C}\right), \lambda$ is the latent heat of vaporization $\left(2.45 \mathrm{MJ} \mathrm{kg}^{-1}\right), \mathrm{k}_{\mathrm{Rs}}$ is the empirical radiation adjustment coefficient $\left({ }^{\circ} \mathrm{C}^{-0.5}\right), \mathrm{R}_{\mathrm{a}}$ is the extraterrestrial radiation $\left(\mathrm{MJ} \mathrm{m}^{-2} \mathrm{~d}^{-1}\right), 0.0135$ is a factor for conversion of units from the American to the International System, and 17.8 is an empirical factor related to temperature units used in the original formulations. Often, Eq. (2a) is written with the Hargreaves coefficient $\left(\mathrm{C}_{\mathrm{HS}}=\mathrm{k}_{\mathrm{Rs}} 0.0135 / \lambda\right)$, thus not explicitly referring the $\mathrm{k}_{\mathrm{Rs}}$ coefficient:

$\mathrm{ET}_{\mathrm{o}-\mathrm{HS}}=\mathrm{C}_{H S}\left(\mathrm{~T}_{\max }-\mathrm{T}_{\min }\right)^{0.5} \mathrm{R}_{\mathrm{a}}\left(\mathrm{T}_{\text {mean }}+17.8\right)$

Jensen et al. (1990) have shown the appropriateness for using $\mathrm{ET}_{\mathrm{o}-\mathrm{HS}}$ when only reduced data sets are available. The HS equation was tested extensively, and good estimation results are often reported (Almorox et al., 2015). However, since it does not account for the effects of wind speed and humidity, it is less accurate in humid climates (Nandagiri and Kovoor, 2006; Trajkovic and Kolakovic, 2009; Martinez and Thepadia, 2010; Tabari, 2010), under high wind speeds (Temesgen et al., 2005; Gavilán et al., 2006; Raziei and Pereira, 2013a; Ren et al., 2016a; Paredes et al., 2018b), as well as in mountain and high elevation environments (Garcia et al., 2004; Ravazzani et al., 2012). Consequently, numerous authors, aiming at improving its performance, developed a variety of approaches to calibrate the respective coefficients as reviewed in Section 5.

The HS equation is often used with a default $\mathrm{k}_{\mathrm{Rs}}$ value, commonly $0.17^{\circ} \mathrm{C}^{-0.5}$ (Almorox et al., 2015). However, a great deal of research aimed at a more accurate estimation of $\mathrm{ET}_{\mathrm{o}-\mathrm{HS}}$ led to search for optimal values for $\mathrm{C}_{\mathrm{HS}}$ and $\mathrm{k}_{\mathrm{Rs}}$, and/or for other parameters of the HS equation originally expressed by constant values in Eq. (2), the additive constant 17.8 and the exponent 0.5 . While there is a rational in optimizing $k_{\mathrm{Rs}}$ because it relates to the atmospheric conditions that influence the availability of incoming solar radiation at the surface, thus the availability of energy for evaporation, searching for improved values for the exponent and the additive constant makes it more difficult to parameterize the HS equation because all three parameters interact and influence each other values. Moreover, it was observed that the gain in accuracy was generally relatively low while the HS equation became more difficult to parameterize since three parameters must be selected. Various authors noticed that there is advantage in seeking for the best value for $\mathrm{k}_{\mathrm{Rs}}$, or for $\mathrm{C}_{\mathrm{HS}}$, but not for the other parameters, namely the exponent, e.g., Hargreaves and Allen (2003); Ravazzani et al. (2012) and Berti et al. (2014). Other researchers added terms to consider impacts of rainfall, wind, or elevation, e.g. Annandale et al.(2002), Diodato and Bellocchi (2007), Kra (2014), Patel et al. (2014), while others searched for regionalization of $\mathrm{C}_{\mathrm{HS}}$, e.g. Gavilán et al. (2006) and Mendicino and Senatore (2013).

When only reduced data sets are available, at limit with $\mathrm{T}_{\max }$ and $\mathrm{T}_{\text {min }}$ data only, FAO56 (Allen et al., 1998) proposed the computation of $\mathrm{ET}_{\mathrm{o}}$ with using estimates of the missing variables. This calculation approach is often called the Penman-Monteith temperature or PMT approach. Various methods, including the use of data from a nearby weather station, were proposed in FAO56 (Allen et al., 1998) for estimation of the missing variables $\mathrm{R}_{\mathrm{s}}$, $\mathrm{e}_{\mathrm{a}}$ and/or $\mathrm{u}_{2}$ required to compute $\mathrm{ET}_{\mathrm{o}}$ (Eq. (1)) if only reduced data sets are available.

When relative humidity or psychrometric data are missing, it was recommended to compute $e_{a}$ assuming that the dew point temperature $\left(\mathrm{T}_{\mathrm{dew}},{ }^{\circ} \mathrm{C}\right)$ could be well estimated by $\mathrm{T}_{\text {min }}$. This approach holds when applied to a reference site where temperature and humidity are measured over an extensive and actively growing grass crop completely shading the ground and not short of water, which corresponds to the conditions assumed when defining the $\mathrm{PM}-\mathrm{ET}_{\mathrm{o}}$. Confirming this assertion, studies have shown that this approach does not hold when observations are performed in non-reference sites and when sites are affected by dryness and local advection, which cause that $\mathrm{T}_{\min }>\mathrm{T}_{\text {dew }}$ (Allen, 1996; Kimball et al., 1997; Temesgen et al., 1999; Paredes and Pereira, 2019; Allen et al., 2020). $\mathrm{T}_{\mathrm{dew}}=\mathrm{T}_{\min }$ was adopted in various applications performed under conditions assumed as reference sites (e.g., Liu and Pereira, 2001; Pereira et al., 2003; Trajkovic, 2005; Popova et al., 2006; Jabloun and Sahli, 2008; Córdoba et al., 2015; Wable et al., 2019), or not affected by dryness (Cai et al., 2007; Martinez and Thepadia, 2010). Considering that most of worldwide applications refer to sites where information on grass cover conditions are limited, there is the need for different approaches in estimating $\mathrm{T}_{\text {dew }}$ from $\mathrm{T}_{\min }$ or $\mathrm{T}_{\text {mean }}$ that minimize impacts of dryness of the sites on $\mathrm{ET}_{\mathrm{o}}$, particularly when computations are based upon temperature data only. Various approaches were reported by several authors, e.g., Temesgen et al. (1999), Hubbard et al. (2003), Todorovic et al. (2013), Ren et al. (2016a), Upreti and Ojha (2017) and Paredes et al. (2018a). A consolidated one was reported by Paredes and Pereira (2019) and is proposed hereafter in Section 4.

The HS Eq. (2) contains an estimate of the incoming solar radiation from the temperature difference TD $=\mathrm{T}_{\max }-\mathrm{T}_{\min }\left({ }^{\circ} \mathrm{C}\right)$, the Hargreaves and Samani radiation equation:

$\mathrm{R}_{\mathrm{sHS}}=\mathrm{k}_{\mathrm{R}_{\mathrm{S}}}\left(\mathrm{T}_{\max }-\mathrm{T}_{\min }\right)^{0.5} \mathrm{R}_{\mathrm{a}}$

where $R_{s}$ HS is daily shortwave solar radiation (MJ m ${ }^{-2} \mathrm{~d}^{-1}$ ) directly expressed as influenced by $\mathrm{k}_{\mathrm{Rs}}$. Therefore, coherently with the recommendation on the use of the HS equation, Allen et al. (1998) proposed to estimate $R_{s}$ with Eq. (3). Previous studies have shown that $k_{R s}$ varies with the site climate, namely dryness/wetness and wind speed (Raziei and Pereira, 2013a; Ren et al., 2016a; Paredes et al., 2018a, b). Paredes and Pereira (2019) reviewed the use of various $R_{s}$ estimation methods from temperature and developed multi-linear regression equations to estimate $\mathrm{k}_{\mathrm{Rs}}$. Their test has shown useful for an accurate computation of $\mathrm{ET}_{\mathrm{o}}$ with the PMT approach for reduced data sets $\left(\mathrm{ET}_{\mathrm{o} \text { PMT }}\right)$. These $\mathrm{k}_{\mathrm{Rs}}$ equations are considered herein and their usability is tested in Section 4, hereafter. More recently, the use of $R_{s}$ from geostationary satellite LSA-SAT and from ERA5 reanalysis were also

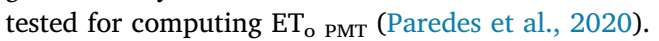

When wind speed data are not available, solutions for the application of the PMT approach include the use of the world average wind speed value $u_{2}$ def $=2 \mathrm{~m} \mathrm{~s}^{-1}$ as the default estimator of wind speed (Allen et al., 1998), and the use of average local or regional wind speed $\left(\mathrm{u}_{2}\right.$ avg $)$ data (Popova et al., 2006; Jabloun and Sahli, 2008; Djaman et al., 2016; Paredes et al., 2018a).

Most studies using the FAO-PMT approach report on its good ac-

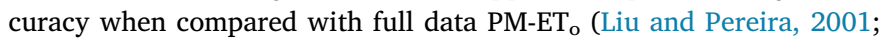
Annandale et al., 2002; Pereira et al., 2003; Popova et al., 2006; Jabloun and Sahli, 2008; López-Moreno et al., 2009; Sentelhas et al., 2010; Almorox et al., 2018). More recent studies report quite good accuracy of $\mathrm{ET}_{\mathrm{o}}$ estimates when using the above referred procedures for estimating $\mathrm{T}_{\mathrm{dew}}, \mathrm{R}_{\mathrm{s}}$ and $\mathrm{u}_{2}$ (Raziei and Pereira, 2013a; Todorovic et al., 2013; Ren et al., 2016a; Paredes et al., 2018a, b). Various authors reported that the PMT approach provided for better results than the HS equation or other temperature based equations, namely for climates marked by humidity (Trajković et al., 2011; Pandey and Pandey, 2016; Ren et al., 2016a; Tomas-Burguera et al., 2017; Ferreira et al., 2019; 
Quej et al., 2019). However, other studies as the one by Singh et al. (2018) applied to India report on the superiority of the HS equation. Aiming at using weather forecasts for irrigation scheduling, the superiority of the PMT approach was reported by Yang et al. (2019a, b).

Recent approaches to estimate $\mathrm{ET}_{\mathrm{o}}$ combine the use of remotely sensed radiation with ground observations or reanalysis data (Bois et al., 2008; Shwetha and Kumar, 2018). Hart et al. (2009) reported on using the NOAA Geostationary Operational Environmental Satellite (GOES) visible satellite data to develop a methodology to extend the California Irrigation Management Information System (CIMIS) $\mathrm{ET}_{\mathrm{o}}$ station estimations to spatial daily $\mathrm{ET}_{\mathrm{o}}$ maps of California. Vyas et al. (2016) used $R_{s}$ from the Indian geostationary satellite, Kalpana- 1 VHRR combined with operational high-resolution short-range weather forecasts on temperature, humidity, and wind speed from the Weather Research and Forecasting (WRF) model to compute $\mathrm{ET}_{\mathrm{o}}$. De Bruin et al. $(2010,2016)$ proposed the LSA-SAF methodology to estimate $\mathrm{ET}_{\mathrm{o}}$ from daily values of downward solar radiation obtained with radiometers onboard the geostationary satellite Meteosat Second Generation (MSG), and from air temperature at $2 \mathrm{~m}$ provided by operational weather forecasts from the European Centre for Medium-range Weather Forecasts (ECMWF). Other applications were reported by Cammalleri and Ciraolo (2013), Cruz-Blanco et al. (2015) and Ramírez-Cuesta et al. (2017). The advantage of using the LSA-SAF methodology to compute $\mathrm{ET}_{\mathrm{o}}$ was recently discussed by Trigo et al. (2018) and De Bruin and Trigo (2019), namely to overcome problems referring to non-reference weather sites, including the effects of aridity and advection. An analysis of the performance of using the $\mathrm{R}_{\mathrm{s}}$ from LSA-SAF in combination with ground-observed $\mathrm{T}_{\max }, \mathrm{T}_{\min }, \mathrm{RH}$ and $\mathrm{u}_{2}$, as well as of using the ET reference product of LSA-SAF in continental Portugal and the islands of Azores is included in the current Special Issue (Paredes et al., 2020). In addition, the successful application of satellite $R_{s}$ in conjunction with ground temperature to compute $\mathrm{ET}_{\mathrm{o}}$ PMT is reported by Shwetha and Kumar (2018) and Paredes et al. (2020). Overall, the use of LSA-SAF products, or similar products from other geostationary satellites, show a great potential to be used for computing $\mathrm{ET}_{\mathrm{o}}$ when only reduced data sets are available.

To overcome the uncertainties inherent to using reduced data sets, an alternative solution is using reanalysis weather data with the PM-ETo equation since global atmospheric reanalysis datasets provide the weather variables data required for $\mathrm{ET}_{\mathrm{o}}$ estimation with high temporal and spatial resolution. The reanalysis products are constructed from numerical weather prediction and data assimilation systems using a variety of atmospheric and sea surface observations to provide for longterm, continuous fields in time and space of atmospheric and land surface variables (Sheffield et al., 2006). However, the use of these data for $\mathrm{ET}_{\mathrm{o}}$ computation may require appropriate bias correction (Hwang et al., 2014; Srivastava et al., 2015; Martins et al., 2017; Paredes et al., 2018c). Main advantages of the reanalysis products are their spatial and temporal consistency and free access (Sheffield et al., 2006). In contrast, limitations of reanalysis products include latency and variable reliability, which depends upon the climatic variable considered, location, period of study and season (Boulard et al., 2016).

Global reanalysis data are available from various sources, namely the ECMWF, presently providing for the ERA5 reanalysis products (Hersbach et al., 2018, 2019), which application for continental Portugal and Azores islands is reported in this Special Issue by Paredes

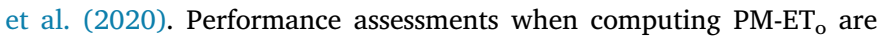
reported by various authors, e.g. Srivastava et al. (2016) using ECMWF ERA-interim and NOAA NCEP reanalysis datasets, Martins et al. (2017) relative to NCEP/NCAR products, and Paredes et al. (2018c) relative to ERA-Interim products. The great potential of using reanalysis products for PM-ET ${ }_{\mathrm{o}}$ computation is shown by Tian et al. (2018) who evaluated the China Meteorological Assimilation Driving Datasets for the SWAT

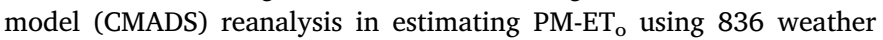
stations across China.

Gridded weather data are often used for computing $\mathrm{ET}_{\mathrm{o}}$ since commonly available variables include solar radiation, near-surface air temperature, air humidity and wind speed. Abatzoglou (2011) compared GRIDMET data with data from 1618 weather stations and found that grass reference evapotranspiration computed with the ASCE Penman-Monteith method showed a median bias of positive $0.5 \mathrm{~mm}$ $\mathrm{d}^{-1}$. The evaluation of the GDAS-based $\mathrm{ET}_{\mathrm{o}}$ from the gridded NOAA Global Data Assimilation System against daily CIMIS reference ET estimates from 85 stations of California was earlier reported by Senay et al. (2008). Other comparisons of gridded-based $\mathrm{ET}_{\mathrm{o}}$ with observations-based $\mathrm{ET}_{\mathrm{o}}$ are reported such as for Iran (Raziei and Pereira, 2013b) and relative to the North-American Land Data Assimilation System, the NLDAS (Lewis et al., 2014). The assessment of six NorthAmerican gridded data sets, including those referred before, is presented by Blankenau et al. (2020) in the current Special Issue. Moreover, this study focuses on correcting gridded data affected by aridity to irrigation environment conditions, thus avoiding positive biases in solar radiation, air temperature and wind speed, and a negative bias in vapour pressure.

Interpolation of observed weather data from nearby stations is another alternative to estimate $\mathrm{ET}_{\mathrm{o}}$ when data is limited or lacking. Such approach was assessed by Tomas-Burguera et al. (2017) for the Iberian Peninsula. They concluded that the best solution was to first interpolate weather data and then compute monthly $\mathrm{ET}_{\mathrm{o}}$. This conclusion was also reported by Raziei and Pereira (2013b) when comparing monthly PM$\mathrm{ET}_{\mathrm{o}}$ computed from observations and gridded data for Iran, and by McVicar et al. (2007) in an application to the Loess Plateau of China. Other examples of interpolation and mapping using gridded databases include the study by Daly et al. (2015) relative to dew point and minimum and maximum vapour pressure deficit, and the one by Strong et al. (2017) focusing on $\mathrm{ET}_{\mathrm{o}}$ and the variables used to its computation.

\section{Material and methods}

As stated before, the main goal of this article is to present a consolidated step-by-step method to parameterize the FAO PenmanMonteith temperature (PMT) approach and the Hargeaves-Samani (HS) equation. Following the related review presented above, the consequent methodology essentially consists of:

1 Reassessing the usability of the $\mathrm{k}_{\mathrm{Rs}}$ multiple linear regression equations developed with the CLIMWAT database (Smith, 1993) for parameterizing the solar radiation Eq. (3) to be used with the PMT approach (Paredes and Pereira, 2019) through computing the PM$\mathrm{ET}_{\mathrm{o}}$ with the PMT approach ( $\mathrm{ET}_{\mathrm{o}} \mathrm{PMT}$ ) using the available independent observation datasets relative to Bolivia, Inner Mongolia, Iran, continental Portugal and Azores islands, and Spain.

2 Developing similar $\mathrm{k}_{\mathrm{Rs}}$ multiple linear regression equations for use with the HS equation (2) using the same CLIMWAT database.

3 Assessing the usability of the developed $\mathrm{k}_{\mathrm{Rs}}$ equations through computing the HS equation using the same observation datasets relative to Bolivia, Inner Mongolia, Iran, continental Portugal and Azores islands, and Spain.

4 Discussing the results of both applications to PMT and HS, mainly in terms of the usability of both approaches.

As referred above, several data sets were used in this study. Data used to derive the predictive $\mathrm{k}_{\mathrm{Rs}}$ equations consisted of the CLIMWAT database (Smith, 1993). Its current version 2.0 consists of observed long-term monthly mean climatic data from over 5000 meteorological stations worldwide including maximum and minimum temperature

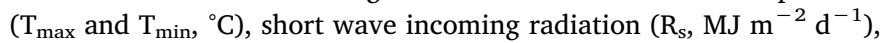
mean relative humidity $(\mathrm{RH}, \%)$ and wind speed $\left(\mathrm{u}_{2}, \mathrm{~km} \mathrm{~d}^{-1}\right)$. The CLIMWAT database has been used in several evapotranspiration studies, namely those reported by Allen (1996, 1997), Temesgen et al. (1999), Droogers and Allen (2002) and Todorovic et al. (2013). Data used in this study refer to the Mediterranean countries with a total 
number of 588 weather stations, hereafter called Med-Climwat.

The independent data sets used to assess the usability of the $k_{\mathrm{Rs}}$ equations with both the PMT approach and the HS equation consist of monthly weather data of Iran (Raziei and Pereira, 2013a,b) and Inner Mongolia (Ren et al., 2016a,b), and daily data of the Altiplano of Bolivia (Chipana et al., 2010), continental Portugal and the Azores Islands (Paredes et al., 2018a,b). Daily data relative to the Spanish weather stations used in the present study were provided by the Spanish Agroclimatic Information System for Irrigation (SIAR) which data spans, for most cases, from 1999 to 2016. Data provided by SIAR were used in various studies on reference evapotranspiration assessment, from Gavilán et al. (2006) to Martins et al. (2017). Data refers to all climatic variables required to compute PM-ET $\mathrm{T}_{\mathrm{o}}$, thus $\mathrm{T}_{\max }\left({ }^{\circ} \mathrm{C}\right), \mathrm{T}_{\min }\left({ }^{\circ} \mathrm{C}\right), \mathrm{RH}$ $(\%), \mathrm{R}_{\mathrm{s}}\left(\mathrm{MJ} \mathrm{m} \mathrm{m}^{-2} \mathrm{~d}^{-1}\right)$ and $\mathrm{u}_{2}\left(\mathrm{~m} \mathrm{~s}^{-1}\right)$. Data quality could be assumed as appropriate since all, but few Portuguese weather stations are synoptic weather stations; data from the non-synoptic weather stations were checked for quality and completeness. Available information allowed assuming that the selected weather stations could be considered as references sites as recommended by Allen et al. (1998). In addition, the efforts of FAO and WMO should be recognized when building the CLIMWAT database aimed at computing the $\mathrm{PM}-\mathrm{ET}_{\mathrm{o}}$ with data from synoptic weather stations assumed as reference sites (Smith, 1993). However, there is insufficient information about weather stations management and related local dryness, aridity or advection impacts, which justifies that $\mathrm{T}_{\text {dew }}$ cannot be assumed equal to $\mathrm{T}_{\text {min }}$ (Temesgen et al., 1999; Todorovic et al., 2013; Ren et al., 2016a; Paredes and Pereira, 2019), thus requiring specific estimation procedures when computing $\mathrm{ET}_{\mathrm{O}}$ PMT as described in the following. As demonstrated in two other papers in this Special Issue (Allen et al., 2020; Blankenau et al., 2020), despite observations could be performed in a reference site, the observed temperature could be larger, up to $5^{\circ} \mathrm{C}$, than that observable for the same site when under irrigation, which would call for a generalized correction of observed air temperatures and humidity. Nevertheless, the approaches proposed herein provide for a correction of station data to approach reference site conditions, in line with more refined propositions by Allen et al. (2020) and Blankenau et al. (2020).

All data sets are distributed into four climate groups defined according to the United Nations Environment Programme (UNEP) aridity index AI (UNEP, 1997) defined as:

$\mathrm{AI}=\mathrm{P}_{\mathrm{t}} / \mathrm{PET}_{\mathrm{TH}}$

where $P_{t}(\mathrm{~mm})$ is the mean annual precipitation and $\mathrm{PET}_{\mathrm{TH}}(\mathrm{mm})$ is the mean annual potential climatic evapotranspiration (Thornthwaite, 1948), both desirably computed from a series of 30 years data or longer. Both $\mathrm{P}_{\mathrm{t}}$ and $\mathrm{PET}_{\mathrm{TH}}$ may be estimated from a nearby weather station.

The distribution of all weather stations by climate types is given in Table 1. Ranges of elevation, $\mathrm{ET}_{\mathrm{o}}$ and $\mathrm{k}_{\mathrm{Rs}}$ computed with the PMT approach are presented in Table 2 referring to the considered climate types. These data ranges evidence that both the Med-Climwat dataset and the datasets used to assess the usability of the developed $\mathrm{k}_{\mathrm{Rs}}$ equations cover a wide range of environmental conditions.
The usability of the developed $k_{\mathrm{Rs}}$ predictive equations for both the PMT and HS approaches focused on the pairwise comparison between the PM-ET $T_{o}$ values computed using all observed variables $\left(\mathrm{O}_{\mathrm{i}}\right)$ and the corresponding predicted $\mathrm{ET}_{\mathrm{O}}$ PMT or $\mathrm{ET}_{\mathrm{O}}$ HS values $\left(\mathrm{P}_{\mathrm{i}}\right)$. As for previous ET studies, the following set of statistical goodness-of-fit indicators (Legates and McCabe Jr., 1999; Pereira et al., 2015b) were used:

a) The regression coefficient $\left(b_{0}\right)$ of a linear regression forced to the origin relating $\mathrm{P}_{\mathrm{i}}$ with $\mathrm{O}_{\mathrm{i}}$, which allows assessing the equality between $\mathrm{ET}_{\mathrm{o}}$ PMT or $\mathrm{ET}_{\mathrm{o}-\mathrm{HS}}$ and the corresponding $\mathrm{PM}_{\mathrm{E}} \mathrm{ET}_{\mathrm{o}}$ values, with a target value $b_{0}=1.0$, with $b_{0}<1.0$ indicating that $P_{i}$ underestimates $\mathrm{O}_{i}$ while $b_{0}>1.0$ indicates overestimation;

b) The coefficient of determination $\left(\mathrm{R}^{2}\right)$ of the ordinary least squares regression between $\mathrm{P}_{\mathrm{i}}$ and $\mathrm{O}_{\mathrm{i}}$, which evaluates the percentage of the variance of $\mathrm{O}_{\mathrm{i}}$ that is explained by the $\mathrm{P}_{\mathrm{i}}$ computational approach of $\mathrm{ET}_{\mathrm{o} \text { PMT }}$ or $\mathrm{ET}_{\mathrm{o}-\mathrm{HS}}$ when using the derived $\mathrm{k}_{\mathrm{Rs}}$ equations. The target value $R^{2}=1.0$ indicates a perfect match and $100 \%$ of variance of the PM-ET ${ }_{\mathrm{o}}$ explained by the $\mathrm{ET}_{\mathrm{o} \text { PMT }}$ or $\mathrm{ET}_{\mathrm{o}-\mathrm{HS}}$ models;

c) The root mean square error (RMSE, $\mathrm{mm} \mathrm{d}^{-1}$ ), which represents the square root of the quadratic mean of the differences between predicted and observed values, i.e. between $\mathrm{ET}_{\mathrm{o}} \mathrm{PMT}_{\mathrm{T}}$ or $\mathrm{ET}_{\mathrm{o}} \mathrm{HS}$ and the corresponding PM-ET ${ }_{\mathrm{o}}$ value. Therefore, the target value is a null difference; and

d) The modelling efficiency (EF), proposed by Nash and Sutcliffe (1970), which measures the relative magnitude of the mean square error $\left(\mathrm{MSE}=\mathrm{RMSE}^{2}\right.$ ) relative to the observed data variance (Legates and McCabe Jr., 1999). Consequently, the best match refers to a minimal MSE, thus to an EF close to 1.0. Acceptable EF values have to be positive since that condition corresponds to a MSE of the predicted $\mathrm{ET}_{\mathrm{o}}$ PMT or $\mathrm{ET}_{\mathrm{o} \text { HS }}$ smaller, desirably much smaller than the variance of $\mathrm{PM}-\mathrm{ET}_{\mathrm{o}}$.

\section{Computing PM-ET from temperature, the PMT approach}

\subsection{Background and computational procedures for PMT}

The consolidated method to compute the $\mathrm{PM}-\mathrm{ET}_{\mathrm{o}}$ temperature approach (PMT) with reduced data sets follows previous studies applied to a wide range of climates (Todorovic et al., 2013; Raziei and Pereira, 2013a; Ren et al., 2016a; Paredes et al., 2018a; Paredes and Pereira, 2019). It consists of a combination of approaches for estimating: (a) the dew point temperature $\left(\mathrm{T}_{\mathrm{dew}}\right)$ from $\mathrm{T}_{\mathrm{min}}$, or from the mean temperature $\left(\mathrm{T}_{\text {mean }}\right)$ in case of humid climates; (b) the short wave incoming radiation $\left(R_{s}\right)$ from the temperature difference ( $T D=T_{\max }-T_{\min }$ ); and (iii) the wind speed $\mathrm{u}_{2}$ using default or regional average values.

(a) Estimating $\mathrm{ET}_{\mathrm{o}}$ when air humidity data are missing:

When relative humidity data or psychrometric observations are missing, Allen et al. (1998) recommended to compute the actual vapour pressure $\left(\mathrm{e}_{\mathrm{a}}, \mathrm{kPa}\right)$ assuming that $\mathrm{T}_{\mathrm{dew}}$ could be acceptably estimated by

Table 1

Number of weather stations of the various datasets and respective climate as defined with the UNEP aridity index.

\begin{tabular}{|c|c|c|c|c|c|c|c|}
\hline \multirow[t]{3}{*}{ Climate and aridity index } & \multicolumn{7}{|c|}{ Number of weather stations per type of climate } \\
\hline & \multirow{2}{*}{$\begin{array}{l}\text { Used to derive the } \mathrm{k}_{\mathrm{Rs}} \text { equations } \\
\text { Med-Climwat* }\end{array}$} & \multicolumn{6}{|c|}{ Used for assessing the usability of the $\mathrm{k}_{\mathrm{Rs}}$ equations } \\
\hline & & Bolivia** & Iran* & Inner Mongolia* & Portugal** & Spain** & Total \\
\hline Arid and hyper-arid climates, $\mathrm{AI}<0.20$ & 83 & - & 13 & 13 & 0 & 6 & 32 \\
\hline Semi-arid, $0.20 \leq \mathrm{AI} \leq 0.65$ & 89 & - & 14 & 27 & 1 & 65 & 107 \\
\hline Moist and dry sub-humid, $0.65<\mathrm{AI}<1.00$ & 281 & 4 & 5 & 7 & 28 & 3 & 47 \\
\hline Humid, $\mathrm{AI} \geq 1.00$ & 135 & - & 5 & - & 27 & 4 & 36 \\
\hline Total & 588 & 4 & 37 & 47 & 56 & 78 & 222 \\
\hline
\end{tabular}

*Monthly data; **daily data. 
Table 2

Ranges of basic characteristics of the sites included in the datasets used: elevation $(\mathrm{m}), \mathrm{ET}_{\mathrm{o}}\left(\mathrm{mm} \mathrm{d}^{-1}\right)$ and $\mathrm{k}_{\mathrm{Rs}}\left({ }^{\circ} \mathrm{C}^{-0.5}\right)$.

\begin{tabular}{|c|c|c|c|c|c|}
\hline \multirow[t]{2}{*}{ Datasets } & & \multicolumn{4}{|l|}{ Climates } \\
\hline & & Humid & Moist and dry sub-humid & Semi-arid & Arid and Hyper-arid \\
\hline & \multicolumn{5}{|c|}{ Ranges of elevation (m) } \\
\hline Used to derive the $\mathrm{k}_{\mathrm{Rs}}$ equations & Med-Climwat & {$[1,1916]$} & {$[0,1775]$} & {$[-200,1585]$} & {$[-276,1378]$} \\
\hline \multirow[t]{6}{*}{ Used to test the usability of derived $\mathrm{k}_{\mathrm{Rs}}$ equations } & Bolivia & - & {$[3789,3950]$} & - & - \\
\hline & Iran & {$[-26,-18]$} & {$[13,1373]$} & {$[143,2048]$} & {$[7,1754]$} \\
\hline & Inner Mongolia & - & {$[286,997]$} & {$[241,1490]$} & {$[940,1561]$} \\
\hline & Portugal & {$[28,1020]$} & {$[5,693]$} & {$[-, 190]$} & - \\
\hline & Spain & {$[340,429]$} & {$[467,750]$} & {$[32,1212]$} & {$[77,435]$} \\
\hline & \multicolumn{5}{|c|}{ Ranges of $\mathrm{ET}_{\mathrm{o}}\left(\mathrm{mm} \mathrm{d}^{-1}\right)$} \\
\hline Used to derive the $\mathrm{k}_{\mathrm{Rs}}$ equations & Med-Climwat & {$[0.2,7.9]$} & {$[0.1,8.8]$} & {$[0.4,9.4]$} & {$[0.8,11.3]$} \\
\hline \multirow{6}{*}{ Used to test the usability of derived $\mathrm{k}_{\mathrm{Rs}}$ equations } & Bolivia & - & {$[1.2,6.3]$} & - & - \\
\hline & Iran & {$[0.5,5.7]$} & {$[0.5,9.1]$} & {$[0.4,11.2]$} & {$[0.5,13.7]$} \\
\hline & Inner Mongolia & - & {$[0.01,6.1]$} & {$[0.03,7.9]$} & {$[0.1,12.5]$} \\
\hline & Portugal & {$[0.2,11.2]$} & {$[0.2,10.9]$} & {$[0.3,10.2]$} & - \\
\hline & Spain & {$[0.2,6.8]$} & {$[0.09,7.2]$} & {$[0.38,10.9]$} & {$[0.43,11.8]$} \\
\hline & \multicolumn{5}{|c|}{ Ranges of $\mathbf{k}_{\mathrm{Rs}}\left({ }^{\circ} \mathrm{C}^{-0.5}\right)^{*}$} \\
\hline Used to derive the $\mathrm{k}_{\mathrm{Rs}}$ equations & Med-Climwat & {$[0.14,0.24]$} & {$[0.13,0.24]$} & {$[0.13,0.24]$} & {$[0.13,0.24]$} \\
\hline \multirow[t]{5}{*}{ Used to test the usability of derived $\mathrm{k}_{\mathrm{Rs}}$ equations } & Bolivia & - & {$[0.13,0.14]$} & - & - \\
\hline & Iran & {$[0.17,0.24]$} & {$[0.12,0.23]$} & {$[0.11,0.23]$} & {$[0.09,0.24]$} \\
\hline & Inner Mongolia & - & {$[0.09,0.16]$} & {$[0.16,0.23]$} & {$[0.18,0.33]$} \\
\hline & Portugal & {$[0.15,0.26]$} & {$[0.11,0.25]$} & {$[-, 0.15]$} & - \\
\hline & Spain & {$[0.13,0.17]$} & {$[0.10,0.11]$} & {$[0.09,0.23]$} & {$[0.14,0.22]$} \\
\hline
\end{tabular}

${ }^{*} \mathrm{k}_{\mathrm{Rs}}$ was computed with the Eq. (3) using a trial and error procedure applied to every site aiming at minimizing the difference between $\mathrm{ET}_{\mathrm{o}}$ PMT and PM-ET .

$\mathrm{T}_{\min }$ (Eq. SI3), thus resulting:

$\mathrm{e}_{\mathrm{a}}=\mathrm{e}^{\mathrm{o}}\left(\mathrm{T}_{\text {dew }}\right)=0.611 \exp \left[\frac{17.27 \mathrm{~T}_{\min }}{\mathrm{T}_{\min }+237.3}\right]$

This approach holds when applied to a reference site covered by an extensive and actively growing grass crop completely shading the ground and not short of water since the PM-ET definition implies the consideration of such grass cover conditions. Allen (1996) and Temesgen et al. (1999) have shown that Eq. (5) does not hold when observations are performed in non-reference sites and/or when sites are affected by dryness and local advection, which cause that $\mathrm{T}_{\min }>\mathrm{T}_{\text {dew }}$. Kimball et al. (1997) also observed that: (i) $\mathrm{T}_{\min }>\mathrm{T}_{\mathrm{dew}}$ in arid sites where average daily differences between $e_{a}$ computed from $T_{\text {min }}$ and $\mathrm{T}_{\mathrm{dew}}$ of $0.8-1.2 \mathrm{kPa}$ occur; (ii) in sites with semi-arid climate those differences vary from 0.1 to $0.6 \mathrm{kPa}$ for winter and summer months, respectively; and (iii) in other less arid conditions, e.g. humid continental and humid subtropical climates, those daily differences average less than $0.3 \mathrm{kPa}$.

As reviewed before, numerous studies assumed $\mathrm{T}_{\mathrm{dew}}=\mathrm{T}_{\min }$ and were likely applied for conditions not far from reference sites. The study by Cai et al. (2007) reported good results of using Eq. (5) except for a site located in a hyper-arid region, typically a site affected by dryness and local advection. Other studies reported less adherence of PMT to humid conditions but do not refer specifically to $\mathrm{T}_{\mathrm{dew}}$ estimation (Martinez and Thepadia, 2010). However, the majority of worldwide weather data are likely reported from sites affected by dryness and advection, thus adopting $\mathrm{T}_{\mathrm{dew}}=\mathrm{T}_{\min }$ may cause less accurate estimates of $\mathrm{ET}_{\mathrm{o}}$. Recently, De Bruin and Trigo (2019) discussed inaccuracies related with non-reference sites and Allen et al. (2020) and Blankenau et al. (2020) discussed about station aridity impacts. In addition, but often not mentioned in literature, data quality also plays a role in the accuracy of estimates (Allen et al., 2011; Kwon and Choi, 2011).

The need for temperature correction to make $\mathrm{T}_{\mathrm{dew}}<\mathrm{T}_{\min }$ was discussed by Allen (1996), Allen et al. (1998), Temesgen et al. (1999) and Annandale et al. (2002). Corrections of 2 or 3 degrees to approach $\mathrm{T}_{\text {min }}$ of $\mathrm{T}_{\mathrm{dew}}$ were referred. Recently, Upreti and Ojha (2017) adopted seasonal correction values varying from $0{ }^{\circ} \mathrm{C}$ during the wet season to $3^{\circ} \mathrm{C}$ during the summer months. Alternative approaches have been considered such as computing $\mathrm{T}_{\mathrm{dew}}$ from $\mathrm{T}_{\min }, \mathrm{T}_{\text {mean }}$ and the temperature difference TD (Hubbard et al., 2003). Using the CLIMWAT database relative to 555 stations in the Mediterranean countries, Todorovic et al. (2013) proposed $\mathrm{T}_{\mathrm{dew}}=\mathrm{T}_{\min }-\mathrm{a}_{\mathrm{T}}$ where the correction factor $\mathrm{a}_{\mathrm{T}}$ should vary with the site characteristic aridity index AI (Eq. 4), so that $\mathrm{a}_{\mathrm{T}}$ is larger for hyper-arid locations and null for moist sub-humid sites. In addition, Todorovic et al. (2013) proposed a different correction for the humid sites, $\mathrm{T}_{\mathrm{dew}}=\mathrm{T}_{\text {mean }}-\mathrm{a}_{\mathrm{D}}$, where daily $\mathrm{T}_{\mathrm{dew}}$ is expected to be above $\mathrm{T}_{\text {min }}$. The appropriateness of this approach was confirmed in applications to Iran (Raziei and Pereira, 2013a), Inner Mongolia (Ren et al., 2016a), the Azores islands (Paredes et al., 2018a) and continental Portugal (Paredes and Pereira, 2019).

Following the referred developments, it is assumed that temperature corrections depend upon the local climate as defined by the UNEP (1997) aridity index (AI, Eq. (4)). The best approaches for computing $\mathrm{T}_{\mathrm{dew}}$ are then (Paredes and Pereira, 2019):

$\mathrm{T}_{\mathrm{dew}}=\mathrm{T}_{\min }-\mathrm{a}_{\mathrm{T}}$ if $\mathrm{AI}<1.00$

$\mathrm{T}_{\mathrm{dew}}=\mathrm{T}_{\text {mean }}-\mathrm{a}_{\mathrm{D}}$ if $\mathrm{AI} \geq 1.00$

The subtractive correction factors vary with the aridity index of the sites as follows:

a) Hyper-arid locations, $\mathrm{AI}<0.05, \mathrm{a}_{\mathrm{T}}=4^{\circ} \mathrm{C}$,

b) Arid locations, $0.05 \leq \mathrm{AI}<0.20, \mathrm{a}_{\mathrm{T}}=2{ }^{\circ} \mathrm{C}$,

c) Semiarid locations and dry sub-humid locations, $0.20 \leq \mathrm{AI}<0.65$, $\mathrm{a}_{\mathrm{T}}=1{ }^{\circ} \mathrm{C}$,

d) Moist sub-humid locations, $0.65 \leq \mathrm{AI}<1.00, \mathrm{a}_{\mathrm{T}}=0{ }^{\circ} \mathrm{C}$,

e) Humid climates, $\mathrm{AI} \geq 1.00, \mathrm{a}_{\mathrm{D}}=2{ }^{\circ} \mathrm{C}$.

Replacing those $\mathrm{T}_{\mathrm{dew}}$ values (Eq. 6) in the saturation vapour pressure equation, it results in the following $e_{a}$ equations to be used when there are no observations of air moisture 
$\mathrm{e}_{\mathrm{a}}=\mathrm{e}^{\mathrm{o}}\left(\mathrm{T}_{\text {dew }}\right)=0.611 \exp \left[\frac{17.27\left(\mathrm{~T}_{\min }-\mathrm{a}_{\mathrm{T}}\right)}{\left(\mathrm{T}_{\mathrm{min}}-\mathrm{a}_{\mathrm{T}}\right)+237.3}\right]$

$\mathrm{e}_{\mathrm{a}}=\mathrm{e}^{\mathrm{o}}\left(\mathrm{T}_{\text {dew }}\right)=0.611 \exp \left[\frac{17.27\left(\mathrm{~T}_{\text {mean }}-\mathrm{a}_{\mathrm{D}}\right)}{\left(\mathrm{T}_{\text {mean }}-\mathrm{a}_{\mathrm{D}}\right)+237.3}\right]$

(b) Estimating $\mathrm{ET}_{\mathrm{o}}$ when solar radiation data are missing:

In the absence of solar radiation and sunshine duration data, Allen (1997) and Allen et al. (1998) proposed to estimate $R_{s}$ using the $R_{s}$ estimator of the equation of Hargreaves and Samani (1982, 1985), which expresses $R_{s}$ as a linear function of the square root of the temperature difference $\mathrm{TD}=\mathrm{T}_{\max }-\mathrm{T}_{\min }$ as:

$\mathrm{R}_{\mathrm{s}}=\mathrm{k}_{\mathrm{R}_{\mathrm{s}}}\left(\mathrm{T}_{\max }-\mathrm{T}_{\min }\right)^{0.5} \mathrm{R}_{\mathrm{a}}$

where $\mathrm{k}_{\mathrm{Rs}}$ is the radiation adjustment coefficient $\left({ }^{\circ} \mathrm{C}^{-0.5}\right)$ and $\mathrm{R}_{\mathrm{a}}$ is the extraterrestrial radiation $\left(\mathrm{MJ} \mathrm{m} \mathrm{m}^{-2} \mathrm{~d}^{-1}\right)$.

Numerous studies focused on the accuracy of Eq. (3) and of other $R_{s}$ equations expressing a dependency on TD. Paredes and Pereira (2019) reviewed related applications, mainly when aimed at computing $\mathrm{ET}_{\mathrm{o}}$, and found that reported accuracies were depending on model parameterization, objectives of applications and goodness-of-fit indicators selected. In alternative to the Eq. (3), the one by Bristow and Campbell (1984) received the preference of various authors, while the model by Thornton and Running (1999) is preferred by others, e.g. Jensen and Allen (2016). Nevertheless, studies aimed at computing the reference ET often ranked high the HS- $\mathrm{R}_{\mathrm{s}}$ equation (e.g. Almorox et al., 2011, 2013; Aladenola and Madramootoo, 2014; Jahani et al., 2017; Quej et al., 2017). Since numerous applications have demonstrated the ap-

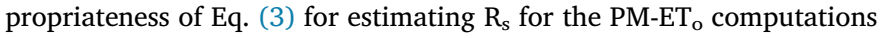
with reduced data sets, the option in recent studies with the PMT approach has been to adopt this Eq. (3). In addition, this equation is simple, which was a main reason why it was originally proposed in FAO56 (Allen et al., 1998).

Although many authors keep using in Eq. (3) the default $\mathrm{k}_{\mathrm{Rs}}$ values 0.16 and $0.19^{\circ} \mathrm{C}^{-0.5}$ for respectively inland and coastal sites as proposed in FAO56 (Allen et al., 1998), research has provided for an accurate estimation of $\mathrm{k}_{\mathrm{Rs}}$ for a variety of environments, including when estimating the empirical coefficient $\mathrm{C}_{\mathrm{HS}}$ of the HS Eq. (2). $\mathrm{k}_{\mathrm{Rs}}$ relates to the atmospheric conditions that influence the availability of incoming solar radiation at crop and natural surfaces, so the availability of energy for evaporation. Allen (1997) suggested estimating $k_{\mathrm{Rs}}$ as a function of elevation to account for the effect of the thickness of the atmosphere on the volumetric heat capacity of the atmosphere. A similar approach was adopted by Annandale et al. (2002). To ease the use of the HS equation without requiring local calibration of $\mathrm{k}_{\mathrm{Rs}}$, Samani (2000) adopted a polynomial relationship with the long-term average temperature difference $\mathrm{TD}_{\mathrm{avg}}\left({ }^{\circ} \mathrm{C}\right)$. Similarly, Thepadia and Martinez (2012) developed a linear $k_{\mathrm{Rs}}$ prediction from the $\mathrm{T}_{\mathrm{avg}} / \mathrm{TD}_{\mathrm{avg}}$ average ratio. Studies show that $\mathrm{k}_{\mathrm{Rs}}$ varies spatially, not only with site elevation but also with the distance to large water bodies, as earlier discussed by Hargreaves and Samani (1982, 1985), Allen (1997) and Hargreaves and Allen (2003). The effect of the proximity to large water bodies, particularly the ocean, may refer to the peculiar behaviour of both wind and air moisture in coastal areas, which were supposed to increase $k_{\mathrm{Rs}}$ relative to inland areas. In addition, recent studies reported that $\mathrm{k}_{\mathrm{Rs}}$ increases with the aridity of the site and with wind speed (Raziei and Pereira, 2013a; Ren et al., 2016a; Paredes et al., 2018a).

First studies reporting the use of Eq. (3) when computing $R_{s}$ with reduced data sets include those by Liu and Pereira (2001), Pereira et al. (2003), Popova et al. (2006) and Jabloun and Sahli (2008), which used simple tests to get the best $\mathrm{k}_{\mathrm{Rs}}$ values. Later, aiming at the calibration of $k_{\mathrm{Rs}}$, trial and error procedures were used by Todorovic et al. (2013), Raziei and Pereira (2013a), Ren et al. (2016a) and Paredes et al.

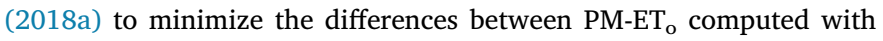

full data and $\mathrm{ET}_{\mathrm{o}}$ PMT computed with $\mathrm{R}_{\mathrm{s}}$ estimated with Eq. (3).

Once calibrated $k_{\mathrm{Rs}}$ values were available from past studies for a large number of locations and diverse climates, Paredes and Pereira (2019) developed various single and multiple linear regressions relating locally calibrated $\mathrm{k}_{\mathrm{Rs}}$ values with various average climatic variables characterizing the same site using data for all 588 Med-Climwat sites. The $\mathrm{k}_{\mathrm{Rs}}$ calibration was performed using a trial and error procedure to minimize the differences between $\mathrm{ET}_{\mathrm{o}} \mathrm{PMT}$ and $\mathrm{PM}-\mathrm{ET}_{\mathrm{o}}$ for all of these sites. Considering the statistical significance of the developed equations, the multiple linear regression Eq. (8) relating $k_{R s}$ with the site averages of TD, $\mathrm{RH}$ and $\mathrm{u}_{2}$ was selected:

$k_{R s}=0.3648-0.0099 T D_{\text {avg }}+0.0194 u_{2 a v g}-0.0017 R H_{\text {avg }}$

This global equation (Eq. (8)) refers to a wide panoply of climates and allowed explaining $69 \%$ of the variance of $\mathrm{k}_{\mathrm{Rs}}$. In practice, the site averages may be computed from available local observations or from a nearby weather station where climate would be similar.

When grouping the sites into four AI defined climate types, the equations selected for each climate type, designated climate-focused $\mathrm{k}_{\mathrm{Rs}}$ equations, are the following:

a) Humid climates ( $\mathrm{AI} \geq 1.00$ )

$$
k_{R s}=0.5191-0.0104 T D_{\text {avg }}+0.0188 u_{2 \text { avg }}-0.0035 R H_{\text {avg }}
$$

b) Moist and dry sub-humid climates $(0.50 \leq \mathrm{AI}<1.00)$

$$
k_{R s}=0.3958-0.0105 T D_{\text {avg }}+0.0186 u_{2 \text { avg }}-0.0021 R H_{\text {avg }}
$$

c) Semi-arid climates $(0.20 \leq \mathrm{AI}<0.50)$

$$
k_{R s}=0.3880-0.0095 T D_{\text {avg }}+0.0224 u_{2 \text { avg }}-0.0022 R H_{\text {avg }}
$$

d) Arid and hyper-arid climates ( $\mathrm{AI}<0.20)$

$$
k_{R s}=0.2169-0.0042 T D_{\text {avg }}+0.0352 u_{2 \text { avg }}-0.0011 R H_{\text {avg }}
$$

The statistical indicators relative to the regression equations 8 and 9 are provided by Paredes and Pereira (2019), which show a strong linear relationship between the dependent variable $\left(\mathrm{k}_{\mathrm{Rs}}\right)$ and the independent variables $\left(\mathrm{TD}_{\mathrm{avg}}, \mathrm{u}_{2}\right.$ avg, $\mathrm{RH}_{\mathrm{avg}}$ ) with values for the multiple coefficient of correlation higher than $0.83, \mathrm{R}^{2}>0.70$, and adjusted $\mathrm{R}^{2}$ above 0.69 . The climate-focused regression Eqs. 9 explain 82, 78, 77 and $74 \%$ of the $\mathrm{k}_{\mathrm{Rs}}$ variance relative to the sites located in humid, sub-humid, semiarid, and arid and hyper-arid climates, respectively. Thus, most of the variance of $\mathrm{k}_{\mathrm{Rs}}$ is explained by the linear multiple regression Eqs. 8 and 9. In these equations, $\mathrm{TD}_{\mathrm{avg}}$ has a negative regression coefficient, which likely relates to the fact that clear-sky conditions occur when TD is high, and more energy is lost as long wave radiation. The wind speed average has a positive regression coefficient, which is likely associated with the clearness of the atmosphere through transporting air moisture away from the evaporation surface. This fact was noticed when first studies defined a larger $k_{\mathrm{Rs}}$ for coastal areas, where wind is often higher than inland (Allen, 1997; Hargreaves and Allen, 2003), as well as in studies by Raziei and Pereira (2013a), Ren et al. (2016a) and Paredes et al. (2018a). $\mathrm{RH}_{\mathrm{avg}}$ has a negative regression coefficient which may indicate that this variable represents the influence of cloudiness and air moisture, thus with less incoming radiation when RH is high. However, these interpretations must be considered with care since in a multiple regression all independent variables play complementary, not individual roles.

\section{(c) Estimating $\mathrm{ET}_{\mathrm{o}}$ when wind speed data are missing:}

Two alternatives are considered when reduced data sets do not include wind speed data: the use of the world average wind speed value 
$\mathrm{u}_{2}=2 \mathrm{~m} \mathrm{~s}^{-1}$ as the default estimator as proposed by Allen et al. (1998), or the local or regional average wind speed data as considered by Popova et al. (2006), Jabloun and Sahli (2008), Raziei and Pereira (2013a) and Paredes et al. (2018a). Generally, impacts of wind speed are less important than those of other variables except for windy and arid areas (Allen et al., 1998); however, the accuracy of $\mathrm{ET}_{\mathrm{o}}$ estimation for windy sites in arid Iran (Raziei and Pereira, 2013a) and in the humid islands of Azores (Paredes et al., 2018a) was higher when using average $\mathrm{u}_{2}$ values characterizing the local climate.

\subsection{The PMT approach}

The above referred approaches for estimating $e_{a}, R_{s}$ and $u_{2}$ when

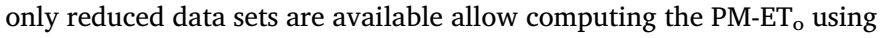
the PMT approach, i.e. those variables when missing are replaced by their respective estimators. The PMT approach is summarized in the flow chart of Fig. 1 to be used as a guide for users. The flow-chart of Fig. 1 indicates the procedures proposed to estimate $R_{s}$ and $e_{a}$ from temperature, and $\mathrm{u}_{2}$ as a local or regional average or as a default value. When any of these weather variables is observed during the entire period of calculation, or for some restricted period only, the flow-chart procedure is applied using the observed values of the variable of interest, not its estimate.

Relative to the $\mathrm{k}_{\mathrm{Rs}}$ computation with Eqs. 8 and 9, the average values for TD, $\mathrm{RH}$ or $\mathrm{u}_{2}$ refer to local averages or to averages computed with data of nearby weather stations with similar climate, which are then used as default values relative to the targeted site.

\subsection{Assessing $E T_{o}$ when $T_{\text {dew }}$ is estimated from $T_{\text {min }}$ or $T_{\text {mean }}$}

The PMT approach is proposed herein with an appropriate correction of the temperature for estimating $\mathrm{T}_{\mathrm{dew}}$ (Eqs. (6) and (7), and Fig. 1). Table 3 presents a comparison of the goodness-of-fit indicators relative to the computation of $\mathrm{ET}_{\mathrm{o}}$ Рмт using the Iranian database (Raziei and Pereira, 2013a) when assuming $\mathrm{T}_{\mathrm{dew}}=\mathrm{T}_{\min }$ or using temperature corrections to estimate $\mathrm{T}_{\mathrm{dew}}$ (Eqs. (6) and (7)). By comparing the regression coefficients $b_{0}$ relative to computing $\mathrm{ET}_{\mathrm{o}} \mathrm{PMT}$ without or with temperature correction it can be observed (Table 3) that the range of $b_{0}$ values is reduced for the latter, with $b_{0}$ becoming closer to 1.0. The underestimation trend observed when assuming $\mathrm{T}_{\mathrm{dew}}$ $=\mathrm{T}_{\min }$ is avoided for sub-humid and semi-arid climates, while for arid and hyper-arid such trend is highly reduced. For all climates, $b_{0}$ values result closer to 1.0, although results for arid and hyper-arid climates may keep some trends for under-estimation. This result is due to reducing the effects of site aridity as often discussed, earlier by Allen (1997), Allen et al. (1998) and Temesgen et al. (1999), and presently by Allen et al. (2020) and Blankenau et al. (2020). The range and the mean of the $\mathrm{R}^{2}$ values are highly improved, becoming closer to 1.0, while the respective standard deviation (s.d.) are reduced for all climates. The average and s.d. of RMSE decrease for all climates, with reductions of the mean close to $20 \%$, which are particularly evident for the climates marked by aridity. These changes are likely the consequence of controlling the station aridity impacts. Nevertheless, very large RMSE values observed in a few hyper-arid locations could not be avoided but just decreased.

This example using the Iranian datasets demonstrates the usefulness of using improved estimates of $\mathrm{T}_{\mathrm{dew}}$ for computing $\mathrm{ET}_{\mathrm{o}}$ PMT. These results also indicate that for sites marked by great aridity there may exist also large impacts of local advection, especially when wind speed is high, although, sites having a very large RMSE may also have a poor management and a deficit irrigated grass cover, which deviate those sites from the reference conditions. However, in general, correcting $\mathrm{T}_{\text {min }}$ for computing $\mathrm{T}_{\mathrm{dew}}$ is positive.

\subsection{Assessing $E T_{o}$ when using default $u_{2} v s$. local or regional $u_{2}$ averages}

To examine the impact of alternative methods to estimate wind speed when calculating $\mathrm{ET}_{\mathrm{o}}$ РMT, their estimates were compared with full data $\mathrm{PM}-\mathrm{ET}_{\mathrm{o}}$ for some arid and windy stations of Inner Mongolia considering two alternatives for estimating $\mathrm{u}_{2}$ :

(a) the default value $\mathrm{u}_{2 \text { def }}=2 \mathrm{~m} \mathrm{~s}^{-1}$, and

(b) the average seasonal value $\mathrm{u}_{2}$ avg.

Both alternatives were assessed using three distinct approaches for computing $\mathrm{k}_{\mathrm{R} s}$ :

(1) a trial and error procedure to minimize differences between $\mathrm{ET}_{\mathrm{o}} \mathrm{PMT}$ and PM-ET,

(2) the global $\mathrm{k}_{\mathrm{Rs}}$ Eq. (8); and

(3) the climate-focused $k_{\mathrm{Rs}}$ Eq. (9d) for arid and hyper-arid climates.

Results in Fig. 2 show that when $k_{\mathrm{Rs}}$ values were locally calibrated using a trial and error procedure it is indifferent to use $u_{2}$ def or $u_{2}$ avg (Fig. 2a and $d$ ) because the $\mathrm{u}_{2}$ impacts are overcome by the appropriateness of $\mathrm{k}_{\mathrm{Rs}}$. This result is similar to those observed in other studies, e.g., Paredes et al. (2018a,b) and likely relates to the fact that when $\mathrm{k}_{\mathrm{Rs}}$ is optimized also solar radiation is best estimated as per Eq. (3). Differently, wind speed estimates play a role when $\mathrm{k}_{\mathrm{Rs}}$ is computed with one of the Eqs. (8) or (9), which lead to improve but not to optimize solar radiation. Hence, a clear trend for under-estimation of $\mathrm{ET}_{\mathrm{o}}$ is observed if using $\mathrm{u}_{2}$ def; contrarily, that under-estimation trend is avoided when using $\mathrm{u}_{2}$ avg (Fig. $2 \mathrm{a}$ and $\mathrm{b}$ ). This behaviour is quite evident in this application, with the average $b_{0}$ increasing from 0.85 to 1.00 or from 0.89 to 1.03 when, respectively, the global (Eq. (8)) or the arid climate-focused Eq. (9d) were applied. Recent studies relative to the application of PMT to the Sahel region (Djaman et al., 2016) and to the use of PMT in China (Yang et al., 2019a,b) have shown that a longterm average wind speed data produced better results than adopting the $\mathrm{u}_{2 \text { def }}$, thus in agreement with results shown above. Therefore, it may be concluded that using a long-term average of wind speed, namely observed in a nearby weather station, contributes to the accuracy of PMT calculations.

\subsection{Assessing $E T_{o}$ when $R_{s}$ is estimated from the temperature difference}

When radiation or sunshine duration measurements are not available, the PMT method uses $R_{s}$ computed with Eq. (3) with $k_{R s}$ values obtained through:

a) A trial and error procedure to select the $k_{\mathrm{Rs}}$ value that minimizes the

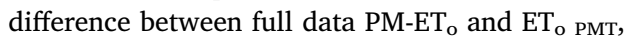

b) The global predictive Eq. (8), or

c) The appropriate climate-focused Eq. (9).

The mean and standard deviation (s.d.) of the $\mathrm{k}_{\mathrm{Rs}}$ values computed for every data sets of Bolivia, Inner Mongolia, Iran, Portugal and Spain for those alternatives when using the PMT approach are given in Table 4. Results show that the highest locally calibrated mean $\mathrm{k}_{\mathrm{Rs}}$ values refer to the hyper-arid climates, where TD is higher, RH is smaller and $\mathrm{u}_{2}$ is often large, followed by the humid climates, where TD is small, $\mathrm{RH}$ is the highest and $\mathrm{u}_{2}$ may also be large in sites near the ocean or in oceanic islands. Samani (2000) reported a similar behaviour when presenting a $\mathrm{k}_{\mathrm{Rs}}$ polynomial function of TD. The lowest values are for the sub-humid climates, likely because they are less affected by climate extremes. The method used to compute $\mathrm{k}_{\mathrm{Rs}}$ seems to play a minor role on the variability of the computed $k_{\mathrm{Rs}}$ since mean values and standard deviations are similar when using the global or the climate-focused Eqs. (8) and (9). 


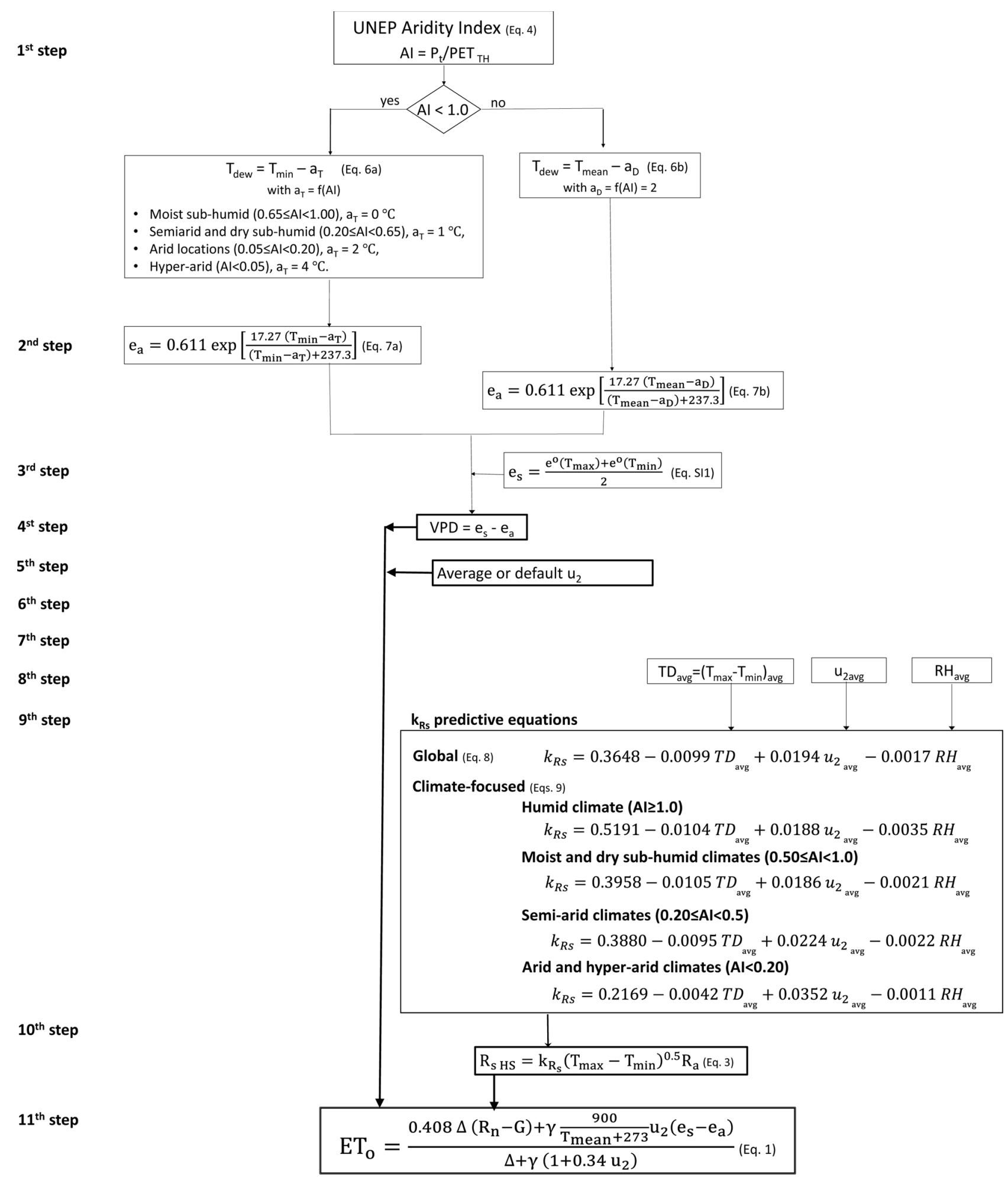

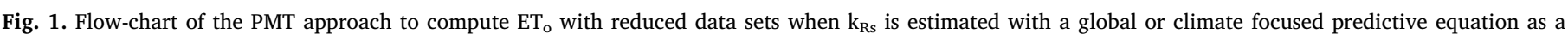

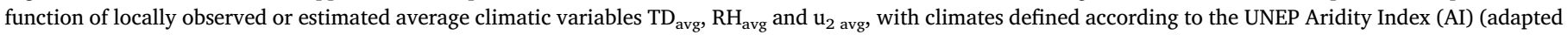
from Paredes and Pereira, 2019).

Aiming at assessing the usability of the $\mathrm{k}_{\mathrm{Rs}}$ Eqs. (8) and (9), $\mathrm{ET}_{\mathrm{o}}$ PMT were computed for all independent data sets of Bolivia, Iran, Inner Mongolia, Portugal and Spain, thus assuring a great variety of environmental and climate conditions (Tables 1 and 2). These $\mathrm{ET}_{\mathrm{o}}$ PMT computations were performed with $\mathrm{T}_{\mathrm{dew}}$ estimated with Eqs. (6) and (7), $\mathrm{u}_{2}$ estimated as for previous studies with the default value $2 \mathrm{~m} \mathrm{~s}^{-1}$, while for $R_{s}$ three alternative ways of calculating $k_{R s}$ were used: site calibration using a trial and error procedure and $\mathrm{k}_{\mathrm{Rs}}$ estimation with the global and the climate-focused Eqs. (8) and (9). All three sets of ET ${ }_{\text {o PMT }}$ were compared with PM-ET or $_{0}$ for the same site, thus providing the respective goodness-of-fit indicators described in Section 3: $b_{0}, R^{2}$, RMSE and EF. These results are summarized in Table 5 grouped according to the climate of the sites, e.g. the humid climate group referring to 36 sites. Paired comparisons of $\mathrm{ET}_{\mathrm{o}} \mathrm{PMT}$ and $\mathrm{PM}_{\mathrm{ET}}$ are shown in scatter 
Table 3

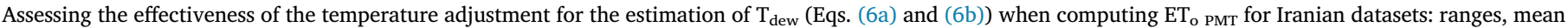
and standard deviation of various goodness-of-fit indicators relative to various climates (adapted from Raziei and Pereira, 2013a).

\begin{tabular}{|c|c|c|c|c|c|c|}
\hline \multirow[t]{2}{*}{ Climate } & \multicolumn{3}{|c|}{ Assuming $\mathrm{T}_{\mathrm{dew}}=\mathrm{T}_{\min }$} & \multicolumn{3}{|c|}{ Estimating $\mathrm{T}_{\mathrm{dew}}$ from Eqs. (6a) and (6b) } \\
\hline & $\mathrm{b}_{0}$ & $\mathrm{R}^{2}$ & $\operatorname{RMSE}\left(\mathrm{mm} \mathrm{d}^{-1}\right)$ & $\mathrm{b}_{0}$ & $\mathrm{R}^{2}$ & RMSE $\left(\mathrm{mm} \mathrm{d}^{-1}\right)$ \\
\hline \multirow[t]{2}{*}{ Humid } & 0.97 to 1.05 & 0.88 to 0.96 & 0.24 to 0.39 & 0.99 to 1.03 & 0.94 to 0.98 & 0.19 to 0.32 \\
\hline & & $0.90( \pm 0.03)$ & $0.34( \pm 0.06)$ & & $0.95( \pm 0.02)$ & $0.27( \pm 0.05)$ \\
\hline \multirow[t]{2}{*}{ Moist and dry sub-humid } & 0.89 to 0.97 & 0.80 to 0.96 & 0.43 to 0.65 & 0.99 to 1.03 & 0.93 to 0.97 & 0.36 to 0.50 \\
\hline & & $0.91( \pm 0.07)$ & $0.52( \pm 0.10)$ & & $0.95( \pm 0.02)$ & $0.42( \pm 0.05)$ \\
\hline \multirow[t]{2}{*}{ Semi-arid } & 0.88 to 0.99 & 0.83 to 0.98 & 0.38 to 0.88 & 0.99 to 1.03 & 0.88 to 0.98 & 0.30 to 0.77 \\
\hline & & $0.93( \pm 0.04)$ & $0.57( \pm 0.17)$ & & $0.95( \pm 0.03)$ & $0.46( \pm 0.12)$ \\
\hline \multirow[t]{2}{*}{ Arid and hyper-arid } & 0.61 to 0.95 & 0.66 to 0.98 & 0.36 to 3.67 & 0.67 to 1.03 & 0.67 to 0.98 & 0.28 to 3.29 \\
\hline & & $0.89( \pm 0.09)$ & $0.88( \pm 0.76)$ & & $0.91( \pm 0.07)$ & $0.73( \pm 0.71)$ \\
\hline
\end{tabular}

${ }^{*} \mathrm{k}_{\mathrm{Rs}}$ was obtained using a trial and error procedure applied to every location; $\mathrm{u}_{2}$ def $=2 \mathrm{~m} \mathrm{~s}^{-1}$ was used.

plots in Fig. 3, also grouped according to the climate of the sites, for example using 94,730 pairs in the humid set. The analysis in Fig. 3 complements the one in Table 5. Results in Fig. 3 show $b_{0}$ values close to 1.0 for all cases, with the lowest value (0.96) for the arid and hyperarid using Eq. (9). $\mathrm{R}^{2}$ values are smaller for humid climates, likely where the variability of climate data is highest. Results in Fig. 3 also show that the highest values of PM-ET $\mathrm{T}_{\mathrm{o}}$ tend to be under-estimated by the PMT approach because these extreme $\mathrm{ET}_{\mathrm{o}}$ values are due to high windy conditions and, in this assessment, the default $\mathrm{u}_{2}$ is used. These results agree with those in Section 4.4, therefore leading to propose that $\mathrm{u}_{2}$ should be estimated by a local or regional wind average, namely computed with data from a nearby weather station.

Table 5 shows the ranges, means and standard deviations of the statistical indicators relative to every site of the independent data sets grouped according to the climate of the sites. The regression coefficients $b_{0}$ vary in a very small range when $k_{R s}$ is site-calibrated and vary in wider ranges when $k_{\mathrm{Rs}}$ are computed with the Eqs. 8 and 9, with the widest range for the global Eq. (8) in arid and hyper-arid sites. Using site calibration of $\mathrm{k}_{\mathrm{Rs}}$, since calibration is performed to minimize differences between $\mathrm{ET}_{\mathrm{O}}$ PMT and $\mathrm{PM}-\mathrm{ET}_{\mathrm{o}}$ sets, the effects of extreme values of any weather variable are controlled. Differently, using a computed $\mathrm{k}_{\mathrm{Rs}}$ value extreme values of weather variable may lead to site-specific trends in $\mathrm{ET}_{\mathrm{O} \text { PMT, }}$, thus to the occurrence of $\mathrm{b}_{0}$ much larger or smaller than 1.0, therefore enlarging the range of computed $b_{0}$. This is the case of sites having wind speed much different than the default value used. Hence, results for the goodness-of-fit indicators would be slightly better if $\mathrm{u}_{2}$ avg were used instead. When comparing all pairs of $\mathrm{ET}_{\mathrm{o}}$ PMT and PM-ET o $_{\mathrm{o}}$ relative to the sites grouped by climate, it may be observed (Fig. 3) that the resulting $b_{0}$ are all close to 1.0 ; the lowest $b_{0}$ is 0.96 for arid and hyper-arid sites when $\mathrm{k}_{\mathrm{Rs}}$ is computed with Eq. (9d). For all other cases, there are no notable differences between results relative to Eqs. (8) and (9).
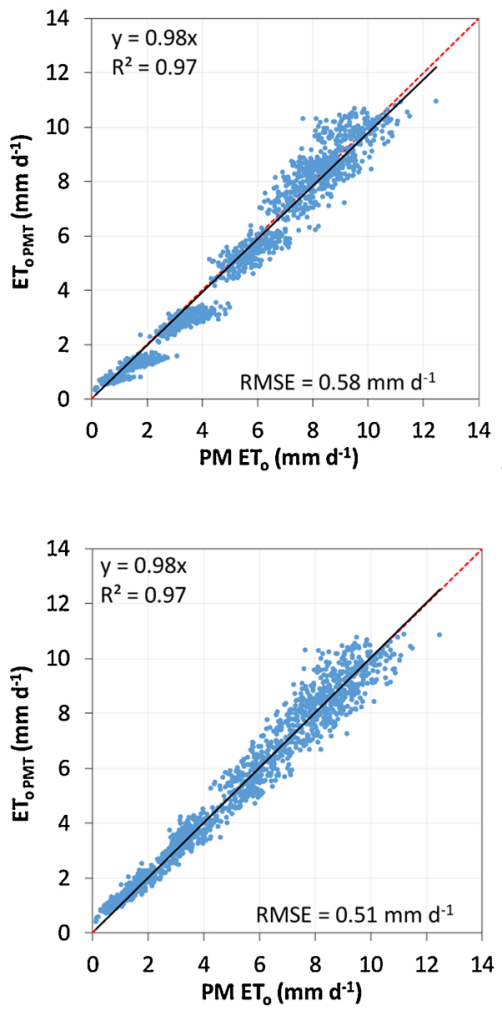

a)
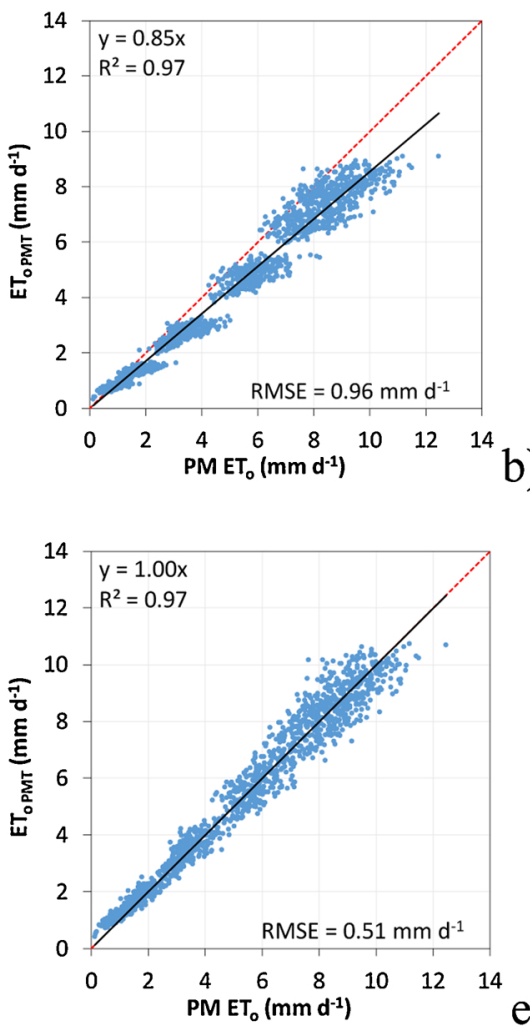

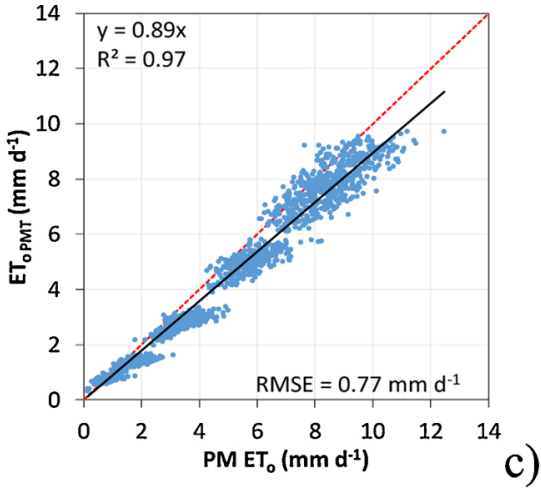

c)

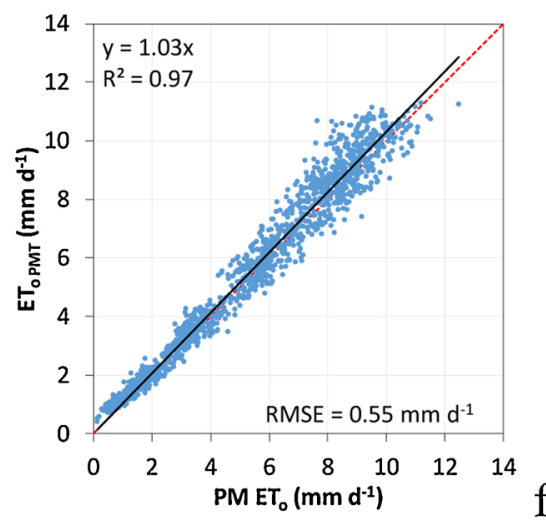

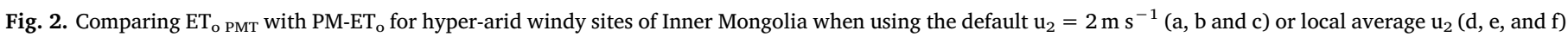

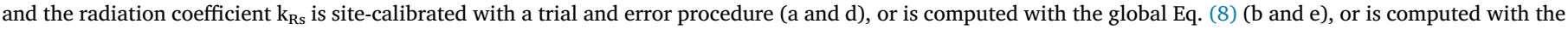
Eq. (9d) for arid and hyper-arid climates (c and f). 
Table 4

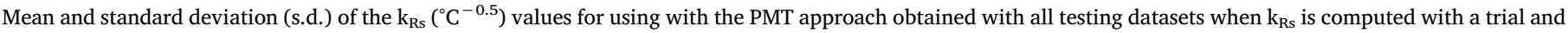
error procedure, using the global Eq. (8), or using the appropriate climate-focused Eq. (9).

\begin{tabular}{|c|c|c|c|c|}
\hline \multirow[t]{2}{*}{ Procedure used to obtain $\mathrm{k}_{\mathrm{Rs}}$} & \multicolumn{4}{|c|}{ Mean and (s.d.) of $\mathrm{k}_{\mathrm{Rs}}\left({ }^{\circ} \mathrm{C}^{-0.5}\right)$ values relative to the climate of the sites } \\
\hline & Humid & Sub-humid & Semi-arid & Arid \& hyper-arid \\
\hline $\mathrm{k}_{\mathrm{Rs}}$ locally calibrated using a trial and error procedure & $0.20( \pm 0.03)$ & $0.14( \pm 0.03)$ & $0.17( \pm 0.04)$ & $0.22( \pm 0.05)$ \\
\hline $\mathrm{k}_{\mathrm{Rs}}$ estimated with the global Eq. (8) & $0.21( \pm 0.04)$ & $0.15( \pm 0.02)$ & $0.18( \pm 0.03)$ & $0.20( \pm 0.03)$ \\
\hline $\mathrm{k}_{\mathrm{Rs}}$ estimated with the adequate climate-focused Eq. (9) & $0.23( \pm 0.06)$ & $0.15( \pm 0.02)$ & $0.18( \pm 0.04)$ & $0.19( \pm 0.04)$ \\
\hline
\end{tabular}

Table 5

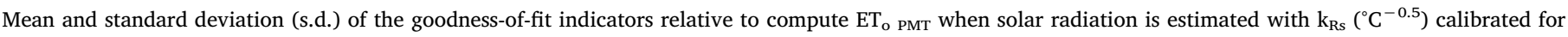
every site or computed with the Eqs. (8) or (9) using independent data sets of Bolivia, Inner Mongolia, Iran, Portugal and Spain.

\begin{tabular}{|c|c|c|c|c|c|c|}
\hline & \multicolumn{2}{|l|}{ Number of } & \multirow[t]{2}{*}{$\mathrm{b}_{0}$ (range) } & \multirow{2}{*}{$\begin{array}{l}\mathrm{R}^{2} \\
\text { Mean and (s.d.) }\end{array}$} & \multirow{2}{*}{$\begin{array}{l}\text { RMSE (mm d } \\
\text { Mean and (s.d.) }\end{array}$} & \multirow{2}{*}{$\begin{array}{l}\text { EF } \\
\text { Mean and (s.d.) }\end{array}$} \\
\hline & Observations & Sites & & & & \\
\hline \multicolumn{7}{|l|}{$\mathbf{k}_{\mathrm{Rs}}$ site-calibrated } \\
\hline Humid & 94,730 & 36 & $0.94-1.01$ & $0.78( \pm 0.14)$ & $0.54( \pm 0.16)$ & $0.76( \pm 0.15)$ \\
\hline Moist \& Dry sub-humid & 145,326 & 47 & $0.97-1.03$ & $0.88( \pm 0.11)$ & $0.59( \pm 0.14)$ & $0.86( \pm 0.15)$ \\
\hline Semi-arid & 412,368 & 107 & $0.96-1.02$ & $0.91( \pm 0.04)$ & $0.61( \pm 0.14)$ & $0.90( \pm 0.04)$ \\
\hline Arid \& Hyper-arid & 47,791 & 32 & $0.96-1.02$ & $0.91( \pm 0.07)$ & $0.65( \pm 0.21)$ & $0.90( \pm 0.07)$ \\
\hline All data & 700,215 & 222 & $0.94-1.03$ & $0.88( \pm 0.10)$ & $0.60( \pm 0.16)$ & $0.87( \pm 0.11)$ \\
\hline \multicolumn{7}{|c|}{$\mathbf{k}_{\mathbf{R s}}$ computed with the global Eq. $(8)$} \\
\hline Humid & 94,730 & 36 & $0.84-1.17$ & $0.78( \pm 0.14)$ & $0.61( \pm 0.15)$ & $0.70( \pm 0.21)$ \\
\hline Moist \& Dry sub-humid & 145,326 & 47 & $0.90-1.18$ & $0.88( \pm 0.11)$ & $0.63( \pm 0.12)$ & $0.83( \pm 0.17)$ \\
\hline Semi-arid & 412,368 & 107 & $0.91-1.16$ & $0.92( \pm 0.04)$ & $0.64( \pm 0.14)$ & $0.89( \pm 0.05)$ \\
\hline Arid \& Hyper-arid & 47,791 & 32 & $0.83-1.39$ & $0.92( \pm 0.07)$ & $0.74( \pm 0.27)$ & $0.87( \pm 0.13)$ \\
\hline All data & 700,215 & 222 & $0.83-1.39$ & $0.89( \pm 0.10)$ & $0.65( \pm 0.16)$ & $0.84( \pm 0.14)$ \\
\hline \multicolumn{7}{|c|}{$\mathbf{k}_{\mathrm{Rs}}$ computed with the climate-focused Eq. (9) } \\
\hline Humid & 94,730 & 36 & $0.86-1.17$ & $0.78( \pm 0.14)$ & $0.59( \pm 0.16)$ & $0.71( \pm 0.19)$ \\
\hline Moist \& Dry sub-humid & 145,326 & 47 & $0.88-1.16$ & $0.88( \pm 0.11)$ & $0.64( \pm 0.14)$ & $0.84( \pm 0.15)$ \\
\hline Semi-arid & 412,368 & 107 & $0.91-1.16$ & $0.92( \pm 0.04)$ & $0.65( \pm 0.12)$ & $0.89( \pm 0.05)$ \\
\hline Arid \& Hyper-arid & 47,791 & 32 & $0.87-1.21$ & $0.92( \pm 0.07)$ & $0.72( \pm 0.22)$ & $0.88( \pm 0.10)$ \\
\hline All data & 700,215 & 222 & $0.86-1.21$ & $0.89( \pm 0.10)$ & $0.64( \pm 0.15)$ & $0.85( \pm 0.13)$ \\
\hline
\end{tabular}

When comparing mean and standard deviations of $\mathrm{R}^{2}$, it may be observed (Table 5) that differences among the three sets of $\mathrm{ET}_{\mathrm{o}}$ PMT relative to alternative ways of determining $\mathrm{k}_{\mathrm{Rs}}$ are nearly nil, i.e. results referring to Eqs. 8 and 9 are similar to those when $\mathrm{k}_{\mathrm{Rs}}$ was site-calibrated. Differences among climate groups are also small; the smaller mean and larger s.d. concern the humid climates, likely due to its larger variability of climate variables relative to other climates. Results in Fig. 3 show that $\mathrm{R}^{2}$ are generally high, from 0.88 to 0.90 , except for humid climates where $\mathrm{R}^{2}$ varies from 0.79 to 0.84 , with the lowest value relative to using Eq. (9a). Overall, $\mathrm{R}^{2}$ results let assuming the usability of Eqs. (8) and (9).

The mean RMSE values are generally low. However, values relative to $\mathrm{ET}_{\mathrm{o}}$ PMT computed with calibrated $\mathrm{k}_{\mathrm{Rs}}$ are smaller than those relative to using Eqs. (8) and (9), although differences between the latter are not notable. Higher mean and s.d. values refer to arid and hyper-arid climates. Lower means refer to humid climates and the smaller s.d. concern semi-arid climates. Mean results are proportional to the corresponding average $\mathrm{ET}_{\mathrm{o}}$ (Table 2), highest in arid and hyper-arid climates and lowest in humid climates. Differently, s.d. values likely relate with climate variability, lesser in semi-arid climates. Overall, EF are quite high, particularly when calibrated $\mathrm{k}_{\mathrm{Rs}}$ are used since then mean errors of estimate are small. Nevertheless, differences of EF values resulting from computations using Eqs. (8) and (9) are small. Results for all the five indicators allow to consider a good usability of both the global and the climate-focused $\mathrm{k}_{\mathrm{Rs}}$ equations.

Comparing the frequency of occurrence of $b_{0}$ and RMSE per class of accuracy relative to the use of the $\mathrm{k}_{\mathrm{Rs}}$ Eqs. (8) and (9) (Fig. 4) a few differences were noticed. The frequency of occurrence of $b_{0}$ values ranging $0.95-1.05$, i.e. not showing a tendency for under- or over-estimation, is the highest for all climate groups except for the humid climates where this condition is only observed for the case of Eq. (9a). When using Eq. (8), the most common interval for $b_{0}$ is $1.05-1.15$, thus indicating a trend for over-estimation. RMSE values ranging 0.50 to $0.75 \mathrm{~mm} \mathrm{~d}^{-1}$ are the most frequent for all climates. Overall, small differences are apparent relative to using Eqs. (8) and (9). Results in Fig. 4 also contribute to assume the usability of Eqs. (8) and (9) to predict $\mathrm{k}_{\mathrm{Rs}}$; however, differences among climates may support the preference for using the climate-focused Eq. (9).

\subsection{Computation of ET $T_{o}$ with PMT when one, two or three weather variables are missing}

One advantage of the PMT approach is that when there are observations of one or two weather variables these may be used together with estimators of those that are missing. Software aimed at estimating $\mathrm{ET}_{\mathrm{o}}$ when some weather data are missing includes the option for combining observed and estimated weather variables in PMT (Annandale et al., 2002; Gocic and Trajkovic, 2010). Various studies reported on this combined use of observed and estimated variables when wind, air humidity and/or radiation data are missing (Liu and Pereira, 2001; Popova et al., 2006; Jabloun and Sahli, 2008; LópezMoreno et al., 2009; Trajkovic and Kolakovic, 2009; Sentelhas et al., 2010; Córdoba et al., 2015; Majidi et al., 2015; Djaman et al., 2016; Paredes et al., 2018a,b; Yang et al., 2019a). However, results are influenced by the fact that, often, neither $\mathrm{T}_{\mathrm{dew}}$ nor $\mathrm{k}_{\mathrm{Rs}}$ are calibrated, thus not always evidencing advantages on using PMT approach proposed in this article. Therefore, it is important to evaluate the goodness-of-fit indicators relative to using the PMT approach for various combinations of missing weather variables using the best estimators of the missing variables. Applications to the Azores islands, which climate is humid 


\section{kss locally calibration}

Humid climates
$(\mathrm{n}=94730)$

$(\mathrm{n}=145326)$

Semi-arid climates

$(n=412368)$

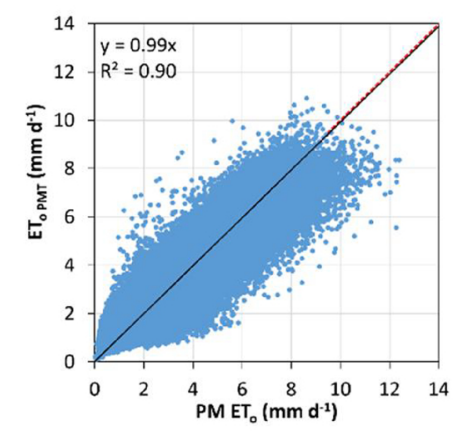

Arid \& Hyper-arid

climates

$(\mathrm{n}=47791)$

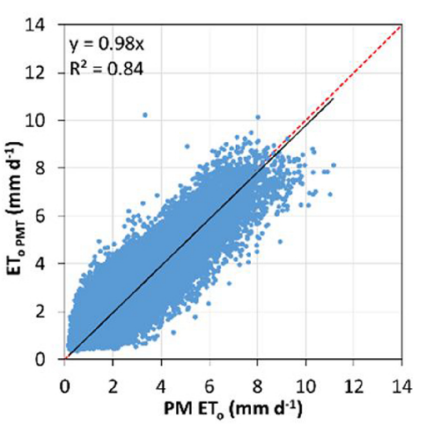

KRs estimated with the global Eq. 8

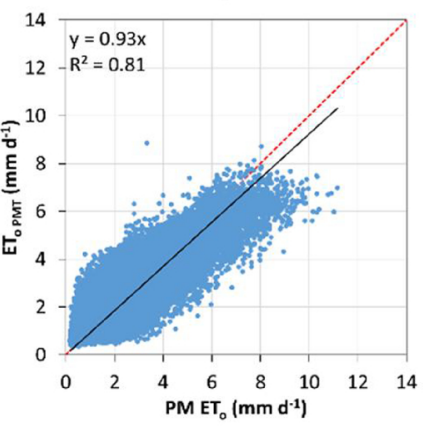

kRs estimated with the climate-focused Eqs. 9
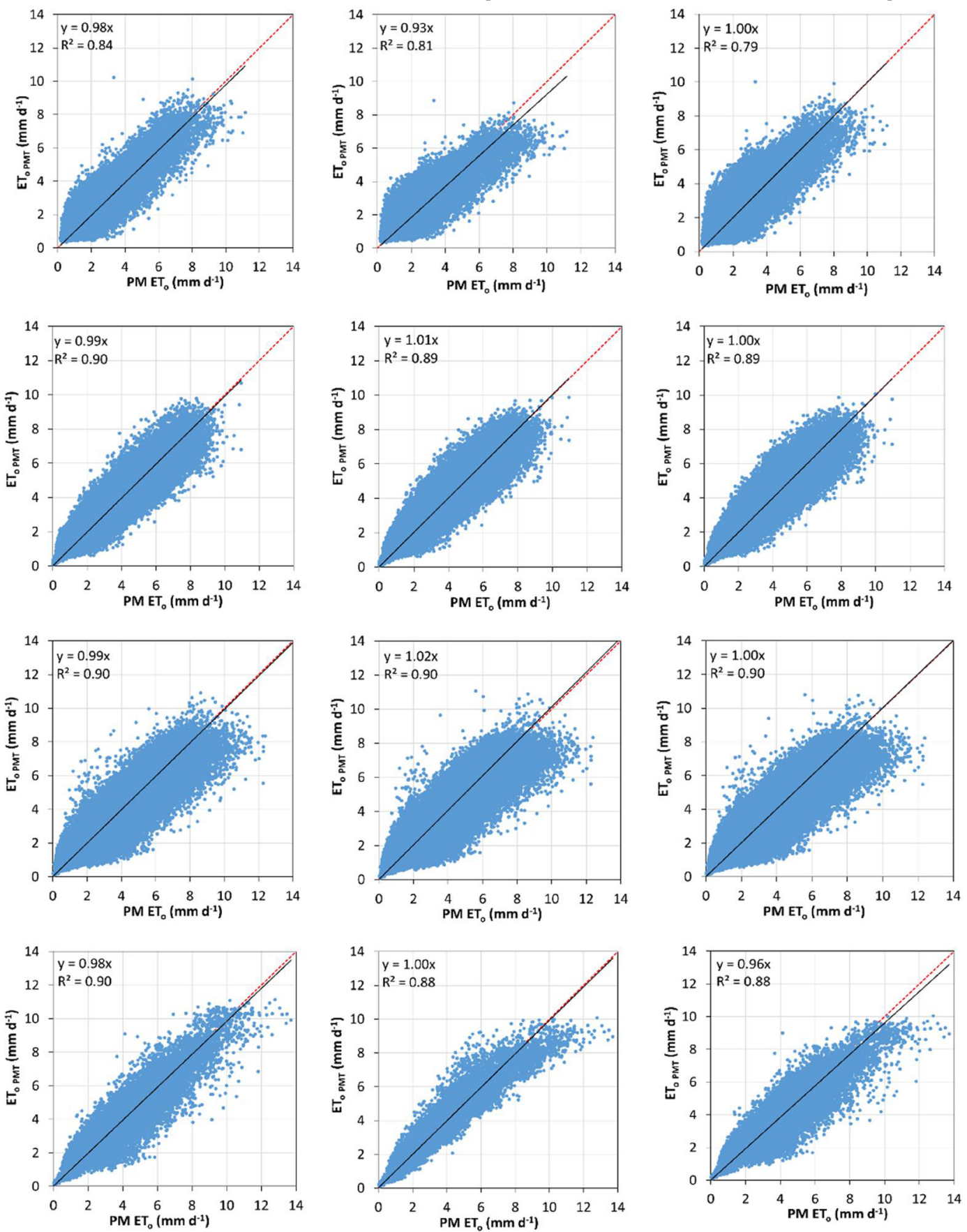

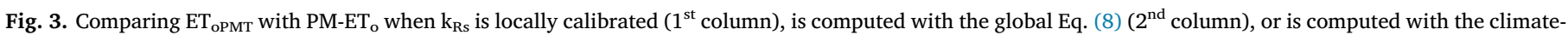

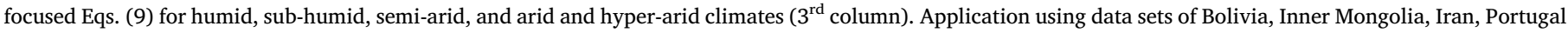
and Spain.

and windy, and continental Portugal, where the climate varies from humid to semi-arid, are reported in Table 6 using the $\mathrm{T}_{\mathrm{dew}}$ estimates with Eqs. (6) and (7), $R_{s}$ estimates using both the global and climatefocused $k_{\mathrm{Rs}}$ Eqs. (8) and (9), and both default and regional average wind speed.

When only air humidity data are missing, the $\mathrm{ET}_{\mathrm{o}}$ PMT is computed associating the observed weather variables with $\mathrm{T}_{\mathrm{dew}}$ estimated with Eqs. (6) and (7). Results for Azores in Table 6 show that $b_{0}$ varies in a large range, with a tendency for under-estimation, which relates to the climatic characteristics of these oceanic islands as discussed by Paredes et al. (2018a, 2020). RMSE is small, averaging $0.40 \mathrm{~mm} \mathrm{~d}^{-1}$, but varies in a wide range, particularly related to sites located near the ocean and where cloudiness varies widely. Nevertheless, EF are high, thus indicating that the mean square error (MSE) of estimates is much lower

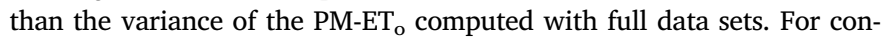
tinental Portugal, $b_{0}$ varies in a shorter range than for Azores since the variability of air humidity is smaller, despite data covers a wide range of climates, from semi-arid to humid, and average $\mathrm{R}^{2}$ is higher (Table 6). These conditions also influence RMSE $\left(0.39 \mathrm{~mm} \mathrm{~d}^{-1}\right)$. Quite high EF values indicate that MSE is much smaller than the variance of PM-ET 
a) Humid climates

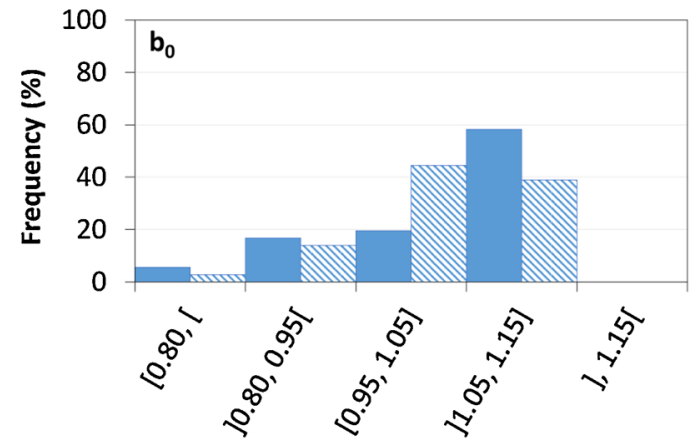

b) Sub-humid climates

c) Semi-arid climates
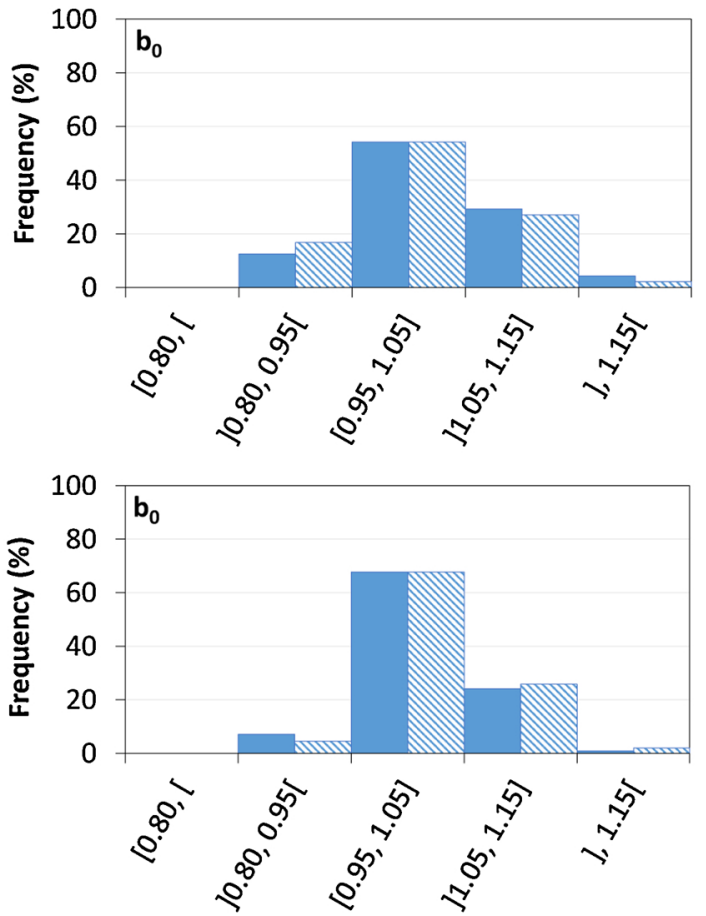

d) Arid and Hyperarid climates

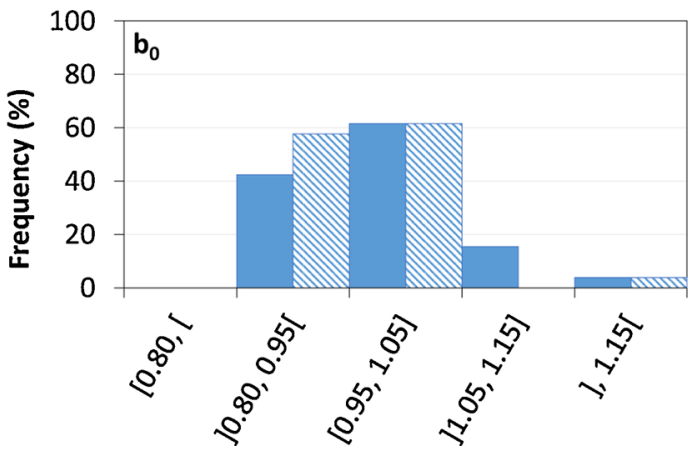

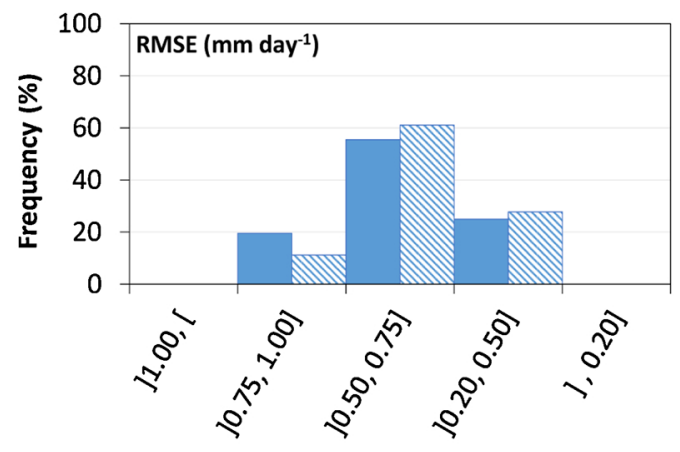
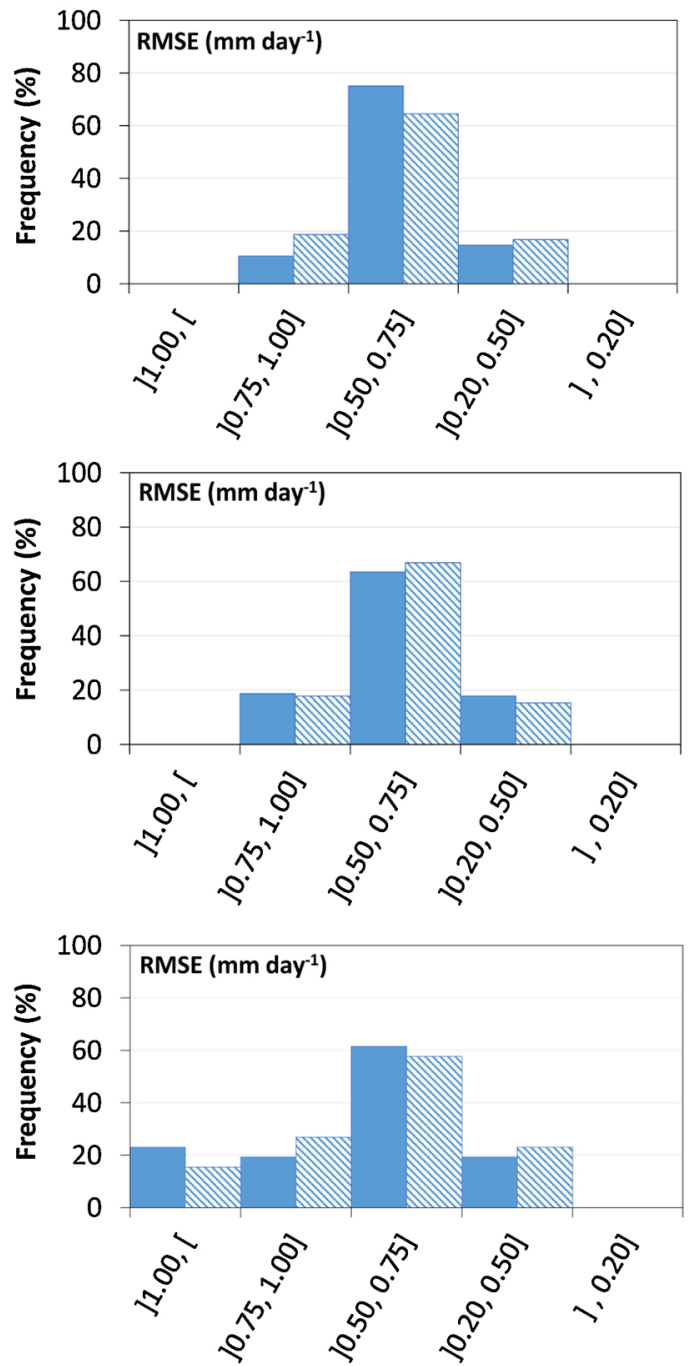

Fig. 4. Frequency of occurrence of the goodness-of-fit indicators $b_{0}$ and RMSE in various classes of accuracy when estimating ET $\mathrm{E}_{\mathrm{O}} \mathrm{PMT}_{\mathrm{T}}$ with $\mathrm{k}_{\mathrm{Rs}}$ computed with the global Eq. (8) (") or with the climate-focused Eqs. (9) (\$). Results are grouped per climate: (a) humid, (b) sub-humid, (c) semi-arid, and (d) arid and hyper-arid. Application using data sets of Bolivia, Inner Mongolia, Iran, Portugal and Spain.

In case when only incoming solar radiation is estimated, two alternative methods for computing $\mathrm{k}_{\mathrm{Rs}}$ were used, the global Eq. (8) or the climate-focused Eq. (9). At Azores, $b_{0}$ shows a range of variation relatively small and narrower than for continental Portugal, with a tendency for over-estimation in the former. The RMSE are higher for the Azores islands than for continental Portugal likely due to more frequent and variable cloudiness. For both datasets, the mean RMSE are similar when using the global or the climate focused equation $(0.52 v s$. $0.51 \mathrm{~mm} \mathrm{~d}^{-1}$ in Azores and 0.36 vs. $40 \mathrm{~mm} \mathrm{~d}^{-1}$ for continental Portugal). Both $\mathrm{R}^{2}$ and $\mathrm{EF}$ are high for both data sets, the latter indicating that the mean square error of estimate is very much smaller than the variance of $\mathrm{PM}-\mathrm{ET}_{\mathrm{o}}$.

When only wind speed are missing, using the local average $\mathrm{u}_{2}$ avg provides for slightly better results than using the default $\mathrm{u}_{2}$ def $=2 \mathrm{~m}$ $\mathrm{s}^{-1}$, which agrees with the analysis presented in Section 4.4 The RMSE are smaller at Azores likely because all sites have a similar high wind speed. That advantage of using $\mathrm{u}_{2}$ avg as estimator of missing wind speed data is also evident when estimated $\mathrm{u}_{2}$ avg is combined with estimated values for $\mathrm{T}_{\mathrm{dew}}$ and $\mathrm{R}_{\mathrm{s}}$.

When $T_{\text {dew }}$ and $R_{s}$ are both missing, their replacement leads to a wider $b_{0}$ range and larger RMSE with a trend for under-estimation of $\mathrm{ET}_{\mathrm{o}}$, more evident for the Azores islands likely due to the referred 
Table 6

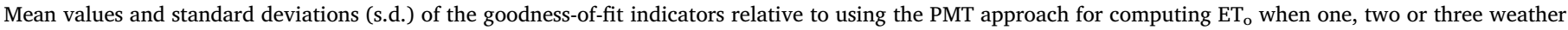
variables are missing; application to the Portuguese data sets.

\begin{tabular}{|c|c|c|c|c|c|c|}
\hline Missing variable & $\mathrm{k}_{\mathrm{Rs}}$ estimator & $\mathrm{u}_{2}$ estimator & $\begin{array}{l}\mathrm{b}_{0} \\
\text { Range }\end{array}$ & $\begin{array}{l}\mathrm{R}^{2} \\
\text { Mean and (s.d.) }\end{array}$ & $\begin{array}{l}\text { RMSE (mm d }{ }^{-1} \text { ) } \\
\text { Mean and (s.d.) }\end{array}$ & $\begin{array}{l}\text { EF } \\
\text { Mean and (s.d.) }\end{array}$ \\
\hline \multicolumn{7}{|l|}{ Azores Islands } \\
\hline $\mathrm{T}_{\mathrm{dew}}$ & & & $0.81-1.04$ & $0.90( \pm 0.05)$ & $0.40( \pm 0.15)$ & $0.84( \pm 0.10)$ \\
\hline \multirow[t]{2}{*}{$\mathrm{R}_{\mathrm{s}}$} & Eq. (8) & & $1.01-1.14$ & $0.82( \pm 0.05)$ & $0.52( \pm 0.05)$ & $0.75( \pm 0.08)$ \\
\hline & Eq. (9) & & $0.98-1.14$ & $0.82( \pm 0.05)$ & $0.51( \pm 0.06)$ & $0.75( \pm 0.07)$ \\
\hline \multirow[t]{2}{*}{$\mathrm{u}_{2}$} & & $\mathrm{u}_{2}$ avg & $0.99-1.02$ & $0.97( \pm 0.02)$ & $0.17( \pm 0.06)$ & $0.97( \pm 0.02)$ \\
\hline & & $\mathrm{u}_{2 \operatorname{def}}$ & $0.93-1.02$ & $0.97( \pm 0.02)$ & $0.19( \pm 0.07)$ & $0.96( \pm 0.02)$ \\
\hline \multirow[t]{2}{*}{$\mathrm{T}_{\text {dew }}$ and $\mathrm{R}_{\mathrm{s}}$} & Eq. (8) & & $0.88-1.15$ & $0.66( \pm 0.07)$ & $0.67( \pm 0.07)$ & $0.57( \pm 0.12)$ \\
\hline & Eq. (9) & & $0.89-1.12$ & $0.66( \pm 0.07)$ & $0.66( \pm 0.07)$ & $0.59( \pm 0.11)$ \\
\hline \multirow[t]{2}{*}{$\mathrm{T}_{\mathrm{dew}}$ and $\mathrm{u}_{2}$} & & $\mathrm{u}_{2}$ avg & $0.81-1.03$ & $0.89( \pm 0.06)$ & $0.40( \pm 0.16)$ & $0.84( \pm 0.11)$ \\
\hline & & $\mathrm{u}_{2 \operatorname{def}}$ & $0.81-1.04$ & $0.89( \pm 0.06)$ & $0.40( \pm 0.16)$ & $0.84( \pm 0.11)$ \\
\hline \multirow[t]{4}{*}{$\mathrm{R}_{\mathrm{s}}$ and $\mathrm{u}_{2}$} & Eq. (8) & $\mathrm{u}_{2}$ avg & $1.00-1.13$ & $0.80( \pm 0.05)$ & $0.54( \pm 0.06)$ & $0.73( \pm 0.07)$ \\
\hline & Eq. (8) & $\mathrm{u}_{2 \text { def }}$ & $0.99-1.15$ & $0.78( \pm 0.05)$ & $0.57( \pm 0.07)$ & $0.70( \pm 0.10)$ \\
\hline & Eq. (9) & $\mathrm{u}_{2}$ avg & $0.97-1.14$ & $0.80( \pm 0.05)$ & $0.54( \pm 0.07)$ & $0.73( \pm 0.07)$ \\
\hline & Eq. (9) & $\mathrm{u}_{2 \operatorname{def}}$ & $0.97-1.11$ & $0.78( \pm 0.05)$ & $0.56( \pm 0.07)$ & $0.70( \pm 0.09)$ \\
\hline \multirow[t]{4}{*}{$\mathrm{T}_{\mathrm{dew}}, \mathrm{R}_{\mathrm{s}}$ and $\mathrm{u}_{2}$} & Eq. (8) & $\mathrm{u}_{2}$ avg & $0.86-1.15$ & $0.66( \pm 0.06)$ & $0.67( \pm 0.07)$ & $0.57( \pm 0.12)$ \\
\hline & Eq. (8) & $\mathrm{u}_{2 \operatorname{def}}$ & $0.87-1.17$ & $0.66( \pm 0.06)$ & $0.69( \pm 0.08)$ & $0.56( \pm 0.13)$ \\
\hline & Eq. (9) & $\mathrm{u}_{2}$ avg & $0.88-1.11$ & $0.66( \pm 0.06)$ & $0.66( \pm 0.07)$ & $0.59( \pm 0.10)$ \\
\hline & Eq. (9) & $\mathrm{u}_{2 \operatorname{def}}$ & $0.88-1.13$ & $0.66( \pm 0.06)$ & $0.67( \pm 0.08)$ & $0.58( \pm 0.12)$ \\
\hline \multicolumn{7}{|c|}{ Continental Portugal } \\
\hline $\mathrm{T}_{\text {dew }}$ & & & $0.91-1.10$ & $0.97( \pm 0.02)$ & $0.39( \pm 0.17)$ & $0.95( \pm 0.04)$ \\
\hline \multirow[t]{2}{*}{$\mathrm{R}_{\mathrm{s}}$} & Eq. (8) & & $0.86-1.10$ & $0.97( \pm 0.02)$ & $0.36( \pm 0.08)$ & $0.96( \pm 0.03)$ \\
\hline & Eq. (9) & & $0.82-1.12$ & $0.97( \pm 0.02)$ & $0.40( \pm 0.11)$ & $0.95( \pm 0.04)$ \\
\hline \multirow[t]{2}{*}{$\mathrm{u}_{2}$} & & $\mathrm{u}_{2}$ avg & $0.98-1.03$ & $0.97( \pm 0.02)$ & $0.35( \pm 0.03)$ & $0.97( \pm 0.03)$ \\
\hline & & $\mathrm{u}_{2 \text { def }}$ & $0.92-1.08$ & $0.97( \pm 0.02)$ & $0.37( \pm 0.06)$ & $0.95( \pm 0.04)$ \\
\hline \multirow[t]{2}{*}{$\mathrm{T}_{\text {dew }}$ and $\mathrm{R}_{\mathrm{s}}$} & Eq. (8) & & $0.89-1.07$ & $0.94( \pm 0.03)$ & $0.51( \pm 0.08)$ & $0.92( \pm 0.03)$ \\
\hline & Eq. (9) & & $0.86-1.10$ & $0.97( \pm 0.02)$ & $0.54( \pm 0.09)$ & $0.92( \pm 0.04)$ \\
\hline \multirow[t]{2}{*}{$\mathrm{T}_{\text {dew }}$ and $\mathrm{u}_{2}$} & & $\mathrm{u}_{2}$ avg & $0.92-1.08$ & $0.93( \pm 0.03)$ & $0.45( \pm 0.09)$ & $0.93( \pm 0.05)$ \\
\hline & & $\mathrm{u}_{2 \text { def }}$ & $0.89-1.15$ & $0.93( \pm 0.03)$ & $0.56( \pm 0.10)$ & $0.91( \pm 0.06)$ \\
\hline \multirow[t]{4}{*}{$\mathrm{R}_{\mathrm{s}}$ and $\mathrm{u}_{2}$} & Eq. (8) & $\mathrm{u}_{2}$ avg & $0.87-1.10$ & $0.94( \pm 0.02)$ & $0.51( \pm 0.08)$ & $0.93( \pm 0.03)$ \\
\hline & Eq. (8) & $\mathrm{u}_{2 \mathrm{def}}$ & $0.89-1.10$ & $0.94( \pm 0.02)$ & $0.50( \pm 0.07)$ & $0.93( \pm 0.02)$ \\
\hline & Eq. (9) & $\mathrm{u}_{2}$ avg & $0.83-1.14$ & $0.94( \pm 0.02)$ & $0.54( \pm 0.09)$ & $0.92( \pm 0.02)$ \\
\hline & Eq. (9) & $\mathrm{u}_{2 \text { def }}$ & $0.86-1.15$ & $0.94( \pm 0.02)$ & $0.53( \pm 0.08)$ & $0.92( \pm 0.03)$ \\
\hline \multirow[t]{4}{*}{$\mathrm{T}_{\mathrm{dew}}, \mathrm{R}_{\mathrm{s}}$ and $\mathrm{u}_{2}$} & Eq. (8) & $\mathrm{u}_{2}$ avg & $0.90-1.08$ & $0.90( \pm 0.03)$ & $0.63( \pm 0.10)$ & $0.89( \pm 0.03)$ \\
\hline & Eq. (8) & $\mathrm{u}_{2 \text { def }}$ & $0.90-1.06$ & $0.90( \pm 0.03)$ & $0.65( \pm 0.09)$ & $0.88( \pm 0.04)$ \\
\hline & Eq. (9) & $\mathrm{u}_{2}$ avg & $0.88-1.12$ & $0.90( \pm 0.03)$ & $0.65( \pm 0.10)$ & $0.88( \pm 0.04)$ \\
\hline & Eq. (9) & $\mathrm{u}_{2 \text { def }}$ & $0.88-1.09$ & $0.90( \pm 0.03)$ & $0.66( \pm 0.10)$ & $0.88( \pm 0.04)$ \\
\hline
\end{tabular}

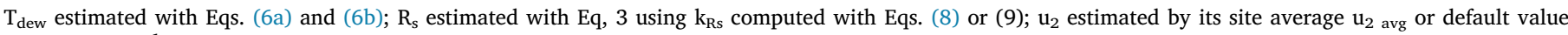
$\mathrm{u}_{2 \text { def }}=2 \mathrm{~m} \mathrm{~s}^{-1}$.

variability of cloudiness in the islands' environment. RMSE are similar when using the $\mathrm{k}_{\mathrm{Rs}}$ Eqs. (8) and (9), respectively with mean RMSE of 0.67 and $0.66 \mathrm{~mm} \mathrm{~d}^{-1}$ in Azores and 0.51 and $0.54 \mathrm{~mm} \mathrm{~d}^{-1}$ in continental Portugal. $\mathrm{R}^{2}$ and $\mathrm{EF}$ are very high for latter, quite higher than for Azores where cloudiness and air humidity variability influence the estimates of $R_{s}$ and $T_{d e w}$. Nevertheless, the high EF values indicate that MSE is generally much smaller than the variance of PM-ET ${ }_{0}$.

If the missing variables are $\mathrm{T}_{\mathrm{dew}}$ and $\mathrm{u}_{2}$, the $\mathrm{b}_{0}$ ranges indicate that there is a clear tendency for under-estimation of $\mathrm{ET}_{\mathrm{o}}$ in Azores, while a lower under-estimation tendency is observed for continental Portugal. This difference, as referred before relatively to replacing $\mathrm{T}_{\mathrm{dew}}$, is likely related to the large variability of air humidity and wind conditions in the oceanic islands. Results show that there is advantage in using $\mathrm{u}_{2}$ avg relative to $u_{2}$ def since smaller ranges for $b_{0}$ are then produced. The RMSE values are small, although higher in continental Portugal, where errors are lower if using $\mathrm{u}_{2}$ avg $\left(0.45 v s .0 .56 \mathrm{~mm} \mathrm{~d}^{-1}\right)$. Nevertheless, quite large mean values for $\mathrm{R}^{2}$ and $\mathrm{EF}$ are observed.

When $R_{s}$ and $u_{2}$ are missing, $b_{0}$ values indicate a tendency for overestimation of $\mathrm{ET}_{\mathrm{o}}$ in case of Azores, particularly if $\mathrm{u}_{2}$ def is used; however, these effects are not visible relative to RMSE. Effects of selecting the global or the climate-focused equation (Eqs. (8) and (9)) are not notable, nor when selecting $\mathrm{u}_{2}$ def or $\mathrm{u}_{2}$ avg. RMSE are small particularly in continental Portugal; while the high variability of cloudiness and wind speed in Azores lead to higher values for RMSE and smaller values for $\mathrm{R}^{2}$ and $\mathrm{EF}$ relative to those in continental Portugal. However, EF values are high. When all three variables have to be estimated, $R^{2}$ and EF decrease relative to all other cases while RMSE increase, more evidently in the Azores oceanic environment. These results show that there is advantage in using the PMT approach combining observed and estimated weather variables, which is confirm in studies referred above. That advantage is not notable when $\mathrm{u}_{2}$ is the only observed variable in addition to temperature, however, a very rare situation. Overall, results 
analysed above clearly indicate that, relative to any temperature equation, it is preferable to use PMT including the observed variables when their accuracy may be recognized.

\section{Estimating $\mathrm{ET}_{\mathrm{o}}$ with the Hargreaves-Samani equation}

\subsection{Background}

The Hargreaves-Samani equation (HS) requires only the input of temperature data:

$\mathrm{ET}_{\mathrm{o}-\mathrm{HS}}=\frac{0.0135}{\lambda} \mathrm{k}_{R S}\left(\mathrm{~T}_{\max }-\mathrm{T}_{\min }\right)^{0.5} \mathrm{R}_{\mathrm{a}}\left(\mathrm{T}_{\text {mean }}+17.8\right)$

where $T_{\max }, T_{\min }$ and $T_{\text {mean }}$ are respectively the maximum, minimum and mean air temperature $\left({ }^{\circ} \mathrm{C}\right)$ during the considered time step of calculation (month, day, or seven-day), $\lambda$ is the latent heat of vaporization $\left(2.45 \mathrm{MJ} \mathrm{kg}^{-1}\right),{ }^{-} \mathrm{k}_{\mathrm{Rs}}$ is the empirical radiation adjustment coefficient $\left({ }^{\circ} \mathrm{C}^{-0.5}\right), \mathrm{R}_{\mathrm{a}}$ is the extraterrestrial radiation $\left(\mathrm{MJ} \mathrm{m} \mathrm{m}^{-2} \mathrm{~d}^{-1}\right), 0.0135$ is a factor for conversion of units from the American to the International System, and 17.8 is an empirical factor related to temperature units (Hargreaves et al., 1985). Commonly, the HS equation is written adopting the Hargreaves coefficient $\mathrm{C}_{\mathrm{HS}}=\frac{1}{\lambda} 0.0135 \mathrm{k}_{\mathrm{Rs}}$, thus

$\mathrm{ET}_{\mathrm{o}-\mathrm{HS}}=\mathrm{C}_{H S}\left(\mathrm{~T}_{\max }-\mathrm{T}_{\min }\right)^{0.5} \mathrm{R}_{\mathrm{a}}\left(\mathrm{T}_{\text {mean }}+17.8\right)$

Then, $\mathrm{k}_{\mathrm{Rs}}$ is not any more visible but considering both Eqs. (2a) and (2b) it may easily be evident that calibrating $\mathrm{C}_{\mathrm{HS}}$ leads to also calibrate $\mathrm{k}_{\mathrm{Rs}}$ and vice-versa. The formulation with the coefficient $\mathrm{C}_{\mathrm{HS}}$ (Eq. (2b, bis)) does not allow the HS- $R_{s}$ equation to be visible as part of the HS$\mathrm{ET}_{\mathrm{o}}$ equation

$\mathrm{R}_{\mathrm{sHS}}=\mathrm{k}_{\mathrm{R}_{\mathrm{S}}}\left(\mathrm{T}_{\max }-\mathrm{T}_{\min }\right)^{0.5} \mathrm{R}_{\mathrm{a}}$

which highlights the conceptual approach behind the HS-ET ${ }_{\mathrm{o}}$ equation. That radiation Eq. (3bis) was analysed in the precedent Sections 2 and 4.1 focusing on its use in the PMT approach.

The HS-ET $\mathrm{H}_{\mathrm{o}}$ equation is simple to use and estimates $\mathrm{ET}_{\mathrm{o}}$ with high accuracy for most locations. It has been tested extensively and good estimates of $\mathrm{ET}_{\mathrm{o}}$ are reported for semiarid and arid environments. Almorox et al. (2015) considered several temperature-based approaches for various climates and reported that the $\mathrm{HS}-\mathrm{ET}_{\mathrm{o}}$ equation provided the most accurate global performance. However, since it does not account for wind speed and humidity, it is less accurate in windy and wet climates. Almorox et al. $(2015,2018)$ reported on the relatively weak dependence of evapotranspiration on the daily temperature differences in tropical climates, where the HS-ET ${ }_{o}$ equation might be less appropriate, such as in low latitudes where daily TD are small, thus leading to underestimate $\mathrm{ET}_{\mathrm{o}}$. Moreover, the HS-ET $\mathrm{E}_{\mathrm{o}}$ equation has shown a general trend for overestimation in humid and cold climates.

Numerous studies have demonstrated the relevance of properly selecting $\mathrm{k}_{\mathrm{Rs}}$ for estimating $\mathrm{ET}_{\mathrm{o}}$ (Samani, 2000; Raziei and Pereira, 2013a; Todorovic et al., 2013; Ren et al., 2016a; Almorox et al., 2018; Paredes et al., 2018b). In their worldwide assessment study, Almorox et al. (2018) reported that $\mathrm{k}_{\mathrm{Rs}}$ takes high values in the desert areas of Australia, northern Africa and northern America, and averagely low values in humid tropical areas of South America and Africa and in cold high latitudes of the northern hemisphere. Coherently with information relative to the PMT approach (Section 4), it has been observed that $k_{\mathrm{Rs}}$ varies spatially with site elevation, the distance to large water bodies, the aridity of the site and its wind speed. The calibration of $\mathrm{C}_{\mathrm{HS}}$ or $\mathrm{k}_{\mathrm{Rs}}$ minimizes errors associated with estimating global radiation, thus improving $\mathrm{ET}_{\mathrm{o}}$ estimation (Samani, 2000; Vanderlinden et al., 2004; Thepadia and Martinez, 2012; Mendicino and Senatore, 2013; Raziei and Pereira, 2013a; Martí et al., 2015; Ren et al., 2016a; Paredes et al., 2018a). However, several research studies not only aimed at calibrating $\mathrm{C}_{\mathrm{HS}}$ but also the exponent and additive parameters of the HS equation 2 (e.g., Gavilán et al., 2006; Trajkovic, 2007). This approach resulted in a variety of versions of the HS-ETo equation, however of local applicability only. Moreover, there is no evidence that calibrating the exponent and the additive coefficients of the HS equation would bring a benefit in accuracy that would overcome the increased complexity of the resulting equation and related parameterization.

Despite the HS equation (2) just uses temperature as input weather data, the fact is that various studies aimed at modifying the equation using other weather data or calibrating the coefficient $\mathrm{C}_{\mathrm{HS}}$ (or the $\mathrm{k}_{\mathrm{Rs}}$ coefficient) using approaches that refer to other than temperature variables. Various studies have identified that $\mathrm{C}_{\mathrm{HS}}$ (or $\mathrm{k}_{\mathrm{Rs}}$ ) vary with climate (Vanderlinden et al., 2004; Ravazzani et al., 2012). Jensen et al. (1997) found that rainfall and $\mathrm{u}_{2}$ were the main variables explaining the differences between $\mathrm{ET}_{\mathrm{o}}$ Hs and PM-ET $\mathrm{F}_{\mathrm{o}}$, while both Raziei and Pereira (2013a) and Ren et al. (2016a) identified the influence of aridity on $k_{\mathrm{Rs}}$ and, particularly for locations marked by aridity, the influence of wind speed. Differently, impacts of wind speed on $k_{R s}$ were referred by Paredes et al. (2018a) for humid oceanic islands. Various authors also recognized impacts of wind speed, $\mathrm{RH}$ and rainfall on $\mathrm{C}_{\mathrm{HS}}$ (Mendicino and Senatore, 2013. Gomariz-Castillo et al., 2018).

Annandale et al. (2002) considered seasonal influences on $\mathrm{ET}_{\mathrm{o}} \mathrm{HS}$ and $\mathrm{R}_{\mathrm{S} H \mathrm{HS}}$ in relation with cloudiness, VPD and wind. To consider the influence of precipitation or wetness in opposition to dryness conditions, various authors adopted seasonal calibrated $\mathrm{C}_{\mathrm{HS}}$ values. Lee (2010) and Aguilar and Polo (2011) calibrated $\mathrm{C}_{\mathrm{HS}}$ differently for the dry and wet season, thus, to take into consideration wetness and dryness effects instead of using a single $\mathrm{C}_{\mathrm{HS}}$ for each location.

An early study by Droogers and Allen (2002) introduced a monthly rainfall parameter into the HS equation. Fooladmand et al. (2008) followed this approach and adopted a rainfall parameter in the HS equation. Diodato and Bellocchi (2007) modified the Droogers and Allen (2002) HS equation and developed another HS equation, the reference evapotranspiration model for complex terrains, REMCT, where a parameter related to rainfall was adopted in addition to other parameters related to climate and elevation.

Martínez-Cob and Tejero-Juste (2004) calibrated $\mathrm{C}_{\mathrm{HS}}$ distinguishing between windy and non-windy locations. Gavilán et al. (2006) considered the impacts of wind speed on $\mathrm{C}_{\mathrm{HS}}$ and adopted linear functions of the temperature difference TD for computing three $\mathrm{C}_{\mathrm{HS}}$ values according to a wind speed scale: low, moderate and high. Other authors proposed additional parameters relative to wind speed to be used in modified versions of the HS equation. Kra (2014) developed a HS version where $\mathrm{C}_{\mathrm{HS}}$ was obtained as a function of $\mathrm{u}_{2}$. Similarly, Cobaner et al. (2017) modified $\mathrm{C}_{\mathrm{HS}}$ using a linear function of $\mathrm{u}_{2}$. Martí et al. (2015) calibrated $\mathrm{C}_{\mathrm{HS}}$ using multiple linear regression equations that included $\mathrm{u}_{2}$ or wind speed levels in addition to geographic parameters. Differently, Patel et al. (2014) used a fuzzy inference system to calibrate $\mathrm{C}_{\mathrm{HS}}$ and the exponent term as a function of characteristic values of $\mathrm{RH}$ and $\mathrm{u}_{2}$ for the location.

Taking into account the numerous research issues aimed at including wind speed and humidity or rainfall parameters in the HS-ET ${ }_{\mathrm{o}}$ equation, or considering wind speed and/or wetness when calibrating $\mathrm{C}_{\mathrm{HS}}$ or $\mathrm{k}_{\mathrm{Rs}}$, a procedure similar to the one used with the PMT approach has been developed for estimating $\mathrm{k}_{\mathrm{Rs}}$ for the HS equation. Thus, a multiple linear regression equation was developed relating $k_{\mathrm{Rs}}$ with the long-term averages of the temperature difference $\left(\mathrm{TD}_{\mathrm{avg}}=\mathrm{T}_{\max }-\mathrm{T}_{\min },{ }^{\circ} \mathrm{C}\right)$, relative humidity $\left(\mathrm{HR}_{\mathrm{avg}}, \%\right)$ and wind speed $\left(\mathrm{u}_{2}\right.$ avg, $\left.\mathrm{m} \mathrm{s}^{-1}\right)$, namely computed with data from a nearby weather station.

\subsection{Developing $k_{R s}$ regression equations for the HS equation}

For every weather station of the Med-Climwat database, using a trial and error iterative procedure, $\mathrm{k}_{\mathrm{Rs}}$ values were calibrated. This procedure consisted of searching the $\mathrm{k}_{\mathrm{Rs}}$ value that minimizes the difference between $\mathrm{ET}_{\mathrm{o}}$ computed with the HS equation $\left(\mathrm{ET}_{\mathrm{o}-\mathrm{HS}}\right)$ and the $\mathrm{PM}^{\mathrm{E}} \mathrm{ET}_{\mathrm{o}}$. After obtaining the $\mathrm{k}_{\mathrm{Rs}}$ values for every weather station, a multiple linear regression was developed using the climate variables $\mathrm{TD}_{\mathrm{avg}}$, $\mathrm{RH}_{\mathrm{avg}}$ and $\mathrm{u}_{2}$ avg of the same weather stations as independent variables. 
Table 7

Statistical indicators of the selected multiple linear regressions using average TD, $\mathrm{u}_{2}$ and $\mathrm{RH}$ as predictors of $\mathrm{k}_{\mathrm{Rs}}$ for the Hargreaves-Samani (global equation) and when sites are grouped per type of climate defined with the UNEP Aridity Index AI (climate-focused equations) using the Med-Climwat datasets.

\begin{tabular}{|c|c|c|c|c|c|c|}
\hline \multirow[t]{2}{*}{ Indicators } & & \multirow[t]{2}{*}{ Global equation } & \multicolumn{4}{|c|}{ Climate-focused equations } \\
\hline & & & Humid & Moist and dry sub-humid & Semi-arid & Hyper-arid and arid \\
\hline Number of sites & & 588 & 135 & 281 & 89 & 83 \\
\hline \multirow[t]{4}{*}{ Regression coefficients } & $\beta 0$ & 0.3023 & 0.3695 & 0.3396 & 0.2962 & 0.2073 \\
\hline & $\beta 1$ & -0.0049 & -0.0066 & -0.0059 & -0.0049 & -0.0023 \\
\hline & $\beta 2$ & 0.0151 & 0.0127 & 0.0125 & 0.0117 & 0.0224 \\
\hline & $\beta 3$ & -0.0017 & -0.0024 & -0.0020 & -0.0014 & -0.0009 \\
\hline Multiple R & & 0.85 & 0.91 & 0.88 & 0.85 & 0.89 \\
\hline $\mathrm{R}^{2}$ & & 0.73 & 0.83 & 0.77 & 0.72 & 0.79 \\
\hline Adjusted $\mathrm{R}^{2}$ & & 0.73 & 0.83 & 0.76 & 0.71 & 0.78 \\
\hline $\mathrm{F}$ value & & 490.9 & 194.7 & 282.3 & 76.9 & 90.8 \\
\hline Significance of $\mathrm{F}$ & & $6.4 \mathrm{E}-155$ & $1.61 \mathrm{E}-45$ & $2.57 \mathrm{E}-81$ & $1.68 \mathrm{E}-24$ & $2.09 \mathrm{E}-24$ \\
\hline \multirow[t]{4}{*}{ Standard error } & Intercept & 0.0065 & 0.0137 & 0.0096 & 0.0139 & 0.0129 \\
\hline & $\mathrm{TD}$ & 0.0002 & 0.0006 & 0.0004 & 0.0005 & 0.0006 \\
\hline & $\mathrm{u}_{2}$ & 0.0007 & 0.0013 & 0.0010 & 0.0015 & 0.0016 \\
\hline & RH & $6.32 \mathrm{E}-05$ & 0.0001 & 0.0001 & 0.0002 & 0.0001 \\
\hline \multirow[t]{4}{*}{ p-value } & Intercept & $1.4 \mathrm{E}-192$ & $2.78 \mathrm{E}-52$ & $1.5 \mathrm{E}-101$ & $1.74 \mathrm{E}-36$ & $1.36 \mathrm{E}-25$ \\
\hline & $\mathrm{TD}$ & 8.97E-70 & 7.29E-19 & $5.45 \mathrm{E}-43$ & $6.25 \mathrm{E}-17$ & 0.000346 \\
\hline & $\mathrm{u}_{2}$ & $1.22 \mathrm{E}-75$ & $1.56 \mathrm{E}-16$ & $1.74 \mathrm{E}-28$ & $1.16 \mathrm{E}-11$ & $2.74 \mathrm{E}-22$ \\
\hline & RH & $1.6 \mathrm{E}-98$ & $2.91 \mathrm{E}-33$ & $2.31 \mathrm{E}-46$ & $1.08 \mathrm{E}-13$ & $1.23 \mathrm{E}-12$ \\
\hline \multirow[t]{4}{*}{ Confidence interval } & Intercept & $0.290,0.315$ & $0.342,0.397$ & $0.321,0.358$ & $0.269,0.324$ & $0.182,0.233$ \\
\hline & $\mathrm{TD}$ & $-0.005,-0.004$ & $-0.009,-0.005$ & $-0.007,-0.005$ & $-0.006,-0.004$ & $-0.003,-0.001$ \\
\hline & $\mathrm{u}_{2}$ & $0.014,0.016$ & $0.010,0.015$ & $0.011,0.015$ & $0.009,0.015$ & $0.019,0.026$ \\
\hline & $\mathrm{RH}$ & $-0.002,-0.001$ & $-0.003,-0.002$ & $-0.002,-0.001$ & $-0.002,-0.001$ & $-0.001,-0.0007$ \\
\hline
\end{tabular}

Following the same method used for the PMT approach (Paredes and Pereira, 2019), a global regression equation was developed using data from all weather stations and four climate-focused regression equations were developed when using separately the data relative to the weather stations located in humid, moist and dry sub-humid, semiarid, and arid and hyper-arid climates.

The statistical results relative to the developed multiple linear regressions are given in Table 7, which show a strong relationship between the dependent variable and the three independent climate selected $\mathrm{k}_{\mathrm{Rs}}=\mathrm{f}\left(\mathrm{TD}_{\mathrm{avg}}, \mathrm{u}_{2}\right.$ avg, $\left.\mathrm{RH}_{\mathrm{avg}}\right)$ is able to explain $73 \%$ of the variance of $\mathrm{k}_{\mathrm{Rs}}$ relative to all weather stations, while the climate focused equations are able to explain from $71 \%$ to $83 \%$ of the variance of $k_{\mathrm{Rs}}$ relative to the four considered climates (Table 7). The F test gives p-values close to zero, so rejecting the null hypothesis. Likewise, the p-values for the intercept and regression coefficients relative to the three independent variables are nearly null. Moreover, the confidence intervals for the intercept and the regression coefficients do not include the null value (Table 7). $\mathrm{TD}_{\text {avg }}$ and $\mathrm{RH}_{\text {avg }}$ have negative regression coefficients, while the regression coefficients of $\mathrm{u}_{2}$ avg are positive similarly to results relative to the PMT approach (Paredes and Pereira, 2019).

The global regression equation, with adjusted $R^{2}=0.73$, writes as:

$k_{R s}=0.3023-0.0049 T D_{\text {avg }}+0.0151 u_{2 \text { avg }}-0.0017 R H_{\text {avg }}$

while the climate-focused equations, whose adjusted $\mathrm{R}^{2}$ varied from 0.71 to 0.83 , are the following:

Humid climates (AI $\geq 1.00)$

$k_{R s}=0.3695-0.0066 T D_{\text {avg }}+0.0127 u_{2 a v g}-0.0024 R H_{\text {avg }}$

Moist and dry sub-humid climates $(0.50 \leq \mathrm{AI}<1.00)$

$k_{R s}=0.3396-0.0059 T D_{\text {avg }}+0.0125 u_{2 a v g}-0.0020 R H_{\text {avg }}$

Semi-arid climates $(0.20 \leq \mathrm{AI}<0.50)$

$k_{R s}=0.2962-0.0049 T D_{a v g}+0.0117 u_{2 a v g}-0.0014 R H_{\text {avg }}$

Arid and hyper-arid climates( $\mathrm{AI}<0.20)$
$k_{R s}=0.2073-0.0023 T D_{\text {avg }}+0.0224 u_{2 a v g}-0.0009 R H_{\text {avg }}$

\subsection{Assessing the usability of the $k_{R s}$ equations with independent datasets}

The usability of Eqs. (10) and (11) was assessed by comparing the goodness-of-fit indicators relative to the $\mathrm{ET}_{\mathrm{o}-\mathrm{HS}}$ computed with a site calibrated $\mathrm{k}_{\mathrm{Rs}}$ using a trial and error procedure, the default $\mathrm{k}_{\mathrm{Rs}}=0.17^{\circ} \mathrm{C}^{-0.5}$, and $\mathrm{k}_{\mathrm{Rs}}$ computed with the Eqs. (10) and (11). That assessment was performed using the same independent data sets used for the PMT usability analysis (datasets of Bolivia, Inner Mongolia, Iran, Portugal, and Spain).

The mean and standard deviation (s.d.) of the $\mathrm{k}_{\mathrm{Rs}}$ values obtained with the above referred datasets when $\mathrm{k}_{\mathrm{Rs}}$ is computed with a trial and error procedure, or using the global Eq. (10), or the appropriate climate-focused Eq. (11) are presented in Table 8. Like for $k_{\mathrm{Rs}}$ computed for PMT (Table 4), the highest mean $\mathrm{k}_{\mathrm{Rs}}$ values refer to arid and hyperarid climates and the lowest are for sub-humid climates. Their variability is low and the respective s.d. are quite small. The mean and standard deviation are similar among procedures used for obtaining the $\mathrm{k}_{\mathrm{Rs}}$ and, differently from the PMT, their values vary little among climates.

Aiming at understanding the performance of the commonly used default value $\mathrm{k}_{\mathrm{Rs}}=0.17 \mathrm{C}^{-0.5}$ in comparison with the $\mathrm{k}_{\mathrm{Rs}}$ computed

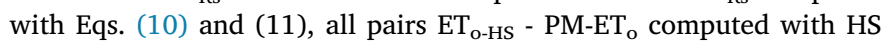
calculated with those three $\mathrm{k}_{\mathrm{Rs}}$ modes were regressed. Fig. 5 shows the

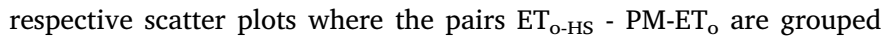
according to the climate of the sites. It shows that when the common default $\mathrm{k}_{\mathrm{Rs}}=0.17^{\circ} \mathrm{C}^{-0.5}$ is used there is a clear tendency for under-estimation in the arid and hyper-arid climates, where $\mathrm{k}_{\mathrm{Rs}}$ values are larger than this default value (Table 8). Nevertheless, the scatter plots show that when $\mathrm{ET}_{\mathrm{o}} \mathrm{HS}$ is computed with that default value not only $\mathrm{R}^{2}$ are reduced relative to the cases using the Eqs. (10) and (11), but also the larger $\mathrm{ET}_{\mathrm{o}}$ HS values are smaller than the larger $\mathrm{PM}_{\mathrm{E}} \mathrm{ET}_{\mathrm{o}}$ values, contrarily to the other cases. These results evidence that the referred default value $\left(\mathrm{k}_{\mathrm{Rs}}=0.17^{\circ} \mathrm{C}^{-0.5}\right)$ should not be used. Nevertheless, 
Table 8

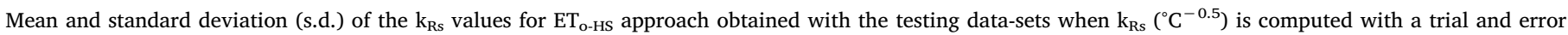

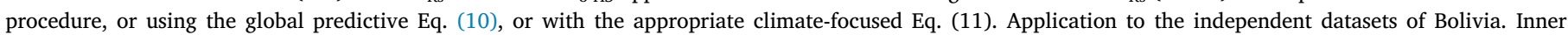
Mongolia, Iran, Portugal and Spain.

\begin{tabular}{|c|c|c|c|c|}
\hline \multirow[t]{2}{*}{ Procedure used to obtain $\mathrm{k}_{\mathrm{Rs}}$} & \multicolumn{4}{|c|}{ Mean and (s.d.) of $\mathrm{k}_{\mathrm{Rs}}\left({ }^{\circ} \mathrm{C}^{-0.5}\right)$ values relative to the climate of the sites } \\
\hline & Humid & Sub-humid & Semi-arid & Arid \& hyper-arid \\
\hline $\mathrm{k}_{\mathrm{Rs}}$ locally calibrated using a trial and error procedure & $0.17( \pm 0.02)$ & $0.16( \pm 0.02)$ & $0.17( \pm 0.02)$ & $0.20( \pm 0.02)$ \\
\hline $\mathrm{k}_{\mathrm{Rs}}$ estimated with the global Eq. (10) & $0.17( \pm 0.02)$ & $0.16( \pm 0.02)$ & $0.17( \pm 0.02)$ & $0.20( \pm 0.03)$ \\
\hline $\mathrm{k}_{\mathrm{Rs}}$ estimated with the adequate climate-focused Eq. 11 & $0.16( \pm 0.02)$ & $0.16( \pm 0.02)$ & $0.17( \pm 0.02)$ & $0.19( \pm 0.03)$ \\
\hline
\end{tabular}

similarly to the PMT approach, Fig. 5 shows that $\mathrm{ET}_{\mathrm{o}}$ HS under-estimates the highest values of PM-ET because these extreme values are due to effects of wind, which is not considered in the HS equation.

All four sets of $\mathrm{ET}_{\mathrm{o}} \mathrm{HS}$ referred previously are compared with PM-ET for each site, which provided for calculating the respective goodness-of-fit indicators defined in Section 3: $b_{0}, R^{2}$, RMSE and EF. These results are given in Table 9, grouped according to the climate of the sites. Table 9 shows the ranges of $b_{0}$ values and the means and standard deviations of $\mathrm{R}^{2}$, RMSE and EF relative to every site of the independent data sets, with indication of the number of observations and sites in each climate group. The regression coefficients $b_{0}$ vary in a very small range when $k_{R s}$ is sitecalibrated, and vary in wider ranges when using the common default $\mathrm{k}_{\mathrm{Rs}}=0.17^{\circ} \mathrm{C}^{-0.5}$, or $\mathrm{k}_{\mathrm{Rs}}$ are computed with the global or the climatefocused Eqs. (10) and (11). The widest range corresponds to using the default $\mathrm{k}_{\mathrm{Rs}}$ while ranges relative to using the $\mathrm{k}_{\mathrm{Rs}}$ equations are closer to the former. Wider ranges are for arid and hyper-arid sites while narrower ones are for semi-arid sites. A trend of over-estimation is detected. Since calibration is performed to minimize differences between $\mathrm{ET}_{\mathrm{o}} \mathrm{HS}$ and PM$\mathrm{ET}_{\mathrm{o}}$ sets, using site calibration of $\mathrm{k}_{\mathrm{Rs}}$ controls the effect of variables whose extreme values produce low or high $b_{0}$ values. Using a regression-predicted $\mathrm{k}_{\mathrm{Rs}}$ value, does not exert such control of extreme values but helps that $\mathrm{ET}_{\mathrm{o}} \mathrm{HS}$ become closer to $\mathrm{PM}-\mathrm{ET}_{\mathrm{o}}$, so highly reducing the variability of $\mathrm{b}_{0}$ for each climate group relative using a default value. Differently, $\mathrm{R}^{2}$ values change little with the procedure to get $\mathrm{k}_{\mathrm{Rs}}$ but they change with climate, with lower values for humid sites and larger for semi-arid. This may happen because sites in humid climates have a larger variability of climate characteristic variables than those in semi-arid climates.

Smaller RMSE and higher EF were obtained when site-calibrated $k_{\mathrm{Rs}}$ were used and contrasting values were computed when the default $k_{R s}$ was used. RMSE and EF close to the former were obtained for the cases when Eqs. (10) and (11) were used. This means that errors are small, particularly the high EF indicate a MSE much smaller than the variance of PM-ET $\mathrm{O}_{\mathrm{o}}$ RMSE are small, ranging from 0.59 to $0.74 \mathrm{~mm} \mathrm{~d}^{-1}$ for humid, and arid and hyper-arid sites when using the global Eq. (10), and ranging from 0.58 to $0.69 \mathrm{~mm} \mathrm{~d}^{-1}$ for the same climates when using the climate-focused Eq. (11). Results for both equations do not show notable differences but the climate-focused equations may be preferable.

The frequency of occurrence of $b_{0}$ and RMSE in various performance classes is shown in Fig. 6 comparing the use of $k_{\mathrm{Rs}}$ computed with the Eqs. (10) and (11) with the use of the default value $0.17^{\circ} \mathrm{C}^{0.5}$. Data in Fig. 6 allows distinguishing the behaviour of the various approaches used, which was not possible if analysing only the aggregated data in Table 9 and Fig. 5. First, Fig. 6 makes it evident that the frequency of occurrence of $b_{0}$ values in the various classes varies with the climate. In humid climates, the larger occurrence in the class closer to 1.0, from 0.95 to 1.05 , refers to the Eq. (10), while the highest occurrence relative to Eq. (11) is in the class $0.80-0.95$, thus indicating a trend for under-estimation. Common to all classes is the occurrence of $b_{0}$ values relative to default $\mathrm{k}_{\mathrm{Rs}}$ in the classes corresponding to larger over- or under-estimation. These results, consequently, favour the use of Eq. (10) in humid climates. Differently, in sub-humid climates the highest occurrence of $b_{0}$ for both equations refers to the class $0.80-0.95$, which indicates a common trend for under-estimation; moreover, the frequency of occurrence in other classes is also similar relative to both equations. Therefore, there is no preference of one over the other equation, while results when using the default $\mathrm{k}_{\mathrm{Rs}}$ indicate over-estimation. For semi-arid climates results show that using Eqs. (10) and (11) refer dominantly to the class closer to 1.0, with Eq. (11) showing more often a trend to over-estimate differently to Eq. (10). The contrary happens for arid and hyper arid climates, where the use of Eq. (10) may lead more often to over-estimation of $\mathrm{ET}_{\mathrm{o}}$. Mainly for arid and hyper arid climates, the use of the default $\mathrm{k}_{\mathrm{Rs}}$ leads to frequent under-estimations.

Relative to RMSE, the large frequency of occurrence (Fig. 6) for all three $\mathrm{k}_{\mathrm{Rs}}$ cases is the class $0.50-0.75 \mathrm{~mm} \mathrm{~d}^{-1}$ with the remaining occurrences in the low error class $0.20-0.50$ in case of $k_{\mathrm{Rs}}$ Eqs. (10) and (11). That frequency relative to the class $0.50-0.75 \mathrm{~mm} \mathrm{~d}^{-1} \mathrm{de}-$ crease for the arid and hyper-arid climates where larger RMSE values occur more often, mainly in case of using the $\mathrm{k}_{\mathrm{Rs}}$ default value. Overall, analysing the frequency of occurrence of both $b_{0}$ and RMSE, the usability of Eqs. (10) and (11) is confirmed since the resulting trends for over- or under-estimation of $\mathrm{ET}_{\mathrm{o}}$ are less frequent than using the $\mathrm{k}_{\mathrm{Rs}}$ default value, while lower values for RMSE are more frequent, particularly for arid and hyper-arid climates. However, there is not an evident superiority of the climate-focused equations over the global one.

The statistical indicators in Table 9 are generally better than those reported from other studies. Vanderlinden et al. (2004), for coastal areas, reported RMSE ranging from 0.60 to $0.95 \mathrm{~mm} \mathrm{~d}^{-1}$ while Mendicino and Senatore (2013) reported a wider range of MAE estimation errors, from 0.32 to $1.24 \mathrm{~mm} \mathrm{~d}^{-1}$. Raziei and Pereira (2013a) reported a RMSE $<0.70 \mathrm{~mm} \mathrm{~d}^{-1}$ for most locations in Iran, while Ren et al. (2016a) reported RMSE ranging from 0.65 to $1.15 \mathrm{~mm} \mathrm{~d}^{-1}$ in arid areas, from 0.45 to $0.92 \mathrm{~mm} \mathrm{~d}^{-1}$ in semiarid areas and 0.46 to $0.61 \mathrm{~mm}$ $\mathrm{d}^{-1}$ in moist sub-humid areas of Inner Mongolia. Paredes et al. (2018a), for the humid and windy climate of Azores, reported RMSE ranging from 0.47 to $0.86 \mathrm{~mm} \mathrm{~d}^{-1}$. Therefore, results in Table 9 favour the use of the $k_{\mathrm{Rs}}$ predictive Eqs. (10) and (11).

Considering the good performance of the HS equation when $\mathrm{k}_{\mathrm{Rs}}$ is computed with the global Eq. (10) or the climate-focused equations 11, it is appropriate to propose a computational flowchart similar to that in Fig. 1. It is presented in Fig. 7. The first step is to estimate the long-term averages $\mathrm{TD}_{\text {avg }}, \mathrm{RH}_{\mathrm{avg}}$ and $\mathrm{u}_{2}$ avg that characterize the local, namely using data from a nearby station. The second step is computing the aridity index AI to provide for a general characterization of the regional climate using long-term averages of the annual values of total annual precipitation $\left(\mathrm{P}_{t}\right)$ and potential evapotranspiration $\left(\mathrm{PET}_{\mathrm{TH}}\right)$. Knowing $\mathrm{AI}$, the user may select to compute $\mathrm{k}_{\mathrm{Rs}}$ through a global or a climatefocused Eq. (10) or (11), which allows to finally compute $\mathrm{ET}_{\mathrm{o}-\mathrm{HS}}$.

\section{Discussion and conclusions}

The PMT approach has the potential for accurately estimating $\mathrm{ET}_{\mathrm{o}}$ with reduced data sets. When air humidity data are not available, adopting the temperature corrections to estimate $\mathrm{T}_{\mathrm{dew}}$ have shown to be highly advantageous relative to the simple assumption of equaling $\mathrm{T}_{\mathrm{dew}}$ $=\mathrm{T}_{\min }$, thus overcoming the errors resulting from station dryness and local advection. Using all data sets available and covering a wide range of climates from humid to hyper-arid, the correction of temperature using Eqs. (6a) through (7b) provides for improving RMSE by $15-20 \%$, 
Default $k_{\text {Rs }}$ value

Humid climates
$(\mathrm{n}=94730)$

Sub-humid climates

$(\mathrm{n}=145326)$

Semi-arid climates

$(n=412368)$
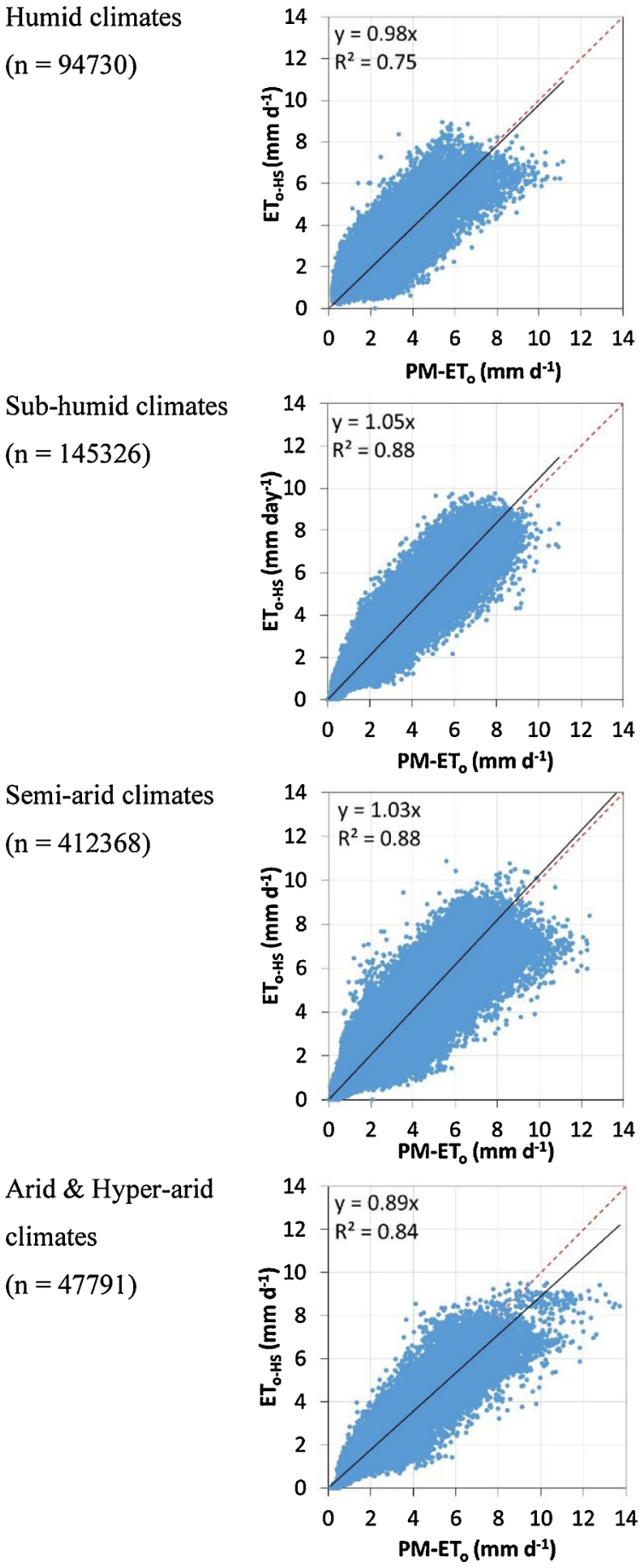

$k_{R s}$ computed with the global Eq. 10
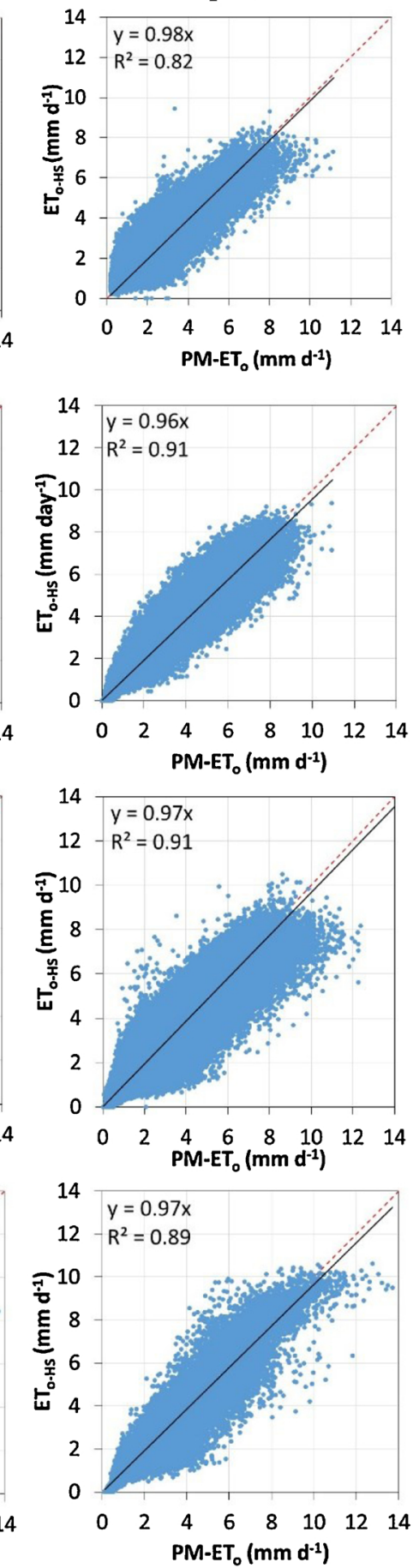

$k_{R s}$ computed with the climatefocused Eqs. 11
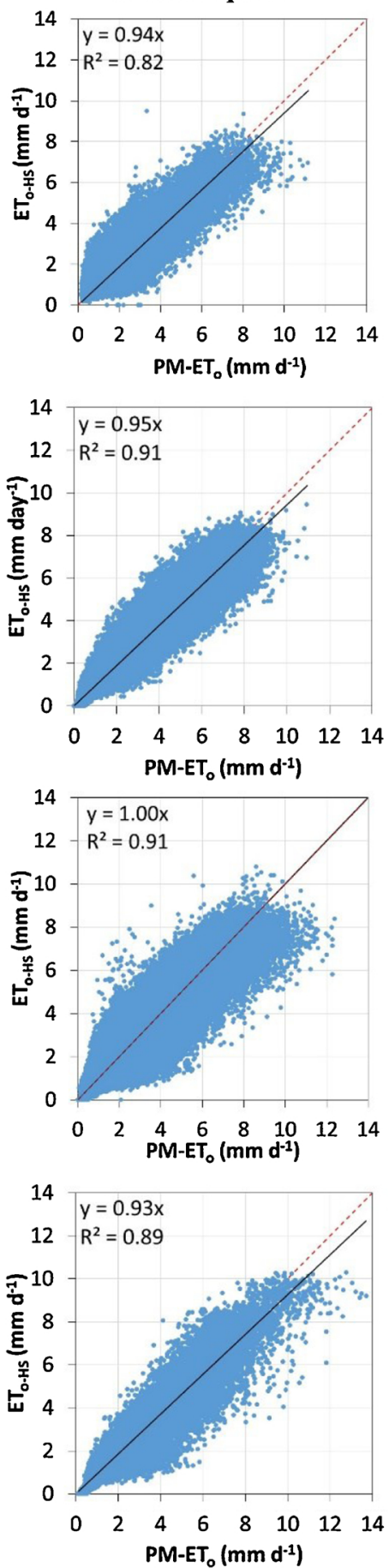

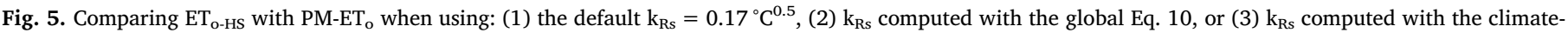

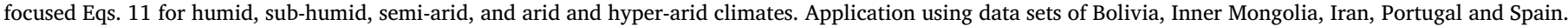

approximately. Nevertheless, despite other methods may be used to correct station data for aridity and local advection, it is important to recognize that correcting $\mathrm{T}_{\mathrm{dew}}$ estimates from $\mathrm{T}_{\min }$ in case of arid climates, or computing $\mathrm{T}_{\mathrm{dew}}$ from $\mathrm{T}_{\text {mean }}$ in case of humid climates, improves the accuracy of $\mathrm{ET}_{\mathrm{o} \text { PMT }}$ estimates.

The radiation Eq. (3) can be accurately used when shortwave solar radiation is not observed. Its use requires that $\mathrm{k}_{\mathrm{Rs}}$ is accurately estimated in alternative to its site calibration, which is time consuming and data demanding because this option implies the availability of local, or near local, full data sets to be used in the calibration process. The alternative use of the regression Eqs. (8) and (9) consists of a simple and accurate solution. The use of these equations requires the knowledge of average values for TD, $\mathrm{RH}$ and $\mathrm{u}_{2}$ that characterize the site, namely using data of a nearby station. Finally, when wind speed data are not available, either $\mathrm{u}_{2}$ avg or $\mathrm{u}_{2}$ def may be used. Results analysed above show that the use of $\mathrm{u}_{2}$ avg produces more accurate estimates of $\mathrm{ET}_{\mathrm{o}}$, which is important in windy areas and in sites marked by aridity.

The analysis performed herein has demonstrated the usability of the proposed $\mathrm{k}_{\mathrm{Rs}}$ regression Eqs. (8) and (9) to compute $\mathrm{ET}_{\mathrm{o}-\mathrm{PMT}}$, whose goodness-of-fit indicators compare well with those relative to using site- 
Table 9

Mean and standard deviation (s.d.), or range, of the goodness-of-fit indicators relative to comparing $\mathrm{ET}_{\mathrm{o}-\mathrm{HS}}$ with PM-ET $\mathrm{o}_{\mathrm{o}}$ when $\mathrm{k}_{\mathrm{Rs}}$ was calibrated for each site, the default value $k_{R s}=0.17^{\circ} \mathrm{C}^{0.5}$ was used, or $\mathrm{k}_{\mathrm{Rs}}$ was computed with the global Eq. (10), or with the climate-focused equations 11 . Application to the independent datasets of Bolivia. Inner Mongolia, Iran, Portugal and Spain.

\begin{tabular}{|c|c|c|c|c|c|c|}
\hline \multirow[t]{2}{*}{ Climate } & \multicolumn{2}{|l|}{ Number of } & \multirow{2}{*}{$\begin{array}{l}\mathrm{b}_{0} \\
\text { range }\end{array}$} & \multirow{2}{*}{$\begin{array}{l}\mathrm{R}^{2} \\
\text { Mean and (s.d.) }\end{array}$} & \multirow{2}{*}{$\begin{array}{l}\text { RMSE (mm d }{ }^{-1} \text { ) } \\
\text { Mean and (s.d.) }\end{array}$} & \multirow{2}{*}{$\begin{array}{l}\mathrm{EF} \\
\text { Mean and (s.d.) }\end{array}$} \\
\hline & Observations & Sites & & & & \\
\hline \multicolumn{7}{|l|}{$\mathrm{k}_{\mathrm{Rs}}$ site-calibrated } \\
\hline Humid & 94,730 & 36 & $0.94-1.04$ & $0.77( \pm 0.14)$ & $0.57( \pm 0.17)$ & $0.75( \pm 0.17)$ \\
\hline Sub-humid & 145,326 & 47 & $0.95-1.04$ & $0.89( \pm 0.11)$ & $0.55( \pm 0.09)$ & $0.88( \pm 0.12)$ \\
\hline Semi-arid & 412,368 & 107 & $0.95-1.03$ & $0.93( \pm 0.04)$ & $0.61( \pm 0.14)$ & $0.90( \pm 0.05)$ \\
\hline Arid \& Hyper-arid & 47,791 & 32 & $0.95-1.01$ & $0.92( \pm 0.07)$ & $0.63( \pm 0.19)$ & $0.91( \pm 0.07)$ \\
\hline All data & 700,215 & 222 & $0.94-1.04$ & $0.89( \pm 0.10)$ & $0.60( \pm 0.15)$ & $0.87( \pm 0.11)$ \\
\hline \multicolumn{7}{|c|}{$\mathrm{k}_{\mathrm{Rs}}$ using the default value of $0.17^{\circ} \mathrm{C}^{0.5}$} \\
\hline Humid & 94,730 & 36 & $0.75-1.43$ & $0.77( \pm 0.14)$ & $0.71( \pm 0.19)$ & $0.64( \pm 0.19)$ \\
\hline Sub-humid & 145,326 & 47 & $0.79-1.35$ & $0.89( \pm 0.11)$ & $0.71( \pm 0.17)$ & $0.80( \pm 0.14)$ \\
\hline Semi-arid & 412,368 & 107 & $0.82-1.35$ & $0.93( \pm 0.04)$ & $0.69( \pm 0.17)$ & $0.87( \pm 0.06)$ \\
\hline Arid \& Hyper-arid & 47,791 & 32 & $0.65-1.39$ & $0.92( \pm 0.07)$ & $1.05( \pm 0.39)$ & $0.77( \pm 0.17)$ \\
\hline All data & 700,215 & 222 & $0.65-1.39$ & $0.89( \pm 0.10)$ & $0.75( \pm 0.25)$ & $0.81( \pm 0.15)$ \\
\hline \multicolumn{7}{|c|}{$\mathrm{k}_{\mathrm{Rs}}$ computed with the global Eq. (10) } \\
\hline Humid & 94,730 & 36 & $0.89-1.15$ & $0.77( \pm 0.14)$ & $0.59( \pm 0.17)$ & $0.72( \pm 0.20)$ \\
\hline Sub-humid & 145,326 & 47 & $0.88-1.19$ & $0.89( \pm 0.11)$ & $0.58( \pm 0.11)$ & $0.85( \pm 0.16)$ \\
\hline Semi-arid & 412,368 & 107 & $0.90-1.13$ & $0.93( \pm 0.04)$ & $0.60( \pm 0.13)$ & $0.91( \pm 0.05)$ \\
\hline Arid \& Hyper-arid & 47,791 & 32 & $0.87-1.43$ & $0.92( \pm 0.07)$ & $0.74( \pm 0.27)$ & $0.86( \pm 0.16)$ \\
\hline All data & 700,215 & 222 & $0.87-1.43$ & $0.90( \pm 0.10)$ & $0.61( \pm 0.17)$ & $0.86( \pm 0.14)$ \\
\hline \multicolumn{7}{|c|}{$\mathrm{k}_{\mathrm{Rs}}$ computed with the climate-focused Eq. (11) } \\
\hline Humid & 94,730 & 36 & $0.86-1.08$ & $0.77( \pm 0.14)$ & $0.58( \pm 0.15)$ & $0.74( \pm 0.17)$ \\
\hline Sub-humid & 145,326 & 47 & $0.84-1.18$ & $0.89( \pm 0.11)$ & $0.60( \pm 0.13)$ & $0.84( \pm 0.20)$ \\
\hline Semi-arid & 412,368 & 107 & $0.92-1.16$ & $0.93( \pm 0.04)$ & $0.60( \pm 0.12)$ & $0.90( \pm 0.05)$ \\
\hline Arid \& Hyper-arid & 47,791 & 32 & $0.84-1.21$ & $0.92( \pm 0.07)$ & $0.69( \pm 0.20)$ & $0.88( \pm 0.13)$ \\
\hline All data & 700,215 & 222 & $0.84-1.21$ & $0.89( \pm 0.10)$ & $0.61( \pm 0.14)$ & $0.86( \pm 0.14)$ \\
\hline
\end{tabular}

calibrated $\mathrm{k}_{\mathrm{Rs}}$ values. It is important to recognize that these results were obtained with independent data sets relative to various environments and a large range of climates, from humid to hyper-arid. The independent variables $\mathrm{TD}_{\mathrm{avg}}, \mathrm{u}_{2}$ avg and $\mathrm{RH}_{\mathrm{avg}}$ should be computed with long time series of temperature, air humidity and wind speed of a nearby station when such data are not available locally.

The usability of both equations 8 and 9 was also tested for various combinations of missing data, i.e., $\mathrm{T}_{\mathrm{dew}}, \mathrm{R}_{\mathrm{s}}$ and $\mathrm{u}_{2}$. Goodness-of-fit results have shown that using the PMT with reduced data sets combining available weather data with estimators of the missing variables produces better performances for $\mathrm{ET}_{\mathrm{o}}$ estimation than using the PMT with temperature data only. This analysis also has demonstrated that RMSE change little when using $\mathrm{k}_{\mathrm{Rs}}$ computed with Eq. (8) or (9), as well as when missing wind speed is estimated with the default $\mathrm{u}_{2}=2 \mathrm{~m} \mathrm{~s}^{-1}$ or an average local value, despite the latter is generally preferable particularly for windy areas. This approach, combining observed and estimated weather variables when these are missing, is certainly an advantage over the use of an ET temperature equation such as HS Eq. 2.

Following the very good results for the usability of the $\mathrm{k}_{\mathrm{Rs}}$ Eqs. (8) and (9) aimed at estimating $\mathrm{R}_{\mathrm{s}}$ for use with the PMT approach, which were developed through multiple linear regressions $\mathrm{k}_{\mathrm{Rs}}=\mathrm{f}\left(\mathrm{TD}_{\mathrm{avg}}\right.$, $\mathrm{u}_{2}$ avg, $\mathrm{RH}_{\mathrm{avg}}$ ), other multiple linear regression equations were developed for $\mathrm{k}_{\mathrm{Rs}}$ to be used with the HS equation, the Eqs. (10) and (11). The independent variables are also the local or regional long-term averages of TD, $\mathrm{RH}$ and $\mathrm{u}_{2}$ computed locally or using data of a nearby weather station. The usability of both global and climate-focused $\mathrm{k}_{\mathrm{Rs}}$ equations were assessed through computing $\mathrm{ET}_{\mathrm{o}} \mathrm{HS}$ with four approaches to calculate $\mathrm{k}_{\mathrm{Rs}}$, - site-calibration, default value $\left(\mathrm{k}_{\mathrm{Rs}}=0.17^{\circ} \mathrm{C}^{-0.5}\right)$ and Eqs. (10) and (11) - and then determining the

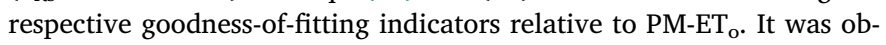
served that the performance of $\mathrm{ET}_{\mathrm{o}} \mathrm{HS}$ was poor when the default was used, and that the statistical indicators relative to RMSE and EF relative to using Eqs. (10) and (11) were close to those when site-calibrated $k_{\mathrm{Rs}}$ were used. Therefore, since the errors of estimate are limited, the usability of both Eqs. (10) and (11) was assumed, although the superiority of the climate-focused equations was not evidenced. However, for both equations, it was observed that the regression coefficient and RMSE of $\mathrm{ET}_{\mathrm{o}-\mathrm{HS}}$ varied with the climate of the sites used in the analysis.

It is important to notice that the goodness-of-fit indicators relative to using the $\mathrm{k}_{\mathrm{Rs}}$ equations relative to the PMT approach and to the HS equation are very similar. Thus, results do not clearly support advocating the use of PMT or HS methods, very slightly better in case of the HS equation, which may be due to using default wind speed instead of a local $\mathrm{u}_{2}$ average value when computing with $\mathrm{ET}_{\mathrm{o} \text { PMT. These results }}$ are different from those of former studies using the same datasets (Todorovic et al., 2013; Raziei and Pereira, 2013a; Ren et al., 2016a; Paredes et al., 2018a), which have shown that quite often PMT outperforms HS: RMSE was smaller for PMT in $68 \%$ of the sites of the Mediterranean region, in $47.5 \%$ of cases observed in Iran, in $76 \%$ of sites of Inner Mongolia and in $65 \%$ of sites of Azores. These results refer to using a site-calibrated $\mathrm{k}_{\mathrm{Rs}}$ for both PMT and HS methods, which are more accurate but much more demanding than using the $k_{R s}$ equations assessed in the current study. Therefore, when only temperature data are available, considering the simplicity of the HS

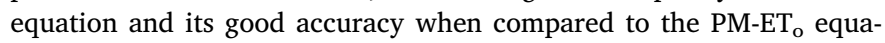
tion, it is possible to advocate the use of $\mathrm{ET}_{\mathrm{o}} \mathrm{Hs}$ for current practical applications such as irrigation scheduling and planning, obviously with $\mathrm{k}_{\mathrm{Rs}}$ computed with the Eqs. (10) or (11). Differently, the PMT approach is recommended when some weather variable in addition to temperature is available because those data may be used in PMT in combination with estimates of the missing weather variables, then with errors of estimates reduced relative to the use of temperature only. 
a) Humid climates

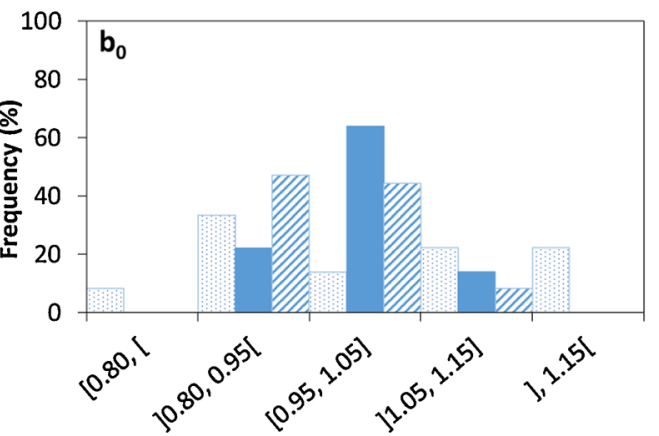

b) Sub-humid climates

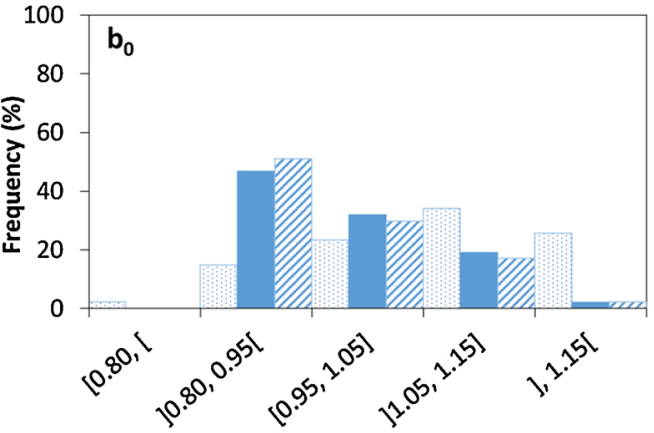

c) Semi-arid climates

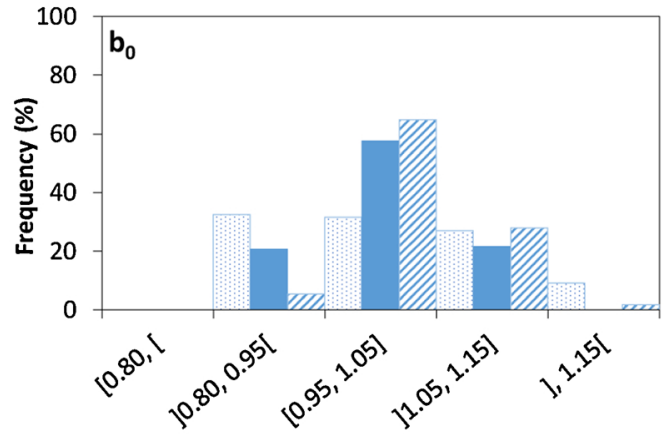

d) Arid \& Hyper-arid climates

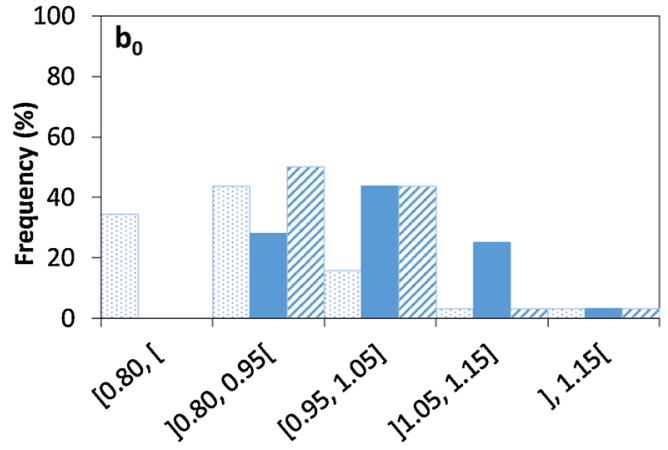

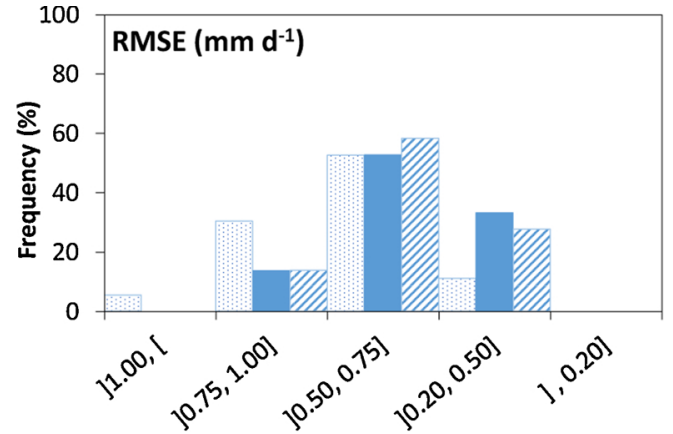
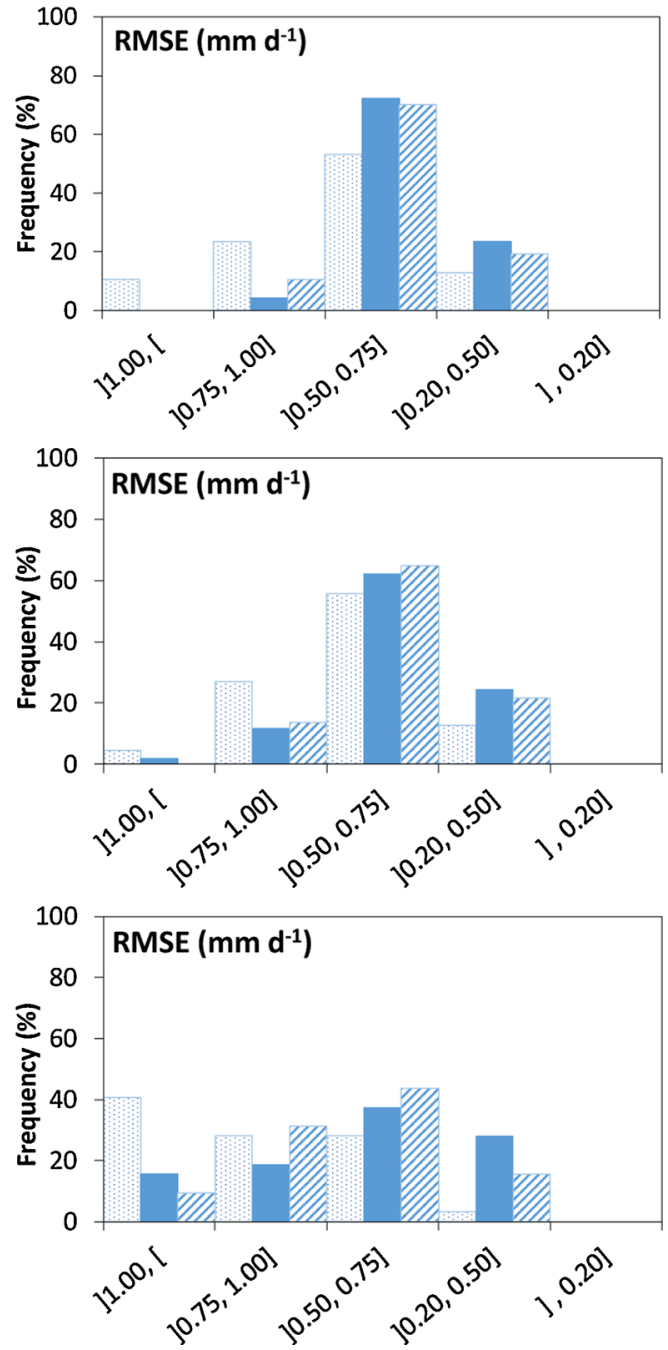

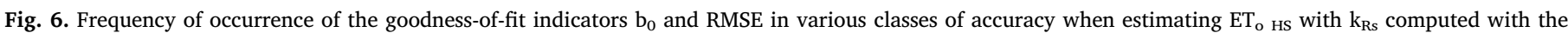

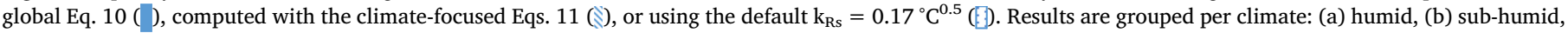
(c) semiarid, and (d) arid and hyper-arid. Application using data sets of Bolivia, Inner Mongolia, Iran, Portugal and Spain.

For studies that imply knowing the trend of $\mathrm{ET}_{\mathrm{o}}$, such as those relative to climate change impacts on crop water and irrigation requirements, or on basin water balance and availability, the HS equation is not recommended because $\mathrm{ET}_{\mathrm{o}} \mathrm{HS}$ is almost linearly dependent of temperature, thus producing a rising trend similar to that of temperature. Differently, the use of the PMT approach, where $\mathrm{T}_{\mathrm{dew}}$ is computed through correcting the temperature for aridity (Eqs. (6) and (7)), and an average wind speed may be used, the dependence trend from temperature is mitigated as observed for Inner Mongolia (Ren et al., 2016b). In fact, trends from the various weather variables that determine evapotranspiration are often contrary to temperature trends. With those study objectives, it may be convenient to use estimated and observed weather data in combination, including interpolated $R_{s}$ from geostationary satellites, as advocated by Paredes et al. (2020) relative to LSA-SAF data, or from gridded sources (Allen et al., 2020), or from nearby weather stations having full data sets (Tomas-Burguera et al., 2017). For research studies where the accuracy of $\mathrm{ET}_{\mathrm{o}}$ is a must, such as studies to define crop coefficients, the PM-ET ${ }_{\mathrm{o}}$ equation should be used.

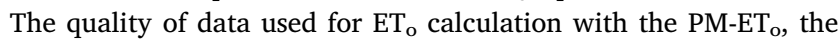
PMT approach or the HS equation is paramount for the accuracy of estimates. That quality depends not only from the equipment used and related data handling, but also from the site characteristics and how close it is from a reference site. QA/QC should cover all aspects influencing $\mathrm{ET}_{\mathrm{o}}$ estimates. It is important to realize that numerous studies 


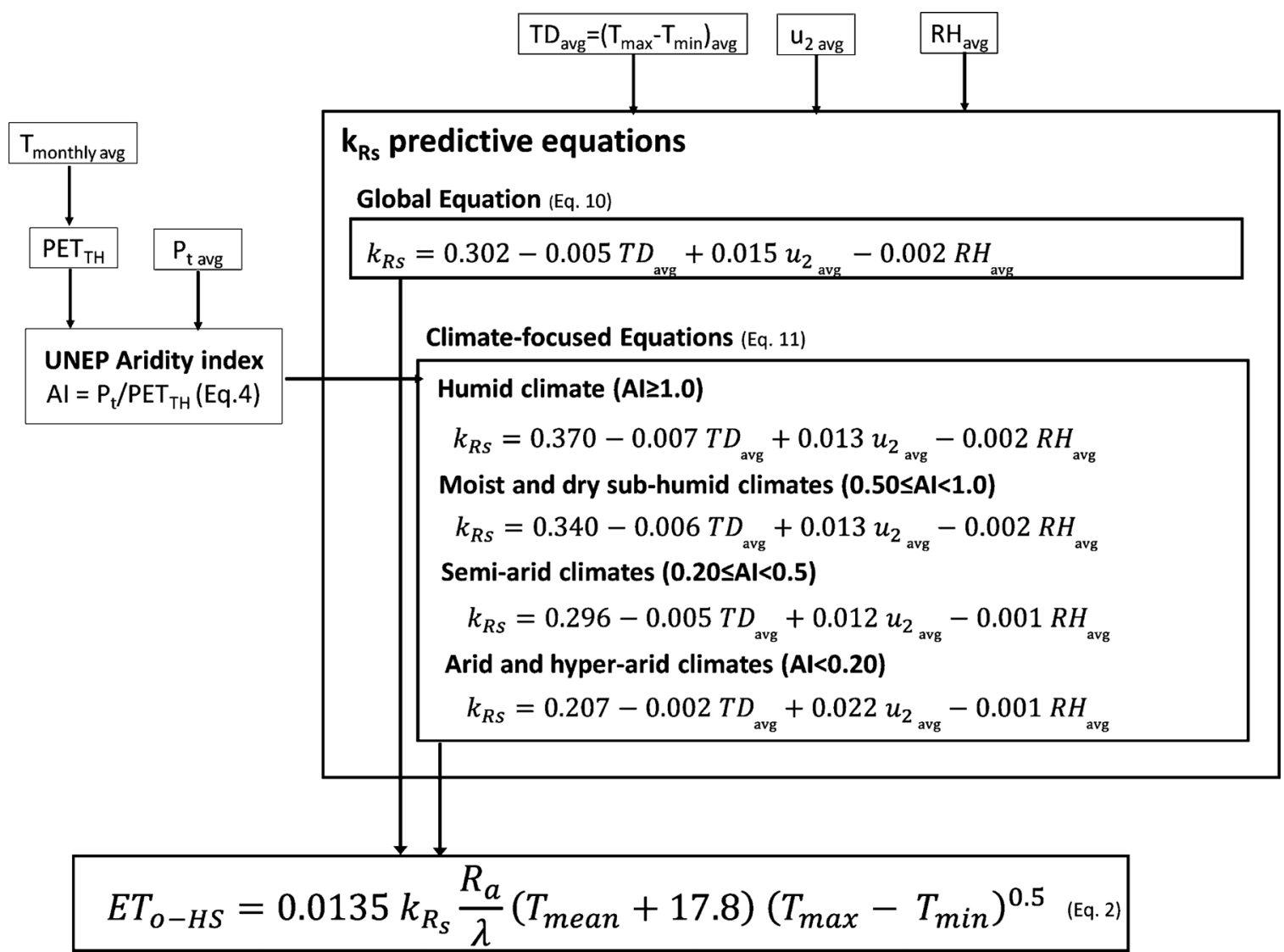

Fig. 7. Flux diagram for the calculation of $\mathrm{ET}_{\mathrm{o}-\mathrm{HS}}$ when $\mathrm{k}_{\mathrm{Rs}}$ is estimated with a global or climate focused predictive equation as a function of locally observed or estimated average climatic variables $\mathrm{TD}_{\text {avg }}, \mathrm{RH}_{\text {avg }}$ and $\mathrm{u}_{2}$ avg, with climates defined according to the UNEP Aridity Index (AI).

performed relative to reference evapotranspiration may be biased due to data quality. Thus, quality control of station conditions and weather data is definitely required, as it is also necessary the assessment of the

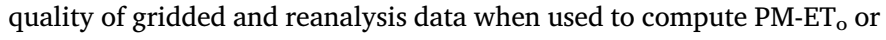
when satellite radiation data is used in combination with observed or estimated ground data. Further research along these lines are required as well as research complementing advances in the use of temperature methods. The availability of accurate methods and data for computing $\mathrm{ET}_{\mathrm{o}}$ is paramount to combine with updated $\mathrm{K}_{\mathrm{c}}$ data when aiming at matching irrigation supply and demand that can provide for irrigation water savings and improved water productivity.

\section{Acknowledgments}

The support of the Fundação para a Ciência e a Tecnologia, Portugal, through the research grants attributed to the first (DL 57/ 2016/CP1382/CT0022) and fourth author (CEECIND/01153/2017) and to the research unit LEAF (UID/AGR/04129/2020) are acknowledged.

\section{References}

Abatzoglou, J.T., 2011. Development of gridded surface meteorological data for ecological applications and modelling. Int. J. Climatol. 33 (1), 121-131.

Aguilar, C., Polo, M.J., 2011. Generating reference evapotranspiration surfaces from the Hargreaves equation at watershed scale. Hydrol. Earth Syst. Sci. Discuss. 15, 2495-2508.

Aladenola, O.O., Madramootoo, C.A., 2014. Evaluation of solar radiation estimation methods for reference evapotranspiration estimation in Canada. Theor. Appl. Climatol. 118, 377-385.

Allen, R.G., 1996. Assessing integrity of weather data for reference evapotranspiration estimation. J. Irrig. Drain. Eng. 122 (2), 97-106.

Allen, R.G., 1997. Self-calibrating method for estimating solar radiation from air temperature. J. Hydrol. Eng. 2 (2), 56-67.
Allen, R.G., Smith, M., Perrier, A., Pereira, L.S., 1994a. An update for the definition of reference evapotranspiration. ICID Bulletin 43 (2), 1-34.

Allen, R.G., Smith, M., Pereira, L.S., Perrier, A., 1994b. An update for the calculation of reference evapotranspiration. ICID Bulletin 43 (2), 35-92.

Allen, R.G., Pereira, L.S., Raes, D., Smith, M., 1998. Crop Evapotranspiration. Guidelines for Computing Crop Water Requirements. FAO Irrigation and Drainage Paper 56. FAO, Rome, Italy p. 300.

Allen, R.G., Pruitt, W.O., Wright, J.L., Howell, T.A., Ventura, F., Snyder, R., Itenfisu, D., Steduto, P., Berengena, J., Baselga Yrisarry, J., Smith, M., Pereira, L.S., Raes, D., Perrier, A., Alves, I., Walter, I., Elliott, R., 2006. A recommendation on standardized surface resistance for hourly calculation of reference $\mathrm{ET}_{\mathrm{o}}$ by the FAO56 Penman-Monteith method. Agric. Water Manage. 81, 1-22.

Allen, R.G., Pereira, L.S., Howell, T.A., Jensen, M.E., 2011. Evapotranspiration information reporting: I. Factors governing measurement accuracy. Agric. Water Manage. 98 (6), 899-920.

Allen, R., Dhungel, R., Dhungara, B., Huntington, J., Kilic, A., Morton, C., 2020. Conditioning point and gridded weather data under aridity conditions during calculation of reference evapotranspiration. Agric. Water Manage (submitted for publication).

Almorox, J., Hontoria, C., Benito, M., 2011. Models for obtaining daily global solar radiation with measured air temperature data in Madrid (Spain). Appl. Energy 88, 1703-1709.

Almorox, J., Bocco, M., Willington, E., 2013. Estimation of daily global solar radiation from measured temperatures at Cañadade Luque, Córdoba, Argentina. Renew. Energy 60, 382-387.

Almorox, J., Quej, V.H., Martí, P., 2015. Global performance ranking of temperaturebased approaches for evapotranspiration estimation considering Köppen climate classes. J. Hydrol. (Amst) 528, 514-522.

Almorox, J., Senatore, A., Quej, V.H., Mendicino, G., 2018. Worldwide assessment of the Penman-Monteith temperature approach for the estimation of monthly reference evapotranspiration. Theor. Appl. Climatol. 131, 693-703.

Annandale, J.G., Jovanovic, N.Z., Benadé, N., Allen, R.G., 2002. Software for missing data error analysis of Penman-Monteith reference evapotranspiration. Irrig. Sci. 21, $57-67$.

Berengena, J., Gavilán, P., 2005. Reference evapotranspiration estimation in a highly advective semiarid environment. J. Irrig. Drain. Eng. 131 (2), 147-163.

Berti, A., Tardivo, G., Chiaudani, A., Rech, F., Borin, M., 2014. Assessing reference evapotranspiration by the Hargreaves method in north-eastern Italy. Agric. Water Manage. 140, 20-25. https://doi.org/10.1016/j.agwat.2014.03.015.

Blankenau, P., Kilic, A., Allen, R., 2020. Bias and other error in gridded weather data sets for the purpose of estimating reference evapotranspiration. Agric. Water Manage 
(submitted for publication).

Bois, B., Pieri, P., Van Leeuwen, C., Wald, L., Huard, F., Gaudillere, J.-P., Saur, E., 2008. Using remotely sensed solar radiation data for reference evapotranspiration estimation at a daily time step. Agric. Forest Meteorol. 148, 619-630.

Boulard, D., Castel, T., Camberlin, P., Sergent, A.-S., Bréda, N., Badeau, V., Rossi, A., Pohl, B., 2016. Capability of a regional climate model to simulate climate variables requested for water balance computation: a case study over northeastern France. Clim. Dyn. 46, 2689-2716.

Bristow, K.L., Campbell, G.S., 1984. On the relationship between incoming solar radiation and daily maximum and minimum temperature. Agric. Forest Meteorol. 31, 159-166.

Cai, J., Liu, Y., Lei, T., Pereira, L.S., 2007. Estimating reference evapotranspiration with the FAO Penman-Monteith equation using daily weather forecast messages. Agric. Forest Meteorol. 145, 22-35.

Cammalleri, C., Ciraolo, G., 2013. A simple method to directly retrieve reference evapotranspiration from geostationary satellite images. Int. J. Appl. Earth Obs. Geoinf. 21, 149-158.

Chipana, R., Yujra, R., Paredes, P., Pereira, L.S., 2010. Determinación de la evapotranspiración de referencia con datos limitados en zonas de altura del Altiplano Boliviano aplicando la metodología de la FAO y la ecuación de Hargreaves-Samani. In: I Cong. Boliviano de Riego y Drenaje, Fac. Agronomia de la UMSA. 12-14 Jul 2010, La Paz, Bolivia.

Cobaner, M., Citakoğlu, H., Haktanir, T., Kisi, O., 2017. Modifying Hargreaves-Samani equation with meteorological variables for estimation of reference evapotranspiration in Turkey. Hydrol. Res. 48 (2), 380-497.

Córdoba, M., Carrillo-Rojas, G., Crespo, P., Wilcox, B., Célleri, R., 2015. Evaluation of the Penman-Monteith (FAO 56 PM) method for calculating reference evapotranspiration using limited data. Application to the wet Páramo of Southern Ecuador. Res. Dev. 35 (3), 230-239.

Cruz-Blanco, M., Santos, C., Gavilán, P., Lorite, I.J., 2015. Uncertainty in estimating reference evapotranspiration using remotely sensed and forecasted weather data under the climatic conditions of Southern Spain. Int. J. Climatol. 35, 3371-3384.

Daly, C., Smith, J.I., Olson, K.V., 2015. Mapping atmospheric moisture climatologies across the conterminous United States. PLoS One 10 (10), e0141140. https://doi.org/ 10.1371/journal.pone.0141140.

De Bruin, H.A.R., Trigo, I.F., 2019. A new method to estimate reference crop evapotranspiration from geostationary satellite imagery: practical considerations. Water 11 (2), 382. https://doi.org/10.3390/w11020382.

De Bruin, H.A.R., Trigo, I.F., Jitan, M.A., Temesgen Enku, N., van der Tol, C., Gieske, A.S.M., 2010. Reference crop evapotranspiration derived from geo-stationary satellite imagery: a case study for the Fogera flood plain, NW-Ethiopia and the Jordan Valley, Jordan. Hydrol. Earth Syst. Sci. Discuss. 14, 2219-2228.

De Bruin, H.A.R., Trigo, I.F., Bosveld, F.C., Meirinka, J.F., 2016. Thermodynamically based model for actual evapotranspiration of an extensive grass field close to FAO reference, suitable for remote sensing application. J. Hydrometeorol. 17, 1373-1382.

Diodato, N., Bellocchi, G., 2007. Modeling reference evapotranspiration over complex terrains from minimum climatological data. Water Resour. Res. 43, W05444. https:// doi.org/10.1029/2006WR005405.

Djaman, K., Irmak, S., Kabenge, I., Futakuchi, K., 2016. Evaluation of FAO-56 PenmanMonteith model with limited data and the Valiantzas models for estimating grassreference evapotranspiration in Sahelian conditions. J. Irrig. Drain. Eng., 04016044. https://doi.org/10.1061/(ASCE)IR.1943-4774.0001070.

Droogers, P., Allen, R.G., 2002. Estimating reference evapotranspiration under inaccurate data conditions. Irrig. Drain. Syst. Eng. 16, 33-45.

Farahani, H.J., Howell, T.A., Shuttleworth, W.J., Bausch, W.C., 2007. Evapotranspiration: progress in measurement and modeling in agriculture. Trans. ASABE 50 (5), $1627-1638$.

Ferreira, L.B., Cunha, F.F., Oliveira, R.A., Fernandes Filho, E.I., 2019. Estimation of reference evapotranspiration in Brazil with limited meteorological data using ANN and SVM - a new approach. J. Hydrol. (Amst) 572, 556-570.

Fooladmand, H.R., Zandilak, H., Ravanan, M.H., 2008. Comparison of different types of Hargreaves equation for estimating monthly evapotranspiration in the south of Iran. Arch. Agron. Soil Sci. 54 (3), 321-330.

Garcia, M., Raes, D., Allen, R., Herbas, C., 2004. Dynamics of reference evapotranspiration in the Bolivian highlands (Altiplano). Agric. Forest Meteorol. 125, 67-82.

Gavilán, P., Lorite, I.J., Tornero, S., Berengena, J., 2006. Regional calibration of Hargreaves equation for estimating reference ET in a semiarid environment. Agric Water Manage. 81, 257-281.

Gocic, M., Trajkovic, S., 2010. Software for estimating reference evapotranspiration using limited weather data. Comput. Electron. Agric. 71, 158-162.

Gomariz-Castillo, F., Alonso-Sarría, F., Cabezas-Calvo-Rubio, F., 2018. Calibration and spatial modelling of daily $\mathrm{ET}_{0}$ in semiarid areas using Hargreaves equation. Earth Sci. Inform. 11, 325-340.

Hargreaves, G.H., 1994. Defining and using reference evapotranspiration. J. Irrig. Drain. Eng. 120 (6), 1132-1139.

Hargreaves, G.H., Allen, R.G., 2003. History and evaluation of Hargreaves evapotranspiration equation. J. Irrig. Drain. Eng. 129, 53-63.

Hargreaves, G.H., Samani, Z.A., 1982. Estimating potential evapotranspiration. J. Irrig. Drain. Eng. 108, 225-230.

Hargreaves, G.H., Samani, Z.A., 1985. Reference crop evapotranspiration from temperature. Appl. Eng. Agric. 1 (2), 96-99.

Hargreaves, G.L., Hargreaves, G.H., Riley, J.P., 1985. Irrigation water requirements for Senegal River basin. J. Irrig. Drain. Eng. 111, 265-275.

Hart, Q.J., Brugnach, M., Temesgen, B., Rueda, C., Ustin, S.L., Frame, K., 2009. Daily reference evapotranspiration for California using satellite imagery and weather station measurement interpolation. Civil Eng. Environ. Syst. 26, 19-33.

Hersbach, H., de Rosnay, P., Bell, B., Schepers, D., Simmons, A., Soci, C., Abdalla, S.,
Alonso Balmaseda, M., Balsamo, G., Bechtold, P., Berrisford, P., Bidlot, J., de Boisséson, E., Bonavita, M., Browne, P., Buizza, R., Dahlgren, P., Dee, D., Dragani, R., Diamantakis, M., Flemming, J., Forbes, R., Geer, A., Haiden, T., Hólm, E., Haimberger, L., Hogan, R., Horányi, A., Janisková, M., Laloyaux, P., Lopez, P., Muñoz-Sabater, J., Peubey, C., Radu, R., Richardson, D., Thépaut, J.-N., Vitart, F., Yang, X., Zsótér, E., Zuo, H., 2018. Operational global reanalysis: progress, future directions and synergies with NWP, ECMWF. ERA Report Series 27. https://doi.org/ 10.21957 /tkic6g3wm.

Hersbach, H., Bell, W., Berrisford, P., Horányi, A.J., M-S, Nicolas, J., Radu, R., Schepers, D., Simmons, A., Soci, C., Dee, D., 2019. Global reanalysis: goodbye ERA-Interim, hello ERA5. ECMWF Newsletter No 159. pp. 17-24. https://doi.org/10.21957/ vf291hehd7.

Hubbard, K.G., Mahmood, R., Carlson, C., 2003. Estimating daily dew point temperature for the Northern Great Plains using maximum and minimum temperature. Agron. J. 95, 323-328.

Hwang, S., Graham, W.D., Geurink, J.S., Adams, A., 2014. Hydrologic implications of errors in bias-corrected regional reanalysis data for west central Florida. J. Hydrol. (Amst) 510, 513-529.

Jabloun, M., Sahli, A., 2008. Evaluation of FAO-56 methodology for estimating reference evapotranspiration using limited climatic data: applications to Tunisia. Agric. Water Manage. 95, 707-715.

Jahani, B., Dinpashoh, Y., Nafchi, A.R., 2017. Evaluation and development of empirical models for estimating daily solar radiation. Renew. Sustain. Energy Rev. 73, 878-891.

Jensen, M.E., Burman, R.D., Allen, R.G., 1990. Evapotranspiration and Irrigation Water Requirements. ASCE Manuals and Reports on Engineering Practice No. 70, 360 p. .

Jensen, D.T., Hargreaves, G.H., Temesgen, B., Allen, R.G., 1997. Computation of ET0 under nonideal conditions. J. Irrig. Drain. Eng. 123 (5), 394-400.

Jensen, M.E., Allen, R.G. (Eds.), 2016. Evaporation, Evapotranspiration, and Irrigation Water Requirements. ASCE Manuals and Reports on Engineering Practice No. 70, 2nd edition. Reston, Virginia 744p.

Kimball, J.S., Running, S.W., Nemani, R., 1997. An improved method for estimating surface humidity from daily minimum temperature. Agric. Forest Meteorol. 85, 87-98.

Kra, E., 2014. FAO-56 Penman-Monteith daily ETo from linear regression calibrated Hargreaves equation with wind terms in tropics with limited data. Int. J. Agron., 402809. https://doi.org/10.1155/2014/402809.

Kwon, H., Choi, M., 2011. Error assessment of climate variables for FAO-56 reference evapotranspiration. Meteorol. Atmos. Phys. 112 (1-2), 81-90.

Lecina, S., Martínez-Cob, A., Pérez, P.J., Villalobos, F.J., Baselga, J.J., 2003. Fixed versus variable bulk canopy resistance for reference evapotranspiration estimation using the Penman-Monteith equation under semiarid conditions. Agric. Water Manage. 60, $181-198$.

Lee, K.-H., 2010. Relative comparison of the local recalibration of the temperature-based evapotranspiration equation for the Korea Peninsula. J. Irrig. Drain. Eng. 136, 585-594.

Legates, D.R., McCabe Jr., G.J., 1999. Evaluating the use of "goodness-of-fit" measures in hydrologic and hydroclimatic model validation. Water Resour. Res. 35, 233-241.

Lewis, C.S., Geli, H.M.E., Neale, C.M.U., 2014. Comparison of the NLDAS weather forcing model to agrometeorological measurements in the western United States. J. Hydrol. (Amst) 510, 385-392.

Liu, Y., Pereira, L.S., 2001. Calculation methods for reference evapotranspiration with limited weather data. J. Hydraul. Eng. 3, 11-17 (in Chinese).

López-Moreno, J.I., Hess, T.M., White, S.M., 2009. Estimation of reference evapotranspiration in a mountainous Mediterranean site using the Penman-Monteith equation with limited meteorological data. Pirineos 164, 7-31.

Majidi, M., Alizadeh, A., Vazifedoust, M., Farid, A., Ahmadi, T., 2015. Analysis of the effect of missing weather data on estimating daily reference evapotranspiration under different climatic conditions. Water Resour. Manage. 29, 2107-2124.

Martí, P., Zarzo, M., Vanderlinden, K., Girona, J., 2015. Parametric expressions for the adjusted Hargreaves coefficient in Eastern Spain. J. Hydrol. (Amst) 529, 1713-1724.

Martinez, C.J., Thepadia, M., 2010. Estimating reference evapotranspiration with minimum data in Florida. J. Irrig. Drain. Eng. 136, 7. https://doi.org/10.1061/ (ASCE)IR.1943-4774.0000214.

Martínez-Cob, A., Tejero-Juste, M., 2004. A wind-based qualitative calibration of the Hargreaves ETo estimation equation in semiarid regions. Agric. Water Manage. 64, 251-264.

Martins, D.S., Paredes, P., Raziei, T., Pires, C., Cadima, J., Pereira, L.S., 2017. Assessing reference evapotranspiration estimation from reanalysis weather products. An application to the Iberian Peninsula. Int. J. Climatol. 37, 2378-2397.

McMahon, T.A., Finlayson, B.L., Peel, M.C., 2016. Historical developments of models for estimating evaporation using standard meteorological data. WIREs Water 3 , 788-818. https://doi.org/10.1002/wat2.1172.

McVicar, T.R., Van Niel, T.G., Li, L.-T., Hutchinson, M.F., Mu, X.-M., Liu, Z.-H., 2007 Spatially distributing monthly reference evapotranspiration and pan evaporation considering topographic influences. J. Hydrol. (Amst) 338, 196-220.

Mendicino, G., Senatore, A., 2013. Regionalization of the Hargreaves coefficient for the assessment of distributed reference evapotranspiration in southern Italy. J. Irrig. Drain. Eng. 139, 349-362.

Monteith, J.L., 1965. Evaporation and environment. The State and Movement of Water in Living Organisms, 19th Symp. Soc. Exp. Biol. Cambridge University Press, Cambridge, UK, pp. 205-234.

Nandagiri, L., Kovoor, G.M., 2006. Performance evaluation of reference evapotranspiration equations across a range of Indian climates. J. Irrig. Drain. Eng. 132 (3), 238-249.

Nash, J.E., Sutcliffe, J.V., 1970. River flow forecasting through conceptual models: part 1. A discussion of principles. J. Hydrol. (Amst) 10, 282-290. 
Pandey, P.K., Pandey, V., 2016. Evaluation of temperature-based Penman-Monteith (TPM) model under the humid environment. Model. Earth Syst. Environ. 2, 152.

Paredes, P., Pereira, L.S., 2019. Computing FAO56 reference grass evapotranspiration $\mathrm{PM}-\mathrm{ET}_{\mathrm{o}}$ from temperature with focus on solar radiation. Agric. Water Manage. 215, 86-102.

Paredes, P., Fontes, J.C., Azevedo, E.B., Pereira, L.S., 2018a. Daily reference crop evapotranspiration with reduced data sets in the humid environments of Azores islands using estimates of actual vapour pressure, solar radiation and wind speed. Theor. Appl. Climatol. 134, 1115-1133.

Paredes, P., Fontes, J.C., Azevedo, E.B., Pereira, L.S., 2018b. Daily reference crop evapotranspiration in the humid environments of Azores islands using reduced data sets. Accuracy of FAO PM temperature and Hargreaves-Samani methods. Theor. Appl. Climatol. 134, 595-611.

Paredes, P., Martins, D., Pereira, L.S., Cadima, J., Pires, C., 2018c. Accuracy of daily estimation of grass reference evapotranspiration using ERAInterim reanalysis products with assessment of alternative bias correction schemes. Agric. Water Manage. 210, 340-353.

Paredes, P., Trigo, I., de Bruin, H., Pereira, L.S., Simões, N., 2020. Assessing the accuracy of daily grass reference evapotranspiration with Meteosat Second Generation products. Agric. Water Manage (submitted for publication).

Patel, J., Patel, H., Bhatt, C., 2014. Generalized calibration of the Hargreaves equation for evapotranspiration under different climate conditions. Soil \& Water Res. 9 (2), 83-89.

Pereira, L.S., 2017. Water, agriculture and food: challenges and issues. Water Resour. Manage. 31, 2985-2999.

Pereira, L.S., Perrier, A., Allen, R.G., Alves, I., 1999. Evapotranspiration: review of concepts and future trends. J. Irrig. Drain. Eng. 125 (2), 45-51.

Pereira, L.S., Cai, L.G., Hann, M.J., 2003. Farm water and soil management for improved water use in the North China Plain. Irrig. Drain. 52, 299-317.

Pereira, L.S., Cordery, I., Iacovides, I., 2009. Coping With Water Scarcity. Addressing the Challenges. Springer, Dordrecht $382 \mathrm{p}$.

Pereira, L.S., Allen, R.G., Smith, M., Raes, D., 2015a. Crop evapotranspiration estimation with FAO56: past and future. Agric. Water Manage. 147, 4-20.

Pereira, L.S., Paredes, P., Rodrigues, G.C., Neves, M., 2015b. Modeling malt barley water use and evapotranspiration partitioning in two contrasting rainfall years. Assessing AquaCrop and SIMDualKc models. Agric. Water Manage. 159, 239-254.

Pereira, L.S., Paredes, P., López-Urrea, R., Hunsaker, D.J., Mota, M., Mohammadi Shad, Z., 2020a. Standard single and basal crop coefficients for vegetable crops, an update of FAO56 crop water requirements approach. Agric. Water Manage. 239, 106196. https://doi.org/10.1016/j.agwat.2020.106196.

Pereira, L.S., Paredes, P., Hunsaker, D.J., López-Urrea, R., Mohammadi Shad, Z., 2020b. Standard single and basal crop coefficients for field crops. Updates and advances to the FAO56 crop water requirements method. Agric. Water Manage (submitted for publication).

Pereira, L.S., Paredes, P., Mota, M., Melton, F., Wang, T., Johnson, L., 2020c. Prediction of crop coefficients from fraction of ground cover and height. Indicative $\mathrm{K}_{\mathrm{c}}$ and $\mathrm{K}_{\mathrm{cb}}$ values for vegetable, field and fruit crops. Agric. Water Manage (submitted for publication).

Popova, Z., Kercheva, M., Pereira, L.S., 2006. Validation of the FAO methodology for computing ETo with missing climatic data. Application to South Bulgaria. Irrig. Drain. 55, 201-215.

Quej, V.H., Almorox, J., Ibrakhimo, M., Saito, L., 2017. Estimating daily global solar radiation by day of the year in six cities located in the Yucatán Peninsula, Mexico. J. Clean. Prod. 141, 75-82.

Quej, V.H., Almorox, J., Arnaldo, J.A., Moratiel, R., 2019. Evaluation of temperaturebased methods for the estimation of reference evapotranspiration in the Yucatán Peninsula, Mexico. J. Hydrol. Eng. 24, 05018029.

Ramírez-Cuesta, J.M., Cruz-Blanco, M., Santos, C., Lorite, I.J., 2017. Assessing reference evapotranspiration at regional scale based on remote sensing, weather forecast and GIS tools. Int. J. Appl. Earth Obs. Geoinf. 55, 32-42.

Ravazzani, G., Corbari, C., Morella, S., Gianoli, P., Mancini, M., 2012. Modified Hargreaves-Samani equation for the assessment of reference evapotranspiration in Alpine river basins. J. Irrig. Drain. Eng. 138, 592-599.

Raziei, T., Pereira, L.S., 2013a. Estimation of ETo with Hargreaves-Samani and FAO-PM temperature methods for a wide range of climates in Iran. Agric. Water Manage. 121, $1-18$.

Raziei, T., Pereira, L.S., 2013b. Spatial variability analysis of reference evapotranspiration in Iran utilizing fine resolution gridded datasets. Agric. Water Manage. 126, 104-118.

Ren, X., Qu, Z., Martins, D.S., Paredes, P., Pereira, L.S., 2016a. Daily reference evapotranspiration for hyper-arid to moist sub-humid climates in Inner Mongolia, china: I. Assessing temperature methods and spatial variability. Water Resour Manage. 30, 3769-3791.

Ren, X., Martins, D.S., Qu, Z., Paredes, P., Pereira, L.S., 2016b. Daily reference evapotranspiration for hyper-arid to moist sub-humid climates in Inner Mongolia, china: II. Trends of $\mathrm{ET}_{\mathrm{o}}$ and weather variables and related spatial patterns. Water Resour. Manage. 30, 3793-3814.

Samani, Z., 2000. Estimating solar radiation and evapotranspiration using minimum climatological data. J. Irrig. Drain. Eng. 126, 265-267.

Senay, G.B., Verdin, J.P., Lietzow, R., Melesse, A.M., 2008. Global daily reference evapotranspiration modeling and evaluation. J. Am. Water Resour. Assoc. 44, 969-979.

Sentelhas, P.C., Gillespie, T.J., Santos, E.A., 2010. Evaluation of FAO Penman-Monteith and alternative methods for estimating reference evapotranspiration with missing data in Southern Ontario, Canada. Agric. Water Manage. 97, 635-644.

Sheffield, J., Goteti, G., Wood, E.F., 2006. Development of a 50-year high-resolution global dataset of meteorological forcings for land surface modeling. J. Climate 19, 3088-3111.
Shwetha, H.R., Kumar, D.N., 2018. Performance evaluation of satellite based approaches for the estimation of daily air temperature and reference evapotranspiration. Hydrol. Sci. J. 63 (9), 1347-1367.

Singh, L.K., Jha, M.K., Pandey, M., 2018. Framework for standardizing less data-intensive methods of reference evapotranspiration estimation. Water Resour. Manage. 32, 4159-4175. https://doi.org/10.1007/s11269-018-2022-5.

Smith, M., 1993. CLIMWAT For CROPWAT: a Climatic Database for Irrigation Planning and Management. FAO Irrigation and Drainage Paper No. 49. Rome. (http://www fao.org/land-water/databases-and-software/climwat-for-cropwat/en/ (last accessed on $17 / 08 / 2019)$ ).

Smith, M., Allen, R.G., Monteith, J., Perrier, A., Pereira, L.S., Segeren, A., 1991. Report on the Expert Consultation on Revision of FAO Methodologies for Crop Water Requirements. FAO, Rome $54 \mathrm{p}$.

Srivastava, P.K., Islam, T., Gupta, M., Petropoulos, G., Dai, Q., 2015. WRF dynamical downscaling and bias correction schemes for NCEP estimated hydro-meteorological variables. Water Resour. Manage. 29, 2267-2284.

Srivastava, P.K., Han, D., Islam, T., Petropoulos, G.P., Gupta, M., Dai, Q., 2016. Seasonal evaluation of evapotranspiration fluxes from MODIS satellite and mesoscale model downscaled global reanalysis datasets. Theor. Appl. Climatol. 124, 461-473.

Steduto, P., Todorovic, M., Caliandro, A., Rubino, P., 2003. Daily ETo estimates by the Penman-Monteith equation in Southern Italy. Constant vs. variable canopy resistance. Theor. Appl. Climatol. 74, 217-225.

Strong, C., Khatri, K.B., Kochanski, A.K., Lewis, C.S., Allen, L.N., 2017. Reference evapotranspiration from coarse-scale and dynamically downscaled data in complex terrain: sensitivity to interpolation and resolution. J. Hydrol. (Amst) 548, 406-418.

Tabari, H., 2010. Evaluation of reference crop evapotranspiration equations in various climates. Water Resour. Manage. 24 (10), 2311-2337.

Temesgen, B., Allen, R.G., Jensen, D.T., 1999. Adjusting temperature parameters to reflect well-watered conditions. J. Irrig. Drain. Eng. 125 (1), 26-33.

Temesgen, B., Eching, S., Davidoff, B., Frame, K., 2005. Comparison of some reference evapotranspiration equations for California. J. Irrig. Drain. Eng. 131 (1), 73-84.

Thepadia, M., Martinez, C.J., 2012. Regional calibration of solar radiation and reference evapotranspiration estimates with minimal data in Florida. J. Irrig. Drain. Eng. 138 (2), 111-119.

Thornthwaite, C.W., 1948. An approach toward a rational classification of climate. Geogr. Rev. (Oxf) 38, 55-94.

Thornton, P.E., Running, S.W., 1999. An improved algorithm for estimating incident daily solar radiation from measurements of temperature, humidity, and precipitation. Agric. Forest Meteorol. 93, 211-228.

Tian, Y., Zhang, K., Xu, Y.-P., Gao, X., Wang, J., 2018. Evaluation of potential evapotranspiration based on CMADS reanalysis dataset over China. Water 10, 1126. https://doi.org/10.3390/w10091126.

Todorovic, M., 1999. Single-layer evapotranspiration model with variable canopy resistance. J. Irrig. Drain. Eng. 125 (5), 235-245.

Todorovic, M., Karic, B., Pereira, L.S., 2013. Reference evapotranspiration estimate with limited weather data across a range of Mediterranean climates. J. Hydrol. (Amst) 481, 166-176.

Tomas-Burguera, M., Vicente-Serrano, S.M., Grimalt, M., Beguería, S., 2017. Accuracy of reference evapotranspiration (ETo) estimates under data scarcity scenarios in the Iberian Peninsula. Agric. Water Manage. 182, 103-116.

Trajkovic, S., 2005. Temperature-based approaches for estimating reference evapotranspiration. J. Irrig. Drain. Eng. 131 (4), 316-323.

Trajkovic, S., 2007. Hargreaves versus Penman-Monteith under humid conditions. J. Irrig. Drain. Eng. 133 (1), 38-42.

Trajkovic, S., Kolakovic, S., 2009. Evaluation of reference evapotranspiration equations under humid conditions. Water Resour. Manage. 23, 3057-3067.

Trajković, S., Stojnić, V., Gocić, M., 2011. Minimum weather data requirements for estimating reference evapotranspiration. Facta Universitatis, Series: Archit. Civil Eng. 9 (2), 335-345.

Trigo, I.F., de Bruin, H., Beyrich, F., Bosveld, F.C., Gavilán, P., Groh, J., López-Urrea, R., 2018. Validation of reference evapotranspiration from Meteosat Second Generation (MSG) observations. Agric. For. Meteorol. 259, 271-285.

UNEP, 1997. World Atlas of Desertification, 2nd edn. United Nations Environment Programme, Arnold, London $182 \mathrm{p}$.

Upreti, H., Ojha, C.S.P., 2017. Estimation of relative humidity and dew point temperature using limited meteorological data. J. Irrig. Drain Eng. 143 (9), 05017005.

Vanderlinden, K., Giráldez, J.V., Van Meirvenne, M., 2004. Assessing reference evapotranspiration by the Hargreaves method in southern Spain. J. Irrig. Drain. Eng. 130, 184-191.

Vyas, S.S., Nigam, R., Bhattacharya, B.K., Kumar, P., 2016. Development of real-time reference evapotranspiration at the regional scale using satellite-based observations. Int. J. Remote Sens. 37, 6108-6126.

Wable, P.S., Jha, M.K., Gorantiwar, S.D., 2019. Assessing suitability of temperature-based reference evapotranspiration methods for semi-arid basin of Maharashtra. J. Agrometeorol. 21 (3), 351-356.

Wright, J.L., Allen, R.G., Howell, T.A., 2000. Conversion between evapotranspiration references and methods. In: Proceedings of Fourth Decennial National Irrigation Symposium. Phoenix, AZ, ASAE, St. Joseph, MI. pp. 251-259.

Yang, Y., Cui, Y., Bai, K., Luo, T., Dai, J., Wang, W., Luo, Y., 2019a. Short-term forecasting of daily reference evapotranspiration using the reduced-set Penman-Monteith model and public weather forecasts. Agric. Water Manage. 211, 70-80.

Yang, Y., Luo, Y., Wu, C., Zheng, H., Zhang, L., Cui, Y., Sun, N., Wang, L., 2019b. Evaluation of six equations for daily reference evapotranspiration estimating using public weather forecast message for different climate regions across China. Agric. Water Manage. 222, 386-399. 